\title{
Identifying critical factors for developing effective rural community technology centers
}

Daphne Gooding

West Virginia University

Follow this and additional works at: https://researchrepository.wvu.edu/etd

\section{Recommended Citation}

Gooding, Daphne, "Identifying critical factors for developing effective rural community technology centers" (2005). Graduate Theses, Dissertations, and Problem Reports. 2648.

https://researchrepository.wvu.edu/etd/2648

This Dissertation is protected by copyright and/or related rights. It has been brought to you by the The Research Repository @ WVU with permission from the rights-holder(s). You are free to use this Dissertation in any way that is permitted by the copyright and related rights legislation that applies to your use. For other uses you must obtain permission from the rights-holder(s) directly, unless additional rights are indicated by a Creative Commons license in the record and/ or on the work itself. This Dissertation has been accepted for inclusion in WVU Graduate Theses, Dissertations, and Problem Reports collection by an authorized administrator of The Research Repository @ WVU.

For more information, please contact researchrepository@mail.wvu.edu. 


\title{
Identifying Critical Factors for Developing Effective Rural Community Technology Centers
}

\author{
Daphne Gooding \\ Dissertation submitted to the \\ College of Human Resources and Education \\ at West Vinginia University \\ in partial fulfillment of the requirements \\ for the degree of
}

Doctor of Education

David L. McCrory, PhD, Chair

Edward Pytlik, PhD

Anne Nardi, $\mathrm{PhD}$

Ruthellen Phillips, EdD

Nancy R. Bunt, EdD

Advanced Education Studies

Morgantown, West Virginia

2005

Keywords: rural technology center, rural community development 


\begin{abstract}
Identifying Critical Factors for Developing

Effective Rural Community Technology Centers
\end{abstract}

Daphne Gooding

The purpose of this research is to inform both existing and developing community technology initiatives as to the critical factors for building effective rural community technology centers. Rural community technology centers which had been operating for at least two years were identified and contacted by telephone. Either a paid or volunteer staff person was interviewed using a semistructured protocol of open-ended questions. Responses were taped, transcribed and coded using standard tools and procedures for qualitative investigation. Codes were grouped in 12 thematic groups. Relative occurrences of codes within each group were analyzed. Participants were asked what criteria were used to measure effectiveness of their centers. Participants also made recommendations about alternative evaluation metrics that could be evidence of the impact of their centers on participants. The findings suggest eleven areas that require attention when developing rural community technology centers or networks. Results also support Maughan's model of a robust communication system and Kling's Social Informatics theory. 


\section{Chapter 1:- Introduction}

The Digital Divide and Community Technology Centers ............... 1

Background of the Research ..................................................... 4

Digital Divide $\quad 4$

$\begin{array}{ll}\text { Community Technology Centers } & 6\end{array}$

$\begin{array}{ll}\text { Rural Community Technology Centers } & 8\end{array}$

$\begin{array}{ll}\text { Effectiveness Measures } & 10\end{array}$

$\begin{array}{ll}\text { Planning for Rural CTC's } & 11\end{array}$

Purpose

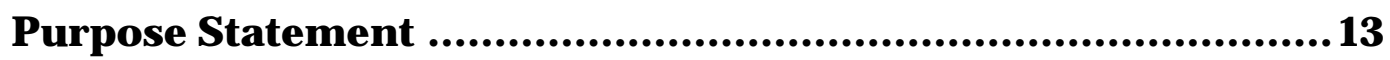

Research Questions ............................................................ 13

Assumptions .......................................................................... 14

Definitions of Terms ....................................................... 14

\section{Chapter 2:- Review of the Literature}

Digital Divide ............................................................... 16

$\begin{array}{ll}\text { Characteristics of the Digital Divide } & 16\end{array}$

$\begin{array}{ll}\text { Causes of the Digital Divide } & 19\end{array}$

Importance of the Digital Divide 22 
Negatively Reinforcing Cycle or the Digital Divide

Strategies for Addressing the Digital Divide

Universal Service Support

24

E-Rate

25

TOP

25

RUS Programs

26

Neighborhood Networks

26

Community Technology Centers Program

27

America Connects Consortium

27

State and Local Initiatives

28

Community Technology Centers

Characteristics of CTC's

Community Networks

33

Use of CTC's and CN's

35

Variety of Missions and Goals

37

Organizations Connecting CTC's

39

Rural Community Technology Centers

Rural Digital Divide

Effect of Information Aparteid on Rural Communities

Definitions of Rural

Challenges for Rural Communities

Blacksburg Electronic Village

La Plaza--Taos, NM 
$\begin{array}{ll}\text { ACEnet } & 47\end{array}$

Big Sky Telegraph and Dillionet--Dillon, MT 47

$\begin{array}{ll}\text { Labrador, Canada } & 48\end{array}$

$\begin{array}{lr}\text { Australia } & 49\end{array}$

Europe $\quad 50$

$\begin{array}{ll}\text { Africa } & 51\end{array}$

Effectiveness Issues and Measure....................................52

Evaluation/ Effectiveness Measures $\quad 52$

America Connects Consortium Suggestions 56

Evaluations of Existing Programs 57

Characteristics of Effective Initiatives 59

Information Technology and Social Change ........................... 63

Communications and Information Infrastructure 63

$\begin{array}{ll}\text { Social Informatics } & 65\end{array}$

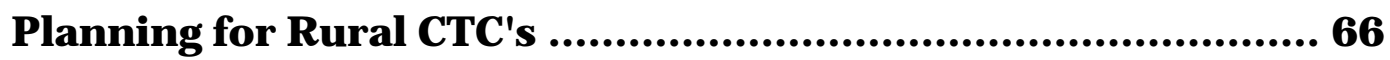

Planning to Meet Rural Challenges 68

Critical Factors for Developing Effective Community Technology

$\begin{array}{ll}\text { Programs } & 71\end{array}$

The Case for Blended Methodology ........................................ 72

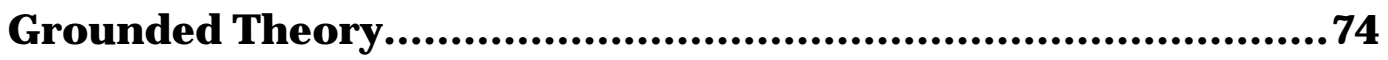

Data Collection and Analysis................................................77

Summary of Review of Literature ............................................ 77 


\section{Chapter 3- Methodology}

Introduction .........................................................................79

Purpose Statement .........................................................79

Research Questions ..........................................................79

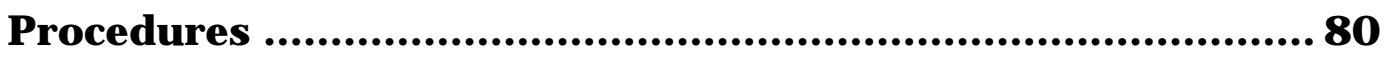

$\begin{array}{ll}\text { Review of Literature } & 80\end{array}$

Inclusion Criteria for Study Subjects $\quad 80$

Identifcation of Study Participants $\quad 81$

Development of the Research Instruments 82

Pilot Testing of Instruments $\quad 84$

Data Collection $\quad 85$

$\begin{array}{ll}\text { Likert Scale Questions } & 87\end{array}$

$\begin{array}{ll}\text { Analysis of Data } & 87\end{array}$

$\begin{array}{ll}\text { Coding Process } & 88\end{array}$

Developing and Refining the Codebook 89

$\begin{array}{ll}\text { Assessing Code Consistency } & 89\end{array}$

$\begin{array}{ll}\text { Survey Data } & 90\end{array}$

\section{Chapter 4- Results}

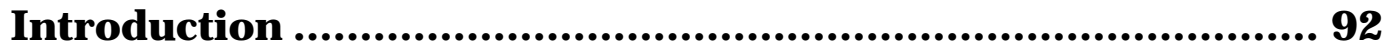

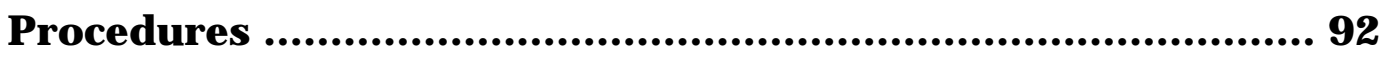


Inclusion Criteria for Study Subjects $\quad 92$

$\begin{array}{ll}\text { Qualitative Data } & 93\end{array}$

$\begin{array}{ll}\text { Organization of Qualitative Data } & 96\end{array}$

$\begin{array}{ll}\text { Quantitative Data } & 99\end{array}$

Research Question 1: How is effectiveness measured in rural community technology centers? .................................................... 99

Research Question 2: What factors are critical for developing effective rural community technology centers? ............................. 102

$\begin{array}{ll}\text { Geographic Factors } & 104\end{array}$

$\begin{array}{ll}\text { Awareness and Planning } & 105\end{array}$

$\begin{array}{ll}\text { Organization } & 107\end{array}$

$\begin{array}{ll}\text { Funding } & 108\end{array}$

$\begin{array}{ll}\text { Populations Served by the Centers } & 110\end{array}$

$\begin{array}{ll}\text { Transportation } & 111\end{array}$

$\begin{array}{ll}\text { Programs } & 112\end{array}$

$\begin{array}{ll}\text { Technical Issues } & 114\end{array}$

$\begin{array}{ll}\text { Program Models } & 117\end{array}$

$\begin{array}{ll}\text { Barriers } & 119\end{array}$

$\begin{array}{ll}\text { Partnerships } & 122\end{array}$

$\begin{array}{ll}\text { Uniques Features } & 123\end{array}$

Research Question 3: What criteria should be used to measure

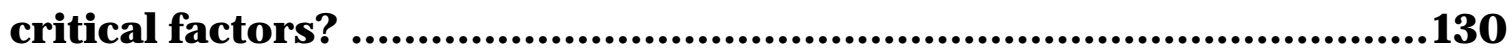

$\begin{array}{ll}\text { Notable Metrics } & 132\end{array}$ 
Overlapping Evaluation Metrics

General Observations and Comments................................... 139

Implications of the Research ............................................. 141

$\begin{array}{ll}\text { Practical Implications } & 141\end{array}$

$\begin{array}{ll}\text { Theoretical Implications } & 143\end{array}$

Chapter 5- Summary, Conclusions and Recommendations for further Research

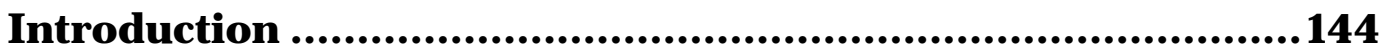

Purpose Statement .............................................................. 144

Research Question 1: How is effectiveness measured in rural community technology centers? ................................................. 145

Research Question 2: What factors are critical for developing effective rural community technology centers?.............................. 146

Summary of Thematic Groups .............................................. 148

$\begin{array}{ll}\text { Partnerships } & 148\end{array}$

$\begin{array}{ll}\text { Geography } & 149\end{array}$

$\begin{array}{ll}\text { Awareness and Planning } & 149\end{array}$

$\begin{array}{ll}\text { Organization } & 150\end{array}$

$\begin{array}{ll}\text { Funding } & 150\end{array}$

$\begin{array}{ll}\text { Population Served } & 150\end{array}$

$\begin{array}{ll}\text { Transportation } & 151\end{array}$ 
$\begin{array}{ll}\text { Programs } & 151\end{array}$

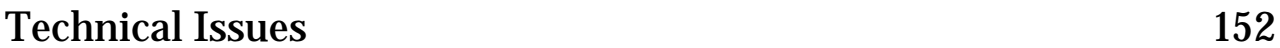

$\begin{array}{ll}\text { Program Models } & 152\end{array}$

$\begin{array}{ll}\text { Barriers } & 153\end{array}$

Unique Features 153

Research Question 3: What criteria should be used to measure

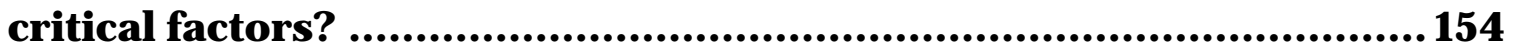

Strength of Qualitative Data............................................... 156

Alternative Interpretations of Data...................................... 157

Implications of the Research Findings.................................... 158

$\begin{array}{ll}\text { Practical Implications } & 158\end{array}$

$\begin{array}{ll}\text { Theoretical Implications } & 161\end{array}$

Recommendations for further Study .................................... 162

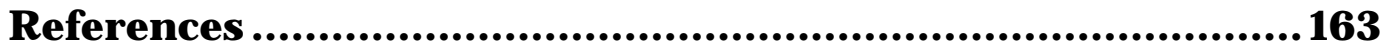

Appendix ...................................................................... 175 


\section{List of Tables and Figures}

Figure 1 Servon and Nelson's (1999) representation of the negatively reinforcing cycle of the digital divide (p. 5) 22

Figure 2: Use of CTC's by participants. From Servon and Nelson (1999). Totals are greater than $100 \%$ because subjects could choose more than one category. 36

Figure 3: Populations served by CTC's. Totals are greater than $100 \%$ because respondents could choose multiple categories. The group labeled "other" included homeless and mentally ill persons, recent immigrants, artists, HIVpositive individuals and people with AIDS, and absentee fathers seeking to

get on track with child support payments (Servon and Nelson, 1999)......... 38

Table 1 Definitions of Urban-Rural Characteristics............................................. 42

Figure 4: Telecommunications Infrastructure and Economic Erosion- a downward spiraling cycle wearing away the economic base in rural communities. 44

Figure 5: Patterson (2000) Tetrad Model of Evaluation of Community Computer Network (Patterson, 2002, p. 66, fig 4.1) ......................................................55

Figure 6: Grounded Theory Research Process as described by Dick (p.3) ............76

Figure 7: Schematic of Codebook Testing Process Flow …..................................... 88

Figure 8: Research Process Flow Diagram ...........................................................91

Table 2: Description of Sites Included in Study ……............................................ 93

Table 3: Interview Questions with Relationship to Research Questions.............97

Figure 9: Study subject responses to Research Question $1(\mathrm{n}>1) \ldots \ldots \ldots \ldots \ldots \ldots \ldots . . . . . . .100$ 
Figure 10: Clustering of factors into thematic groupings. 103

Figure 11: Geographic factors related to rural Community Technology Centers..... 105

Figure 12: Counts of Factors in the Awareness and Planning Thematic Group.106 Figure 13: Organizational Structure Factors 108

Figure 14: Funding Sources used by Rural Community Technology Centers and

Networks. 109

Figure 15: Populations Served by Rural Community Technology Centers and

Networks. 110

Figure 16: Transportation to and from Centers. 112

Figure 17: Factors Influencing Effective Programming 114

Figure 18:Technical Factors Affecting Rural Community Technology Programs

Figure 19: Program Models Employed by Rural Community Technology

Programs 119

Figure 20: Barriers to Developing Effective Rural CTC's.................................... 121

Figure 21: Partnerships Developed by Rural CTC's............................................. 123

Figure 22: Alternative Evaluation Metrics Discussed by Subjects...................... 132

Figure 23: Schematic Representation of Evaluation Metrics Suggested in

Research Questions 1 and 3. 135

Figure 24: Relative Incidences of Evaluation Metric Discussed in both Research

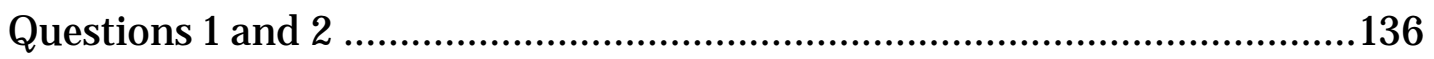

Figure 25: Relationship of Thematic Groupings...............................................148

Figure 26: Evaluation Metrics........................................................................... 155 


\section{Acknow ledgments}

Above all, I wish to give thanks to the object of my faith: the loving God and Savior who cares about the world and all its inhabitants. The opportunity to continue learning has been a pure blessing.

My family must be applauded not only for persevering through these years of graduate education, but also for encouraging me when I was completely overwhelmed. My husband, J ohn, and children Erin, J oanna, Elizabeth, J udith and J on Isaac have endeavored to fill in for me in so many places.

I also thank my graduate committee for walking this long road with me and offering wise counsel when I most needed it. 


\section{H A P T E R 1}

\section{Introd u ction}

\section{The Digital Divide and Community Technology Centers}

In 1995, Trevor Haywood's book, Info-Rich, Info-Poor, described a world divided by a gaping information chasm. On one side of the great divide were the elite "information- haves;" on the other side were the teeming masses of "havenots" (Haywood, 1995, p. ix). Haywood predicted that the rapid escalation in computing technology and the information-based economy would serve to widen the info-gap rather than realize a social equalization. The likely scenario, according to Haywood, was that information wealth would concentrate with the already rich, while the information poor, especially from developing countries, urban centers, and rural communities, would grow poorer. A new information aristocracy would evolve (Haywood, 1995). Poverty, homelessness, violence, crime and political instability would result from the economic structures demanded by the global information economy. This disparity would consequently set the stage for worldwide unrest and revolt (Haywood, 1995).

In July 1999, the U.S. Department of Commerce published Falling through the Net: A report on the telecommunications and information gap in America. This study demonstrated that African Americans, Hispanics, senior citizens, lowincome persons, and residents of rural areas were significantly less likely to have access to computers and the Internet than other groups. This condition has been 
termed the "Digital Divide." Studies of Digital Divide issues emphasized that rural communities were at risk for being left behind in the new information technology- based global economy. Lack of sufficient population density served as a disincentive for commercial investment in infrastructure and human resource development necessary to support the expansion of information technology (Manohar, 2001).

Community Technology Centers have been established as part of a strategy for addressing digital divide issues. Both the U.S. Department of Commerce's Technology Opportunities Program (TOP, formerly TIIAP), grant program and the Department of Education's Community Technology Center (CTC) grant program formed part of the national approach for addressing the Digital Divide. Additionally, the National Science Foundation funded Community Technology Centers Network (CTCNet) to form a national network of Community Technology initiatives (Servon \&Nelson, 1999).

Slightly earlier than the Community Technology Centers initiative in the United States, Telecentres and Telecottages were developed internationally. The first Telecottages were in Scandinavian countries, notably Sweden. Similar programs were established in both developed and developing countries. Telecottages and Telecentres in Sweden, Wales, Australia, Canada, Senegal, and South Africa have been the object of rolling online case studies (Fuchs, 1998).

Community Technology Centers and international Telecottages have been shown to bridge the information gap. In the United States, this has been well demonstrated in urban areas, particularly low income inner city communities 
(Servon \& Nelson, 1999). Australia, Canada, and Sweden have demonstrated the value and effectiveness of Telecottages in remote regions of developed nations. Wales exhibited successful Telecottage initiatives in de-industrialized rural areas. Canada, Senegal, and South Africa reported the effective implementation of telecottages in rural areas that were beginning to transition from traditional and tribal ways of life into the Information Age (Fuchs, 1998).

Planning guides for Community Technology Centers have been published by CTCNet and the Neighborhood Network initiative of the United States Department of Housing and Urban Development (HUD). These guides were produced without specific attention to rural needs and without attention to evaluation. Because rural areas are especially at risk for being excluded from the Information Age, and because rural community technology centers and telecottages have demonstrated value as bridges spanning the information chasm, effective, sustainable rural community technology centers could serve as information access centers in otherwise excluded rural communities. Questions surfaced regarding needs specific to rural communities wishing to develop CTCs. Additionally, questions about metrics for evaluating the impact of rural CTCs and the critical factors for developing effective rural community technology programs emerged.

This research was undertaken to begin the investigation of factors necessary for rural communities to develop effective and dynamic community technology centers. 


\section{Background of the Research}

\section{Digital Divide}

The dawn of the Information Age has prompted two points of view among scholars. Perelman (1998) summarized the two views of the information age. One perspective was that since information is replacing physical resources as the basis of wealth, the elimination of the physical barriers to affluence should usher in an era when the abolition of poverty is relatively easy. The other side of the argument warned of the ominous implications of an impending end of work, where many would be left wandering in a modern affluent culture that no longer needed their labor. Much to the optimist's chagrin, Perelman asserted that class would become more pronounced in determining access to information. According to Perelman, it was indeed unfortunate that for the most part, information technologies would not be applied to improve quality of life for people, but rather to enlarge control over people and processes, mostly at the expense of workers. Both information and education would become more privatized. Thus, middle and upper class households would have the capacity to offer their children access to information technology that children from poorer families could not even dream about (Perelman, 1998).

In his speech to the Networks for People conference, Mario Morino (2000) defined the digital divide by emphasizing that citizens living in the lowest income areas experienced a very different life from those in middle and higher income situations. Morino continued by alerting his listeners to the possibility of 
developing a permanent social underclass (2000). Servon \&Nelson (1999) introduced several labels for this phenomenon: digital divide, information apartheid, information poverty, and information gap, which have been used to draw attention to the inequity in access to communication and information technologies.

The digital divide has become the focus of a great deal of writing by various authors. During the Clinton-Gore administration (1993-2000), bridging the digital divide became the focus of policy making. Former vice-president Al Gore was quoted at the National Press Club, "We want to avoid creating a society of 'haves and have-nots'. The most important step we can take to ensure universal service is to adopt policies that result in lower prices for everyone. But we'll still need a regulatory safety net to make sure almost everyone can benefit" (Stefik, 1999, p. 248). Both those who viewed the Information Age with optimism and those with a pessimistic perspective agreed that the digital divide is serious and worthy of strategic action.

\section{Community Technology Centers}

Overcoming the digital divide might indeed entail more than providing basic access to computers and the Internet. Maughan (2001) described the essential components of any robust communication and information system as: 1 . Devices, 2. Networks, 3. Skills, 4. Budget, and 5. Policies. Kling (2000a) coined the term Social Informatics to describe the body of research that pertains to the design, uses, and consequences of access to communication and information technologies. Public access to the Internet could be analyzed in terms of social 
informatics. These two perspectives lay the theoretical groundwork for this investigation.

In order to bridge the digital divide by providing access to computers and the Internet, numerous national and local organizations in the United States have developed Community Technology Centers. These centers usually have from two to 20 computer stations in a public area. Community access to the computers is generally encouraged. Often a community computing center is used for one or more ongoing programs, e.g. after-school programs, GED classes, basic computer literacy classes, and job readiness programs. Servon and Nelson described Community Technology Centers as "locally based nonprofit organizations that link community residents to IT resources" (1999, p. 8). The goals of CTC's were usually social in nature, rather than technical: building community awareness, encouraging involvement in local decision making, and developing economic opportunities in disadvantaged communities.

Community Technology Center Network (CTCNet) was originally (19952000) located at the Educational Development Center, Newton, MA. CTCNet is a national membership organization that promotes and supports the growth of nonprofit, community-based efforts to provide computer access and learning opportunities to the general public and particularly to disadvantaged populations. CTCNet received its original funding from the National Science Foundation. The U.S. Department of Education has funded many of the CTCaffiliates through its yearly Community Technology Centers grant program. CTCNet has more than 700 affiliates throughout the United States, including 
community networks, public housing facilities, adult literacy programs, job training and entrepreneurship programs, YW- and YMCAs, public libraries, schools and after-school programs (Chow, C., Ellis J ., Mark, J ., \&Wise, B., 1998).

The U.S. Department of Housing and Urban Development (HUD) had also been proactive in developing community technology centers through the Neighborhood Networks program. The Neighborhood Networks program operated in privately-owned, HUD-subsidized housing complexes. HUD offered no direct financial support to Neighborhood Networks, rather it encouraged owners to allocate some reserve funds to the Neighborhood Network center. HUD also helped to locate used computer equipment for Neighborhood Networks. Regional HUD offices fostered partnerships among residents, owners, and management to promote Neighborhood Networks. In 2001, HUD began offering regional technical support seminars for Neighborhood Network centers. Neighborhood Networks and CTCNet are not mutually exclusive. Neighborhood Network Centers may also be CTCNet affiliates (Neighborhood Networks Business Plan Outline and Guidance, 1998).

Other community-based organizations have established community technology centers as well as those listed above. Churches or church-related organizations, Boys and Girls Clubs, community groups, libraries and civic organizations are examples of these organizations. These groups may or may not be CTCNet affiliates and may or may not participate in other regional or national organizations. 
Mark, Cornebise, and Wahl (1997) conducted a qualitative study of the impact of CTCNet affiliates. Interviews with 130 users at five CTCNet sites provided data about people's experiences at centers, as well as opportunities for improving programs. The results demonstrated that participants self-reported highly positive experiences at CTCs. Chow, et. al., (1998), compiled and analyzed survey data to assess the impact of CTCNet affiliates. No definitive study has been found that identifies and classifies the areas that are critical for developing effective rural community technology programs in the United States.

\section{Rural Community Technology Centers}

Rural Community Technology initiatives have been launched in diverse locations. Notable international examples are the Scandinavian Telecottages; the Southern Labrador Telecentre in Forteau, Labrador; Walcha, Byron Shire, and Cygnet (Tasmania) Telecottages, Australia; Antur Tanat Cain Telecottage, Wales; Mamelodi Community Information Services, South Africa. These Telecottages formed the basis for the case studies assembled and reported by Fuchs (1998).

Distinct projects in the United States include Blacksburg Electronic Village, Blacksburg, VA; La Plaza of Taos, NM; West Virginia Public Library system, and DillonNet, Dillon, MT. Blacksburg Electronic Village and La Plaza have been the focal point of research studies.

Blacksburg, VA (pop. 36,000), the home of Virginia Polytechnic Institute, is in rural Montgomery County. Since beginning to offer Internet access to the community in 1993, Blacksburg has developed the reputation of being "the most wired community" in the world. Andrew Cohill, founder of Blacksburg Electronic 
Village (BEV) considers the most important part of the network to be the local network, that is, the human infrastructure of the local community. "Community is the root of communications," stated Cohill (1999, p.5). Much of the research on BEV has been collected, summarized and reported by Cohill and Kavanaugh (2000).

Taos County, in the Sangre de Cristo Mountains of northern New Mexico is a truly rural county. The largest city, Taos, has a population of approximately 4300. In 1994, the Taos Tele-community, named La Plaza after the idea of the plaza in Spanish communities, was born. La Plaza served the diverse needs of a tri-cultural community. The people of Taos were Anglo, Hispanic, and Native American. La Plaza provided Internet connectivity to all Taos County residents regardless of whether they lived in the town of Taos in the center of the county, Picuris and Chamisal Pueblo, or the remote Hispanic village, Costilla. Free public access sites were positioned all over the county. Residents also could dial up to local servers instead of making expensive long distance calls. Youth and Family Centers, health clinics, village offices, and libraries brought citizens in contact with one another. La Plaza became a model of rural community technology practice and has thus been supported by major contributions from the AOL Foundation, the Kellogg Foundation, and the National Telecommunications Infrastructure Assistance (NTIA) program (La Plaza Archives, 2002).

Dillon Net developed as an unofficial partnership with Western Montana College of the University of Montana. Dillon Net was a community-networking project that served Beaverhead County (population 8000) and maintained one 
outpost in J ackson, Montana, population 38 humans, 53 dogs (Heid, 1999). Obviously there exist numerous rural community technology centers and rural community networks. Little has been done to bring the collected knowledge of the projects together in a systematic approach.

Effectiveness Measures

CTCNet published a set of evaluation tools for Community Technology Centers. These tools include instruments for assessing basic computing skills, staff background, technology needs, the technical environment (hardware and software), onganizational mission definition, and both student and staff evaluations of individual programs and Web sites. While these tools are useful for tracking purposes and building a solid case in proposals to potential funding agents, none of these tools described what an effective CTC is. Moreover, none of these tools were developed with rural CTCs and the rural context as the focus (Chow, Ellis, \& Walker, 2000).

HUD required that all Neighborhood Network Centers submit a business plan to become official Neighborhood Network sites. A form for the business plan has been made available through the Neighborhood Network Web site. Neither the Neighborhood Network business plan nor the CTCNet guide was designed specifically for rural community centers, nor do they supply discussions of effectiveness or instruments for measuring effectiveness. There is a clear need for tools that address effectiveness issues and measures for Community Technology Centers that serve rural communities. 
Planning for rural CTC's

None of the available planning tools was specifically designed for rural community technology centers. CTCNet's guide (Stone, 2000) addressed general priorities for any center. Cohill \& Kavanaugh compiled research and experience from Blackburg's Electronic Village (Cohill \& Kavanaugh, 2000). But one might question whether Blacksburg, VA, with a population of approximately 36,000 could be described as rural. Big Sky Telegraph was born in Dillon, Montana at Western Montana College of the University of Montana. The Big Sky initiative served educators in extremely remote rural areas of southwestern Montana. Based on the Big Sky Telegraph experiences, Odasz (1995 \& 1996) has written an implementation planning guide as part of the funding strategy. This guide was made available to interested communities through the archives of the Online Chronicle of Distance Education and Communications (Fall 1995, Community Networking, Part I, online at http:// www.fcae.nova.edu/disted/ fall95/article.html\#community and Spring 1996 Community Networking: An Implementation Guide, Part II online at http:// www.fcae.nova.edu/ disted/spring96/articles.html ).

Each of the rural technology initiatives has accumulated wisdom and experience during its development. This investigation was undertaken to collect this experience into a form that would report to rural communities how they might be successful in bridging the digital divide by developing effective community technology centers. Determining the crucial factors for developing effective rural 
community technology centers would inform the planning process for rural communities.

\section{Purpose}

The purpose of this research is to inform both existing and developing community technology initiatives as to the critical factors for building effective rural community technology centers. The digital divide is not just a technical problem. The digital divide, particularly as it pertains to low-income persons and communities, is an indicator of larger problems of social disenfranchisement and economic inequality. According to Perelman (1998):

Indeed, a fault line is beginning to run through our society dividing information haves from information have-nots. Our access to information, in turn, is an important determinant of our personal circumstances. It helps us to form our images of ourselves. It signals us about the sort of opportunities that we should pursue. It gives us an entrée to good jobs. Information is a major input in the production of what we economists denote as human capital. The processing of information even helps to shape the structure of our brains (p. 10).

Many rural communities were interested in reaping the benefits of full participation in the global information economy. While communities realized that modern computing and communications technology constituted a vital factor 
within a strategy of community change (Breeden et al, 1998), they were uncertain what steps to take to create and sustain effective community technology centers which could function to bridge the digital divide for rural communities and residents. Building and sustaining a community-based technology center could represent considerable outlays of money, equipment and personnel. As rural communities must stretch their resources as far as possible; they needed to know that they would obtain positive returns on their investments. According to Breeden, et al, there was a clear need for community technology practitioners to "study what works and why" (1998). At the same time, many rural citizens were eager to learn skills and find ways to improve their quality of life and add value to their communities using communication and information technologies. Rural areas were, however, conspicuously lacking in the information infrastructure and human capital required to traverse the digital divide.

\section{Purpose Statement}

The purpose of this research is to identify the critical factors for developing effective rural community technology centers.

\section{Research Questions}

The following research questions were developed to guide this research:

1. How is effectiveness measured in rural community technology centers? 
2. What factors are critical for developing effective rural community technology centers?

3. What criteria should be used to measure critical factors?

\section{Assumptions}

Throughout this research the following assumptions were made:

1. Information reported by centers and personnel at community technology centers was accurate.

2. Documents relating to community technology centers contained accurate information.

3. Information supplied by participants reflected normal operations and conditions.

4. Telephone communications reflected normal operating situations.

5. Researcher biases were not superimposed in the study group or by any individual in the study group.

\section{Definitions of Terms}

For the purposes of this research, the following definitions and abbreviations are used:

1. CTC- any community technology center. A community technology center is a physical site in a community which houses computers and associated equipment, in order to serve the community with access to these technologies. 
2. Neighborhood Networks- an initiative of the US Department of Housing and Urban Development (HUD) which encourages building community computing centers in HUD subsidized housing.

3. Telecottage term used for rural community technology centers in countries other than the US.

4. Telecentre- term used for community technology centers serving urban areas in countries other than the US.

5. Content- Programs and information delivered via the computer. This might include applications, information, or activities.

6. Technical support- assistance required to initiate and maintain proper functioning of computers, networks, or Internet access and human factors at community technology centers.

7. Community Networks--Information systems developed to serve communities with access to both local and national or international information. To be included in this study Community Networks were required to offer technology access to the public.

8. Rural Community Technology Center (RCTC)- any community technology center located in and serving an area defined as less urbanized, non-adjacent or rural adjacent or non-adjacent by United States Department of Agriculture (USDA) guidelines.

9. Rural Community Network- a community network serving an area that qualifies as less urbanized, non-adjacent or rural adjacent or non-adjacent by USDA guidelines. 


\title{
C H A P T E R 2
}

\section{Review of the Literature}

\author{
Digital Divide
}

Characteristics of the Digital Divide

Both Trevor Hayword (1995) and J eremy Rifkin (1995) envisioned a new era of information-based global economies in which persons who possessed computer and information skills were "haves" and those without electronic information skills were "have nots." Hayword continued his predictions by saying that the wide gap between information haves and have nots would lead to extreme social and cultural consequences such as the establishment of a permanent underclass. This underclass would have virtually no hope of crossing the dividing chasm and would thus become the seat of institutionalized poverty and unrest. Members of the information elites would form a permanent upper class whose members would live in a separate world from the persistent lower class (Hayword, 1995). Morino (2000) agreed by stating "citizens living in our lowest income areas experience a vastly different world from others"(p. 2). This situation, according to Morino constituted the “Digital Divide." Morino was equally concerned with the risk of establishing a permanent underclass in the U.S.

These predictions directly opposed many of the early predictions about the great equalizing force of the Internet and the World Wide Web. Optimists saw new communication and information technologies as the potential path to overcoming existing social, cultural, economic, ethnic and racial barriers. According to this 
school of thought, electronic communication and information systems would be the democratizing force that finally brought equality that had been so illusive. Much to the optimist's chagrin, Perelman (1998) asserted that class would become more pronounced in determining access to information. Both information and education would become more privatized. Thus, middle and upper class households would offer their children access to information technology that children from poorer families could not even dream about.

Various names have been used to describe the disparity in access to information resources in the age of electronic communications. Servon and Nelson introduced the terms "digital divide," "information apartheid," and "information poverty" to draw attention to the inequity in access to communication and information technologies (1999, p. 1).

In J uly 1995, the National Telecommunications Infrastructure Authority (NTIA) of the U.S. Department of Commerce published the first of its groundbreaking studies that made a quantitative and systematic study of the inequities in access to computers and telecommunications. The Department of Commerce (1995) stated the need to go beyond the traditional focus on telephone penetration to gauge the nation's progress toward universal service. The Department of Commerce collected data on computer and modem access through the US Census Bureau's Current Population Survey. Data was subsequently crosstabulated according to: income, race, age, educational attainment, and region, as well as three geographic categories-- rural, urban, and central city. The results of this data collection and analysis were that information disadvantages were disproportionately found in rural areas and central cities of the U.S. (U. S. 
Department of Commerce, 1995). Moreover, the NTIA study reported that though the central city poor have the lowest overall telephone subscription, the rural poor have the lowest personal computer penetration and among homes with computers the lowest percentage of modem use (U.S. Department of Commerce, 1995).

Chandler (2000) defined the Digital Divide as "that growing gulf between the haves and the have-nots in the world of computers. Those without access to computers and the World Wide Web- heavily concentrated among minorities and the poor- are increasingly being left behind in the new economy and the new wired world that goes with it" (p. 1). Consequently, during his administration "President Clinton declared this digital divide the paramount civil rights issue of the 21st Century" (Chandler, 2000, p. 2). Based on case studies, Rose (1997) concluded "for the most part, have-nots are poor urban and rural minorities," whereas "people owning computers are middle-to-upper income whites and Asians" (p. 2.1.1).

The existence of the digital divide became a matter of discussion. Critics claimed that since computer ownership and access was growing in all demographic groups, the information disparity was winding down and disappearing. However, the study published by Servon and Nelson (1999) pointed out that while information access was growing for all groups, the rate of growth for minorities, low-income, less educated, and single parent households, especially those in rural areas and central cities, was so much slower than for other groups that the gap in access to computers and telecommunications was actually widening. Kling (2000a) reported that in 1999 the divide in home Internet access between 
Hispanic and White households and between Black and White households had widened by $6 \%$.

Causes of the Digital Divide

Servon and Nelson (1999) offered reasons to explain the existence of the technology gap:

1. Money-- Lower household income correlated to lower rates of computer and Internet access. This fact was related to the cost of both equipment and services. In addition, since the Internet was highly consumer oriented, the overwhelming majority of its content consisted of commercial sites that were designed with the intent of attracting those most likely to purchase goods or services. Lower income families were being forced to consider computer and Internet access as a luxury (p. 3).

2. Unequal investment in infrastructure-- Investment in critical infrastructure was much lower in low-income urban neighborhoods and rural areas. Even though computers and telecommunication were thought to transcend geographic boundaries, the same geographic locations that were centers of economic poverty resulted in electronic information poverty. Unfortunately these conditions of poverty tend to reinforce one another (p. 4).

3. Lack of understanding of the problems of access-- Failure on the part of policy makers to comprehend the complexity of the problem. 
National and state level programs to reduce or eliminate the information gap have tended to focus on established institutions such as schools, libraries and health care organizations. These are not the organizations that are frequented by low- income persons ( $p$. $4)$.

Based on the following observations, Wolpert contended that there existed a technology red-lining for low-income populations:

1. High-tech development has been most intense where low-income groups are least represented;

2. Minorities were under-represented in firms experiencing the greatest growth in information technology;

3. Technology education and skills training was much weaker in urban public schools than in suburban areas (Wolpert cited in Rose, 1997, p. 2.2).

Although both low-income urban and rural communities are affected by the digital divide, the U.S. Department of Commerce (1995) reported that no situation compared with the plight of the rural poor with respect to personal computers and the incidence of modems. The newest incarnation of the information gap is access to advanced telecommunication capabilities. While access to dial-up Internet service is increasingly available to all areas with telephone service, access to broadband applications is eluding rural communities. 
Broadband service refers to those applications which require faster download speeds. Broadband services allow audio and video transmission, as well as rapid loading of graphic-rich information. Cable modem, Digital Subscriber Lines, T1 lines and faster are methods of supplying broadband services.

Less than five percent of towns of 10,000 or less had cable modem service, more than 65 percent of all cities with populations over 250,000 had such service. While more than 56 percent of all cities with populations exceeding 100,000 had Digital Subscriber Line (DSL) available, less than five percent of cities with populations less than 10,000 had such service. Deployment of both cable modems and DSL service in remote rural areas was far lower than in other areas (NTIA, 2000).

While access to the main information conduit, or "backbone", was generally not a significant problem for rural areas, there was little incentive to connect small towns and rural areas to the backbone by secondary lines. This was referred to as the "last mile" and continues to be a significant problem for rural areas within the contiguous United States. Additionally, isolated areas such as the many scattered and remote villages in Alaska or on islands, lacked fiber connection to the mainland. In both of these situations, lack of last mile connections and lack of fiber to the mainland, the highly publicized broadband applications for education, business and other resources simply were not reaching rural areas and would not extend to the most needed areas until changes in policy were implemented (NTIA, 2000). 
Importance of the Digital Divide

One might wonder why the digital divide has become such an important issue. What are the ramifications of this disparity in access to information technology? Emphasis has been placed on the economic consequences of the digital divide. Servon and Nelson (1999) considered the relationship between access to information technology and economic inclusion. The authors discussed the changes resulting from a global information-based economy. The following diagram illustrates the negatively reinforced problem:

Negatively Reinforcing Cycle of Digital Divide

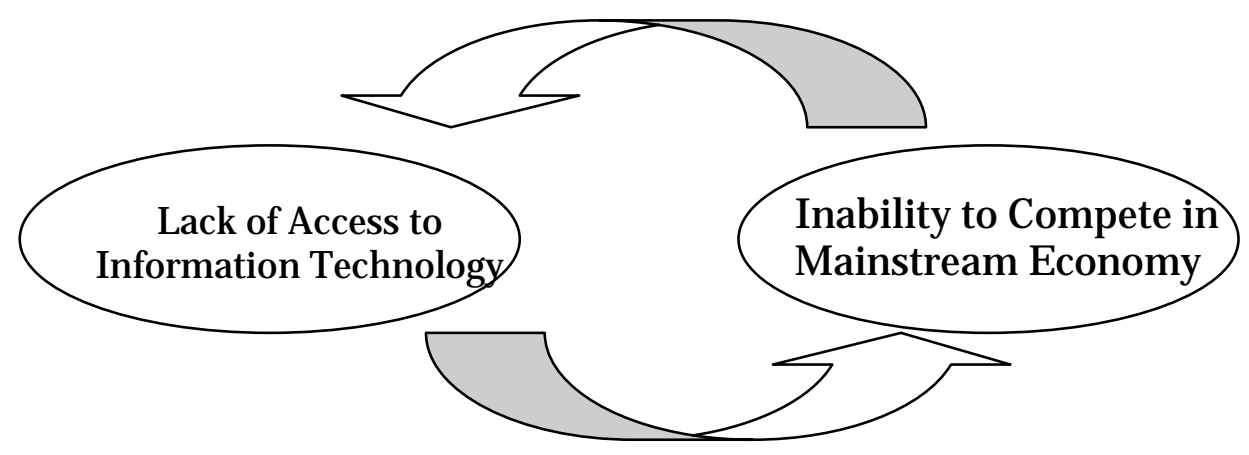

Figure 1 Servon and Nelson's (1999) representation of the negatively reinforcing cycle of the digital divide (p. 5)

Lack of access to information technology leads to inability to compete in the mainstream economy which in turn leads to lack of access to information technology. The NTIA (2000) called the digital divide “America's leading 
economic and civil rights issue" (p. xii). Penuel and Kim stated that the "digital access divide may in fact contribute to an opportunity divide in the new millennium" (2000, p. 2).

Morino (2000) looked beyond the obvious economic reasons for alleviating information apartheid:

If we lift our vision beyond access to technology alone, we can rally and focus these resources on the community infrastructure that helps individuals in low-income communities improve their own lives. We can apply technology to strengthen, to scale and even to redefine this infrastructure (p. 5).

Morino (2000) was convinced that the digital divide was a social divide and that overcoming social divides was investing in strengthening community infrastructure: "Isn't the ultimate possibility to apply the technology's potential to address the underlying challenges that are the true source of fundamental social divides in America?” (p. 2)

Morino (2000) is convinced that the value in overcoming the digital divide is:

people and organizations can be empowered to achieve improved outcomes with technology. We must always remember that the power of technology is not the computers, the complex of networks or the vast databases of information. Rather, it is people and their imagination, knowledge and resourcefulness that bring about change. Technology enables people to apply their imagination and 
knowledge and to do so more effectively, on larger scale and, most importantly, in ways not otherwise possible (p.6).

Strategies for Addressing the Digital Divide

In the U.S., the federal government has undertaken several initiatives to eliminate the digital divide. In ajoint publication, The National Telecommunications and Information Administration (U.S. Department of Commerce) with the Rural Utilities Service (U.S. Department of Agriculture) issued Advanced Telecommunications in Rural America, the Challenge of bringing Broadband Service to all Americans, in April, 2000. This extensive report included a description of the federally funded initiatives targeted toward populations which were underserved by information technologies: Universal Service Support mechanisms, E-Rate, Technology Opportunities Program (TOP) (formerly TIIAP), Neighborhood Networks, Rural Utilities Service (RUS), Community Technology Centers (CTC).

Universal Service Support

Section 254 of the Communications Act codified what had formerly been public policy. For more than 60 years this policy sought to provide ubiquitous and affordable telephone service throughout the United States. As a result of the Telecommunications Act of 1996, the Federal Communications Commission must ensure that universal service mechanisms target high cost areas such as rural locations. Although the definition of universally supported services was originally applied to telephone service, there has been growing support for broadening the 
definition to include advanced telecommunications services. E-Rate, which is discussed below, is a result of this idea.

\section{E-Rate}

E-Rate has been in operation since 1998. The E-Rate program affords lowincome schools, libraries and health care providers discounted rates of Internet access based on the percentage of students receiving free and reduced rate lunches. This program has brought Internet access to low income and rural areas in the contiguous United States, Alaska and Hawaii (National Telecommunications and Information Administration \& Rural Utilities Service, 2000).

TOP

The Technology Opportunity Program of the National Telecommunications and Information Administration (NTIA) of the U.S. Department of Commerce was known formerly as TIIAP, Telecommunications and Information Infrastructure Assistance Program. Since TOP/TIIAP was launched in 1994, it has supported programs in all 50 states, the District of Columbia, and U.S. Virgin Islands (NTIA \&RUS, 2000). This program specifically awards matching grants to state, local and tribal governments, health care providers, schools, libraries, police departments, and community-based non-profit organizations. TOP-funded projects have been model programs with funds used for equipment, training, communication services, and evaluation. The Economic Development Agency (EDA) of the Department of Commerce has funded telecommunications projects that have economic development impact. EDA-funded projects during fiscal year 
2000 emphasized the commercialization and deployment of technology for economic development (NTIA \&RUS, 2000).

\section{RUS Programs}

The Rural Utilities Service of the U.S. Department of Agriculture has provided loans for telecommunications infrastructure for over 50 years. RUSfinanced companies comprise approximately two-thinds of all rural telecommunications carriers. These telecommunications companies are now proving that advanced telecommunications services can be provided to remote regions. The Pine Ridge Indian Reservation of South Dakota is one of the poorest counties in the United States. RUS financing has allowed the Golden West Telecommunications Cooperative to deploy advanced service-capable loops at Pine Ridge. Now all Golden West subscribers have DSL (Digital Subscriber Line) capability (NTIA \& RUS, 2000).

RUS also awards grants and loans for distance learning and tele-medicine initiatives serving rural areas. RUS-funded programs have begun to make an impact in health care and education which raise the standard of living in rural communities to that of suburban counterparts (NTIA \& RUS, 2000).

Neighborhood Networks Program

The U. S. Department of Housing and Urban Development (HUD) encouraged the development of computer learning centers in HUD assisted or insured multi-family housing units. Since HUD offered no direct funding for Neighborhood Network Centers, the success of each Neighborhood Network Center was wholly dependent upon a working relationship between owners, 
housing management agencies, and residents. HUD allowed a portion of reserve funds to be allocated to developing and maintaining the Neighborhood Network Center. Many of the Neighborhood Network sites boast the graduation of residents from high school and college, the establishment of micro-businesses, and improved health of residents through access to telemedicine (NTIA \& RUS, 2000).

Community Technology Centers Program

The U.S. Department of Education's Community Technology Centers Program was designed to provide computer and Internet access and training for working-class families throughout the nation. CTC's purpose was quoted as to "promote the development of model programs that demonstrate the educational effectiveness of technology in urban and rural areas and economically distressed communities" (NTIA \& RUS, 2000, p. 38). The CTC initiative awards competitive three-year grants to public, non-profit, private, and for-profit entities. Total CTC funding for 1999 was \$10 million; FY 2000 authorized funding was \$32.5 million. All CTC-funded programs were expected to become community resources.

America Connects Consortium

In the second half of 2000, the America Connects Consortium contract was established under the US Department of Education's CTC program. The Consortium was led by Education Development Center, Inc. and included CTCNet, ICF Consulting, Alliance for Nonprofit Management, Alliance for Technology Access, CompuMentor, Information Technology Association of America and the National Alliance of Business. This initiative was supported by a $\$ 2$ million contract from the Department of Education as well as significant contributions 
from both the nonprofit and the business sector. The vision and goals of America Connects Consortium as extracted from its literature were:

Our Vision: To help centers create strong programs that leverage powerful computer technology to improve academic achievement, teach new job-related skills, build small businesses, and empower the most disadvantaged Americans to become "digital citizens."

Our goal: To find and apply the best tools, techniques, and teaching methods available, and to bring together community technology stakeholders from different sectors- including business, education, community development, youth development, and government- to solve common problems (America Connects Consortium, 2001).

\section{State and Local Initiatives}

In addition to the federally funded approaches for alleviating the digital divide, individual states and localities have supported strategies for addressing the information gap. Washington State passed legislation to encourage utilities to offer affordable broadband to rural areas. Several other states and local communities are using "demand aggregation" as a mechanism to attract the private sector investment needed to provide advanced services (NTIA \& RUS, 2000, p. 40).

Ultimately, many of these strategies to address the existing information technology apartheid utilized community technology access centers as the delivery mechanism for communities and individuals. The NTIA-RUS report emphasized 
continued support and expansion of those government programs, such as the Erate program, that ensure access to new technologies including broadband services. The report also urged the Federal Communications Commission to consider a definition of universal service and new funding mechanisms to ensure that residents in rural areas have access to telecommunications and information services comparable to those available to residents of urban areas. Support for alternative technologies would be crucial to the deployment of advanced services in rural America. NTIA has committed to increasing investment in research and development to promote the next generation of broadband technologies. NTIA and RUS thus have obligated themselves to collect and disseminate "promising practices" that can promote private sector investment in advanced telecommunications services for rural regions (NTIA \& RUS, 2000, p. iii). NTIA and RUS made the following recommendations:

1. Increase support for programs that would expand broadband infrastructure and innovative applications of information and communications technologies in rural America.

2. Adopt an evolving definition of "universal service" that would support advanced services in all regions of the nation.

3. Consider universal service funding mechanisms to fulfill the Act's mandate.

4. Reform RUS lending policies to stimulate private sector investment in broadband services.

5. Ensure continued support for the E-rate.

6. Publicize recent changes in the rural health care discount program. 
7. Collect and disseminate "promising practices" for accelerating private sector investment in rural broadband services.

8. Increase research to discover "last mile" solutions for rural America (pp. 41-44).

In early 2000, the Clinton Administration made budget proposals which included the following eight points:

1. $\$ 2$ billion in tax incentives over 10 years to encourage private sector donation of computers, sponsorship of community technology centers, and technology training for workers.

2. $\$ 150$ million to help train all new teachers entering the workforce to use technology effectively.

3. \$25 million to accelerate private sector deployment of broadband networks in under-served urban and rural communities.

4. \$10 million to prepare Native Americans for careers in information technology and other technical fields.

5. $\$ 100$ million to create 1,000 Community Technology Centers in low-income urban and rural neighborhoods.

6. $\$ 50$ million for a public/ private partnership to expand home access to computers and the Internet for low-income families.

7. $\$ 45$ million to promote innovative applications of information and technology and other technical fields. 
8. $\$ 100$ million in new loan authority and $\$ 2$ million in grants for RUS to target towards the provision of broadband and Internet service in rural areas. (NTIA \& RUS, 2000, p. 39).

Whether the Bush Administration, or succeeding administrations, will consider the digital divide a priority for action remains to be seen. Although \$32.5 million had been appropriated for the Community Technology Centers grant program in fiscal year 2002, less than \$15 million was released for the program (US Department of Education, 2002).

\section{Community Technology Centers}

As has already been discussed, residents of low-income communities have been disproportionately cut off from computer training and access. In an attempt to rectify this situation, community access centers have been developed in distressed communities. These centers offer computer access and training at low cost or no cost to information have-nots (Rose, 1997). Outside the United States, Telecentres and Telecottages have been launched to serve as loci of diffusion of skills and access to tools associated with information technology. The general purpose of the Telecentres has been to help people arrive at the point of personal information capacity (Fuchs, 1998). Ehrich and Kavanaugh (2000), in discussing the Blacksburg Electronic Village, note that making computing facilities available to the general public was part of their strategy to address concerns of the digital divide. 
However, along with the potential for greater linkage comes the potential for increased disparity for children who live in homes without the economic means to provide network access.... One of our goals is to increase the availability of computing facilities in the county libraries and to make new school computing laboratories open to the community after school hours. (p. 167).

In the $21^{\text {st }}$ century global economy, modern computing and communications technology constitute a vital factor within a strategy of community change and improvement (Breeden, Cisler, Guilfoy, Roberts, and Stone, 1998). The U. S. Department of Commerce assumed a pivotal role would be implicit for community information providers such as schools and libraries. In fact, according to the Department of Commerce (1995) report, Falling through the Net, community access centers would provide, at least during the interim period, a means for access to those who might not otherwise have access to electronic information services.

Characteristics of CTC's

Community technology centers are difficult to categorize. Servon and Nelson (1999) define Community Technology Centers as "locally based nonprofit organizations that link community residents to IT resources" (p. 8). The authors added that the goals of community technology programs are usually social: building community awareness, encouraging local involvement in community decision making, or developing economic opportunities in disadvantaged 
communities. Community Technology Centers have numerous synonyms. They are variously known as Community Access Centers; Community Technology Centers; Community Resource Centers; as well as Community Computing Centers (National Center for Small Communities, 2000). According to Fuchs (1998), “They (telecentres) bring 'state of the market' technologies and skills to 'back of the market' communities. This transforms the human, organizational and commercial capabilities of manginal communities and peripheral areas to participate in the Information Society" (Introduction, paragraph 12).

Community Networks

Though strictly speaking, Community Networks and Community Technology Centers are not synonymous, the two organizations are so closely related that they are virtually impossible to separate. According to Strickland (1998), a Community Network is an association that serves the communications and information needs of a community. In general, a community network is an organization which serves a community advocacy function and provides community organizations with the means to disseminate information and encourage public discussion and education. Cohill and others recommended that some public access centers be part of every community network to facilitate access for those who would otherwise lack access and to educate the citizens on how to access and use the resources available via computers and telecommunications (e.g. Cohill, 2000b). Thus, for purposes of this research, community networks are included as study subjects and sources of information. 
Community technology centers have been established around the globe from Finland to Australia. The first documented center in the United States was the Playing to Win Network, which began in New York City's Harlem district in 1981 (CTCNet, General History). Community technology centers may be either free-standing or incorporated into pre-existing community- based organizations. Rose (1997) categorized community technology programs into the following groups:

- Independent, free-standing agencies dedicated to the mission of technology access;

- Programs embedded within a multi-service agency;

- General public-oriented technology centers open to community members without restriction. These offer access and training on computer and telecommunications technology, including video convergence technology;

- Population-specific centers aimed at specific groups with specific needs, e.g. homeless persons, senior citizens, residents of a particular housing community;

- Multi-service centers, i.e. the CTC is part of an organization which delivers a range of services e. g. Child care, after school programming, housing, social services advocacy; 
- Community technology networks which operate not only their own CTC but also offer programs at other community-based organizations (p. 3.1).

Servon and Nelson (1999) reported that 57.4\% of their survey respondents operated through previously established organizations: $24.6 \%$ were housing project communities; $18.9 \%$ were schools; $15.6 \%$ were libraries; $38.6 \%$ were at multiple locations. Geographically, 64\% described themselves as urban; $8.1 \%$ were suburban; $13.8 \%$ rural; $13.8 \%$ mixed. While these centers represented different mission and goals, the core operating values were described as "core values that function as the base for a new kind community:" conviviality \& culture; education; strong democracy; health \&human services; economic equity; opportunity, and sustainability; as well as information and communication technology (pp. 8-12).

Use of CTC's and CN's

Servon and Nelson (1999) report that participants used CTC's as illustrated in the chart in Figure 2: 


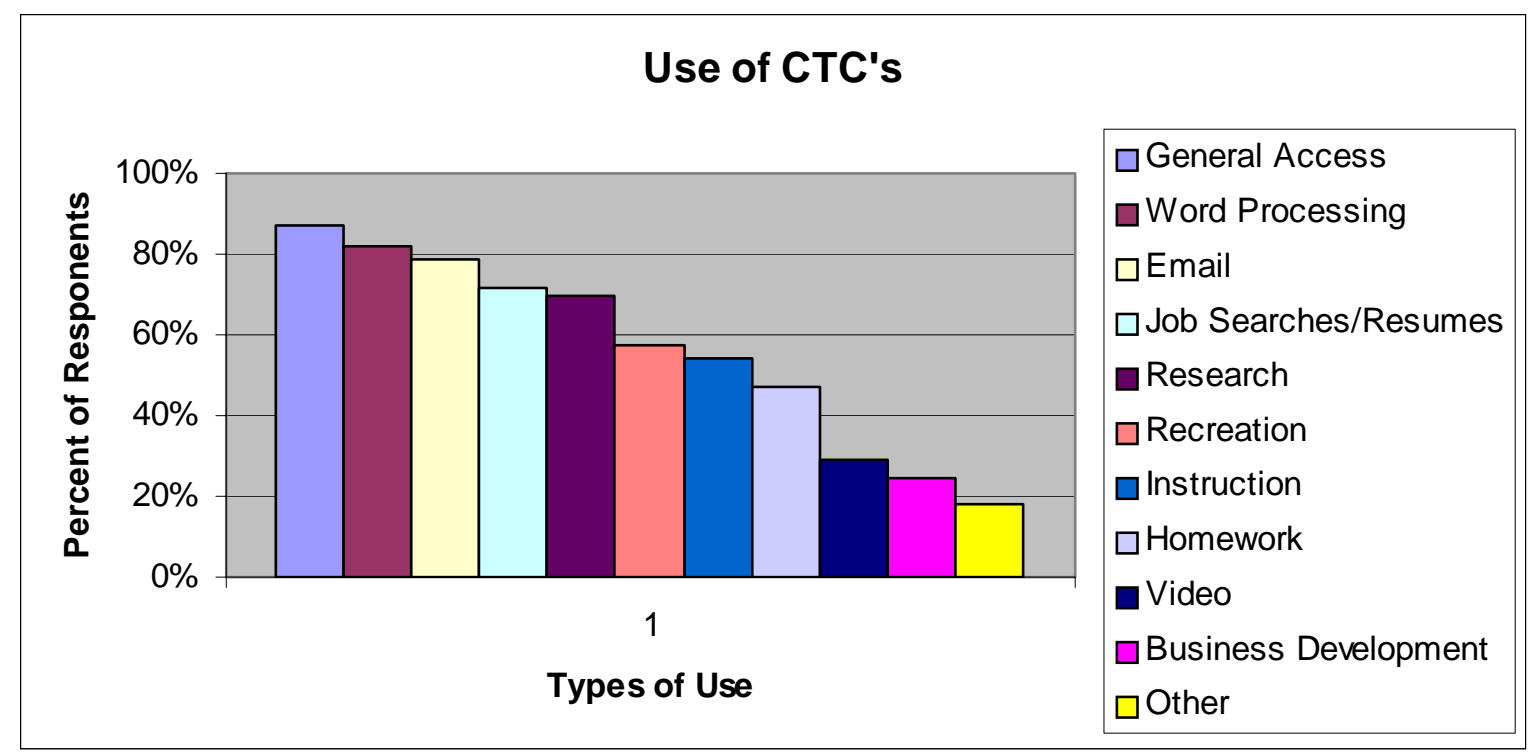

Figure 2: Use of CTC's by participants. From Servon and Nelson (1999). Totals are greater than $100 \%$ because subjects could choose more than one category.

The Children's Partnership (Lazarus \& Francisco, 2000) reported that adults in underserved communities wanted the following content in technologybased programs:

1. Practical information on local community

- local jobs listings including jobs requiring entry-level skills

- local housing listings

- Community information

2. Information at a basic literacy level

- Preparation for securing a high school equivalency degree 
- Online resources as opposed to print materials

- Online learning materials with multimedia components

3. Content for non-English speakers

- Online translation tools

- Online instructional materials

- Information in native languages

4. Cultural information

- Cultural exploration and development

- Cultural spaces about ethnic and local cultural interests

- Health information and other vital information geared to particular racial and ethnic groups (p. 5).

Variety of Missions and Goals

Community Technology Centers operated in a variety of organizations with diverse missions. Program offerings are equally varied. Breeden, et al (1998) reported that beyond the obvious goal of teaching technology dependent skills to constituents, CTC's listed the following as reasons why computers and technology training were important to programs:

- Employment-- 60 percent of all newjobs require technology skills. Higher order thinking skills will be required to keep the digital sweatshop from taking control. 
- Equity-- so low-income neighborhoods have the same chance as everyone else.

- Empowerment-- a tremendous sense of individual satisfaction. Attitudes toward learning and self-confidence increased.

- Education-- computers have educational potential.

- Community information source-- share information about communities. (pp. 1-3)

Community technology centers reported serving a wide variety of populations as illustrated by Figure 3:

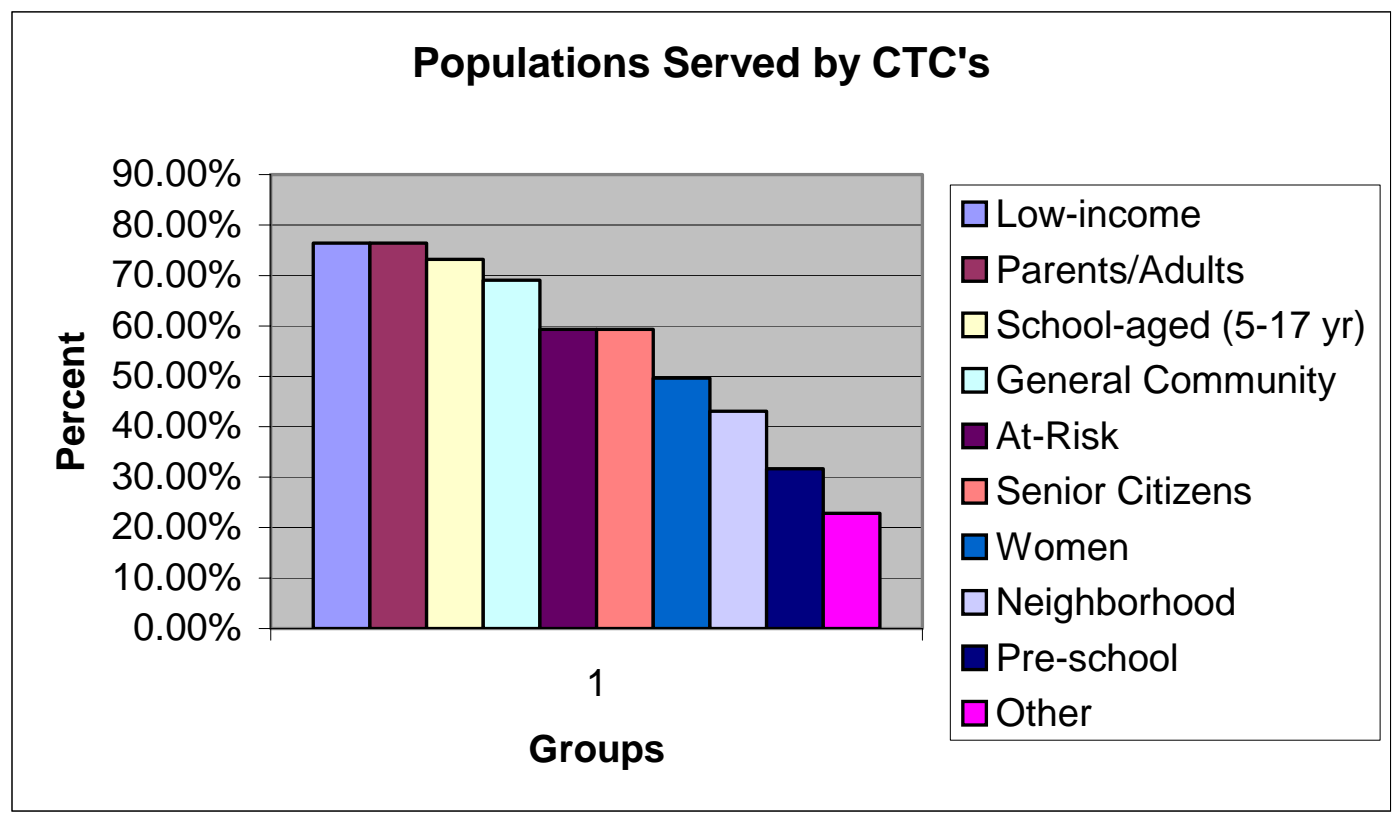

Figure 3: Populations served by CTC's. Totals are greater than $100 \%$ because respondents could choose multiple categories. The group labeled "other" included homeless and mentally ill persons, 
recent immigrants, artists, HIV-positive individuals and people

with AIDS, and absentee fathers seeking to get on track with child support payments (Servon and Nelson, 1999).

Organizations Connecting CTC's

Major organizations have developed as support networks and communities of practice for community technology centers: CTCNet, Neighborhood Networks, and Association for Community Networks. Community Technology Center Network (CTCNet) reported more than 500 affiliated centers at the 2001 Conference in San Diego, CA. Neighborhood Networks celebrated its 2000 Best Practices and Technical Assistance Symposium by awarding best practice honors to 35 programs located in HUD sponsored housing communities from Fairbanks, Alaska to J acksonville and Ocala, Florida (U.S. Department of Housing and Urban Development, 2000).

The Association for Community Networks (AFCN) maintains an online list of links to community networks around the globe. Visitors to the AFCN Website (www.afcn.org) are able to link to community networking centers from St. Petersburg, Russia to Victoria, Australia (http:/ / www.vicnet.net.au/). In November 2000, Barcelona, Spain was the host of the first worldwide conference devoted to community networks and community technology programs. 


\section{Rural Community Technology Centers}

\section{Rural Digital Divide}

The digital divide is particularly poignant as it affects rural areas. The U.S. Department of Commerce (1995) reported that no situation in the U.S. compared to the plight of the rural poor with respect to lack of access to computers and modems. Additionally, Rose (1997) described the digital divide dilemma as disproportionately affecting rural communities and central cities. The National Center for Small Communities (1999) asserted that many rural residents lack single-party, touch-tone service with digital switching, and line quality adequate for voice, data, and fax transmission at 28,800 bps. Blacksburg, VA with a population of approximately 35,000, was considered the "most wired community" in the world. Blacksburg reported that $86 \%$ of its residents use the Internet. Surprisingly, in rural Montgomery County, which surrounds Blacksburg only 20\% of residents use the Internet (Kavanaugh, Cohill, \& Patterson, 2000). Clearly residents of rural communities are at increased risk of lacking information access that is necessary for prosperity in the $21^{\text {st }}$ century information economy.

Rural analysts have argued that competition among service providers is not spreading to rural areas. Although in large cities and suburban communities a wide range of fast and affordable service providers are available, rural and small communities are lucky to have any options. Some providers required long distance calls for their rural customers. Telecommunications service providers preferred urban areas where costs are spread over many more customers and distribution volume is high (NCSC, 1999). 
In general, the telecommunications backbone is not the problem for rural information infrastructure. The "last mile" is the greatest challenge to bringing advanced telecommunications to rural residents. Low population density is linked to high cost of service for any communications technology, especially for wireline services (NTIA \& RUS, 2000). Even though there already exists a wide range of innovative access technologies, the network economy will inhibit diffusion of these technologies into high cost, sparsely populated rural areas. More than market forces will be needed to bring advanced telecommunications services to rural areas (Manohar, 2001).

Effect of Information Apartheid on Rural Communities

The effect of lack of information access and telecommunications infrastructure cannot be understated. The rate of deployment of advanced telecommunications services was deemed critical to the future economic growth of every region. In particular, rural areas could benefit greatly from high-speed connections to urban and world markets (NTIA \&RUS, 2000 ). Lack of information infrastructure with the resulting lack of access to telecommunications services exacerbates conditions of disenfranchisement by limiting the development of computer and telecommunications skills. This situation negatively affects not only businesses and services that are traditionally considered telecommunications and computer dependent, but all sectors of the economic environment.

Definition of Rural

"Rural” can have different connotations. Rural communities can be characterized by population size and distance from urban centers. Frequently the 
word "rural" evokes images of isolation, homogeneous culture, strong sense of local identity, and economy based on natural resources. Some of these stereotypes are not justified. Rural communities may be ethnically diverse and often are depopulated due to de-industrialization of a region (Flora et al, 1992).

Definitions of rural have evolved over time. In 1874, the U.S. Census Bureau identified rural counties as those with towns of fewer than 8000 residents. By 1980, the concept of non-metropolitan counties was developed. Non-metropolitan counties could include cities of 50,000 population and smaller. Rural was restricted to open countryside or towns of fewer than 2500 residents. Currently, the U.S. Census Bureau defines standard metropolitan area (SMA) as a county or group of counties with at least one city of 50,000 or more inhabitants. Those areas not meeting the SMA criteria are non-metropolitan counties. Other federal agencies defined rural areas as open country, communities of up to 20,000 residents in non-metropolitan areas, and towns of 10,000 having rural character but lying within standard metropolitan areas. Clearly there is no one definition of rural. The Economic Research Service of the U.S. Department of Agriculture has introduced the following set of definitions to further classify non-metropolitan counties: 
Table 1

\section{Definitions of Urban-Rural Characteristics}

\begin{tabular}{|c|c|c|}
\hline $\begin{array}{c}\text { Urban } \\
\text { Character }\end{array}$ & Location & Definition \\
\hline \multirow[t]{2}{*}{ Urbanized } & Adjacent & $\begin{array}{l}\text { Counties with an urban } \\
\text { population of at least 20,000 that are } \\
\text { adjacent to a metropolitan county, } \\
\text { with "adjacent" defined as both } \\
\text { touching an SMA at more than a } \\
\text { single point and having at least } 1 \\
\text { percent of the labor force commute } \\
\text { to the central county of the SMA for } \\
\text { work }\end{array}$ \\
\hline & Nonadjacent & $\begin{array}{l}\text { Counties with an urban } \\
\text { population of at least } 20,000 \text { that are } \\
\text { not adjacent by the above definition }\end{array}$ \\
\hline \multirow{2}{*}{ Less urbanized } & Adjacent & $\begin{array}{l}\text { Counties with an urban } \\
\text { population of } 2,555 \text { to } 19,999 \text { and } \\
\text { adjacent by the definition given for } \\
\text { urbanized adjacent }\end{array}$ \\
\hline & Nonadjacent & $\begin{array}{l}\text { Counties with an urban } \\
\text { population of 2,500 to } 19,999 \text { and } \\
\text { not adjacent by the definition given } \\
\text { for urbanized adjacent }\end{array}$ \\
\hline \multirow{2}{*}{ Rural } & Adjacent & $\begin{array}{l}\text { Counties with no places of } 2,500 \text { or } \\
\text { more population and adjacent by } \\
\text { the definition given for urbanized } \\
\text { adjacent. }\end{array}$ \\
\hline & Nonadjacent & $\begin{array}{l}\text { Counties with no places of } \\
\text { 2,500 or more population and not } \\
\text { adjacent by the definitions given for } \\
\text { urbanized adjacent. }\end{array}$ \\
\hline
\end{tabular}

(Flora, et al, 1992, pp. 8-9)

Within this study, "rural" refers to rural adjacent or non-adjacent and less urbanized, nonadjacent communities described in the above table. 
Challenges for Rural Communities

As was previously stated, rural communities are areas of relatively low population density. This low population density results in lack of infrastructure, higher cost of building and maintaining infrastructure, and lack of market incentives for investment in infrastructure. Infrastructure can refer to water, sewage, transportation and especially information infrastructure. Without infrastructure to support advanced telecommunications, access to opportunities and services supported by advanced telecommunications are limited. Consequently, fewer opportunities for economic development, education, health care, social and cultural enhancement exist. Out-migration leads to negative population growth and fewer residents participating in traditional rural vocations. The economic base erodes and the cycle continues in a negatively reinforced spiral.

The following diagram (Figure 4) is an oversimplification, but does help illustrate the situation: 


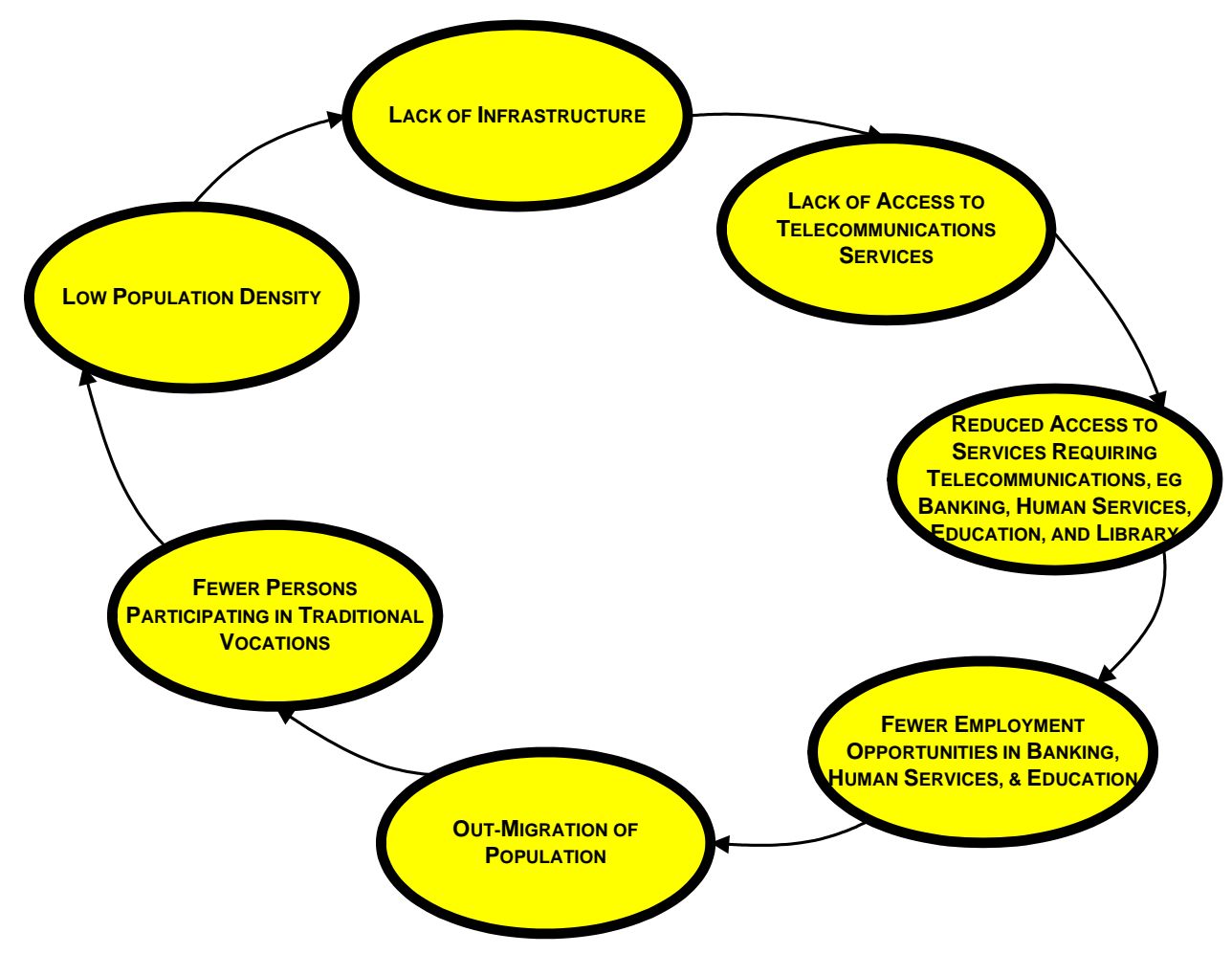

Figure 4: Telecommunications Infrastructure and Economic

Erosion- a downward spiraling cycle wearing away the economic base in rural communities.

Clearly the challenges which rural communities face are problematic. No simple, one-dimensional solutions exist. The following case descriptions illustrate the variety of strategies rural communities have employed to bridge the digital divide by establishing community technology access centers.

Blacksburg Electronic Village

Blacksburg, population approximately 35,000, in rural Montgomery County, is the home of Virginia Tech. In the late 1980's, faculty and staff of Virginia Tech expressed interest in having access to the university network from their homes. Blacksburg's town government and the local telephone company 
formed a partnership that led to Blacksburg Electronic Village (BEV). Five years after the founding of BEV, Blacksburg reported that $83 \%$ of its residents used the Internet. In the surrounding rural county, $20 \%$ of the residents reported using the community network (Cohill, 1999).

Blacksburg Electronic Village has been the subject of several published reports on community networking and community access centers. BEV initiated a program with the support of TIIAP that had the following goals:

1. Educate a wide variety of rural, underserved users in Montgomery County to integrate Internet-based services into daily life and work;

2. Evaluate and test the replication of the BEV model of community networking through a formal partnership with another community;

3. Assist other communities interested in networking by augmenting and enhancing the BEV clearinghouse of information and documentation;

4. Evaluate the effectiveness of training and replication efforts using both quantitative and qualitative methodologies.

This effort was conducted using a computer lab in a public school and another in a public library. Cohill (1999) believed that every problem encountered in the development of successful community networking projects was an education problem, rather than a technology problem. Cohill and other researchers made a series of recommendations for community technology and community networking projects that will be discussed more fully in the following section on success factors. 
La Plaza-Taos, NM

Taos, NM is a city of approximately 4300 residents and serves as the county seat of Taos County (pop. approximately 25,000). Taos is home to a triethnic community: Hispanic, Anglo, Pueblo- Native American. La Plaza Telecommunity began operations in December 1994. La Plaza is considered a model for other rural community technology projects and has received the AOL Rural Telecommunications Leadership Award, a TIIAP Grant, funding from the United Cerebral Palsy Foundation to ensure access by differently-abled residents, as well as funding from state sources (Strickland, 1998).

Strickland extensively studied the development of La Plaza. The central mission of La Plaza was "to provide free access and training through a public access facility to all Taos residents" (1998, p. i.). Though the La Plaza Telecommunity later transitioned into a fee-based Internet service provider, free public access sites continued to be maintained in the towns of Taos, Questa, and Peñasco. Scholarship Internet access accounts provided dial-up service to homes for $\$ 7.00$ per month. La Plaza (2002) provided outreach trainers at public access sites, maintained a Web portal of locally relevant information, afforded users space to build personal Web sites, and participated with local and regional artists to show and market their work.

Strickland's study of La Plaza's early development outlines something of a rocky beginning. Indeed Stickland (1998) describes "making big, whooping mistakes, and hopefully, learning something from them" (p. 235). The management difficulties that nearly destroyed La Plaza provided some glaring perspectives on how not to build a community technology project. According to 
Strickland, community technology initiatives represented organizations which intersected both people and technology. Consequently, the technical problems associated with community technology programs were insignificant in comparison to the social problems that might reside in the community. In the case of La Plaza, the online community, which had been described as a way to free users from isolation became a vehicle for community members to express hostility and to get noticed in their isolation. One of Strickland's interviewees was more generous and stated "No one knows how to build a TeleCommunity service. No one. Cut them some slack so that they have a chance to write the book" (p. 234).

\section{ACEnet}

The Appalachian Center for Economic Networks (ACEnet) is a community economic development initiative with headquarters in Athens, OH. Currently, ACEnet focuses on specialty food products and the technology sectors to develop economic opportunities. ACEnet provided basic services that businesses needed to start and expand, and created networks of entrepreneurs to interact with each other. Sharing information and employing economies of scale usually available only to large businesses became possible via the network (About ACEnet, 2000). ACEnet works with public access computer centers to incubate business capacity.

Big Sky Telegraph and Dillonet—Dillon, MT

Dillon, MT is home to Western Montana College of the University of Montana. Big Sky Telegraph (BST) began in 1988 as an initiative of Western Montana College. Big Sky offered online courses for rural teachers in one- and two- room Montana schools (Odasz, n. d.). Though BST was not strictly a 
community technology center offering public access to computer technology,

Dillonet was born from the experience of BST. Dillonet was a community network which offered locally important information and maintained public access centers in Dillon (population 4000) and several very small villages. This initiative grew from the vision of two retired local schoolteachers. Dillonet started out as a single, used PC in a small office but grew to six computers in local public offices, and 12 loaner computers which could be borrowed for $\$ 3$ per day. Nine small communities have Dillonet public access centers. Participants at Dillonet sites paid for their instruction by volunteering their own time to teach others the newly acquired skills. Dillonet was named a finalist in both the international "Bangemann Challenge Community Innovations Competition" and the "America Online Rural Innovations Competition" (Odasz, n. d.).

One Dillonet public access site was in J ackson, MT (pop. 48). The J ackson community technology center was in an old public hall which also served as home to the volunteer who maintained the site. Residents of this community began to use Internet access to locate obscure parts for ranch machinery, market local products, and comparison shop without leaving the community. The founders of Dillonet explained that they have only provided citizens with the opportunity to learn computer skills, Internet browsing and searching skills, and helped them create their first web pages.

Labrador, Canada

The Southern Labrador Telecentre is located in Forteau. Forteau is a community of 600 people on the south coast of Labrador, Canada, one of seven 
communities that encompass the Labrador Straits. The total population of the region is approximately 2000 persons. The region's economy was traditionally built around fishing. The fishing industry of this vicinity supported a successful fishing industry until 1992 when fish stocks dropped to an all-time low. The Telecentre became a key partner in community planning to deal with the fishing crisis. This community technology center became the region's key information resource as well as an active business support center (Fuchs, 1998).

Australia

Australian rural communities began to feel increasingly disadvantaged in the late $20^{\text {th }}$ century. Global economic restructuring and trade liberalization, as well as a decline in government services and entitlements, were responsible for the unsettling of the former prosperity of rural Australia. The Federal Department of Primary Industries and Energy decided to test the Telecentre/ Telecottage model in response to the circumstances. The town of Walcha (population 1700) developed a relationship with the University of New England in Armidale. Federal funding was obtained to set up a technology-based community education and training center. The Walcha Telecottage was opened in July, 1992 (Fuchs, 1998).

In late 1992, Cygnet Telecottage was launched in Cygnet on the south coast of Tasmania. Cygnet Telecottage formed a strong bond with local government. The Port Cygnet Council acted as the sponsoring agency and provided support to the endeavor. In J anuary 1993 a similar project was initiated in Byron Shire with the support of the Byron Shire Council. A change in Federal government policies 
and financial difficulties with the Byron Shire Council ultimately were responsible of the failure of Byron Shire Telecottage Network (Fuchs, 1998).

\section{Europe}

In Wales (U. K.), farming, mining, and steel production formed the foundation of the economy. Since the decline of these industries, most rural jobs have been low paying service and retail sector jobs which employ over half of the rural population. At Llangedwyn Mill, a medieval grain mill was acquired by Antur Tanat Cain (Antur means enterprise, Tanat and Cain are local rivers) with the idea of building a complex to house artists and craft workers as well as to provide space to accommodate small businesses. Antur Tanat Cain received a government contract to provide job training for local unemployed persons. One of the tasks of the job-training plan was a survey of the local cemeteries to preserve a written and photographic record of all gravestones in the region. Computers were obtained to use in databasing the cemetery information.

The habitually wet weather of the British Isles often kept the cemeteries surveyors from their work. Workers requested that they be allowed to use the computers to learn other applications on days when inclement weather made outdoor work impossible. From this unlikely beginning, the Antur Tanat Cain Telecottage was born and spread to other Welsh towns and villages to become the TeleCottages Wales (Fuchs, 1998). TeleCottages Wales has become sustainable by offering business consultant services throughout their communities (Telem@, 2002). 
In Faergelanda, Sweden, share capital was used to launch Telecottage Faergelanda. The founders included local government, the regional adult education school, Dalslandsc Folkhogskola, the business community, the rural health care service, and a rural development agency. Each founding agency expected to have access to better-trained workers who were coached at the Telecottage. Additionally, the Telecottage was expected to generate its own revenue from doing business. By 1998, there were seven enterprises working with computers and information technology in Faergelanda that could be identified as direct spin-offs of the Telecottage (Fuchs, 1998).

\section{Africa}

The people of Mamelodi, South Africa knew the problems that they faced as a disadvantaged community in a world approaching a global information society. The process of establishing a Community Based Information Service (CBIS) in Mamelodi, South Africa, involved convening delegates from youth, women, entrepreneurial, political, education, health, church, non-profit, community-based organizations, government and other organizations. The convention became a workshop to explain the concepts of information access and the issues affecting the lives of community residents. Mamelodi Community Information Services (MACIS) was established out of this convention. The community's role was to ensure that MACIS was driven by the information needs of the community it served. Residents of Mamelodi were convinced that MACIS provided them with the information that they needed to survive (Fuchs, 1998). 
The salient point is that there exist many examples of effective rural community technology projects worldwide. Studies on these initiatives have been case studies or foundation reports. Little has been done to collect and distill the experiences of these rural technology projects. Building a body of knowledge for rural communities desiring to develop community technology centers or projects would prove valuable to local leaders.

\section{Effectiveness Issues and Measures}

Evaluation/Effectiveness Measures

The question of how to measure or evaluate the success of community technology projects is a critical issue. CTCNet has published an evaluation kit for community technology centers. This package contains sample forms designed to collect data in an assortment of areas. The package contains the following:

- Self-Assessments of basic computer skill,

- Staff Background Questionnaire to assess interests and skills of staff (paid and volunteer),

- Technology Needs Survey of the center,

- Center Benchmark Tool used yearly to track equipment and materials,

- Organizational Communication Strategies instrument,

- Mission Definition Tool,

- Generic Member Survey designed to understand member needs and interests, 
- Demographic Survey for participants,

- Student Survey designed to understand the needs and interests of students in grades 6-12,

- Participant Skills Assessment and Inventory,

- Participant Interview prepared by CTCNet Research and Evaluation team,

- Staff Interview Protocol,

- Community/ Board Member Interview protocol,

- Technology Center User Survey,

- Course Evaluation Interview Protocol,

- Course Evaluation Questionnaire,

- Web Site Evaluation for Secondary Grades (Chow, Ellis, \&Walker, 2000).

While each of these tools may prove useful to individual community technology centers, none of these instruments will yield information concerning how to develop an effective or successful center. The study by Penuel and Kim (2000) emphasized that traditional assessments used to measure school success are inappropriate for community technology centers. Outcome measures closely tied with specific goals of community technology centers must be developed, argued Penuel and Kim. Measures of participants' career aspirations and trajectories, expectations for the future, and technical skills were examples of more appropriate measures of program effectiveness, according to these authors (2000). 
In the case of Blacksburg Electronic Village, Kavanaugh, Cohill and Patterson (2000) elaborated on findings based on a series of quantitative and qualitative studies conducted with support from various local, state, and national agencies: profiles of users, use and expectation of the Internet, trends among the general population, impact of networking on community, changes on business trends, public access and training at the public library. At BEV, an advisory panel developed an evaluation strategy based on three assumptions: 1) the social construction of technology, 2) the interpretation of use and design, 3) the importance of a multidisciplinary approach to evaluation. Early on, the panel realized that the conventional Shannon and Weaver communication model did not capture the nuances of communication as applied to BEV. In fact, none of the existing communication models: 1. General models of information society; 2. Models that described the flow of information traffic; 3. Models providing a vision of the regulatory environment surrounding the creation of information technology and business, provided a conceptual fit for BEV. BEV needed a simple model that captured the range of communication theory. Thus the Tetrad model of evaluation of community network was proposed. 


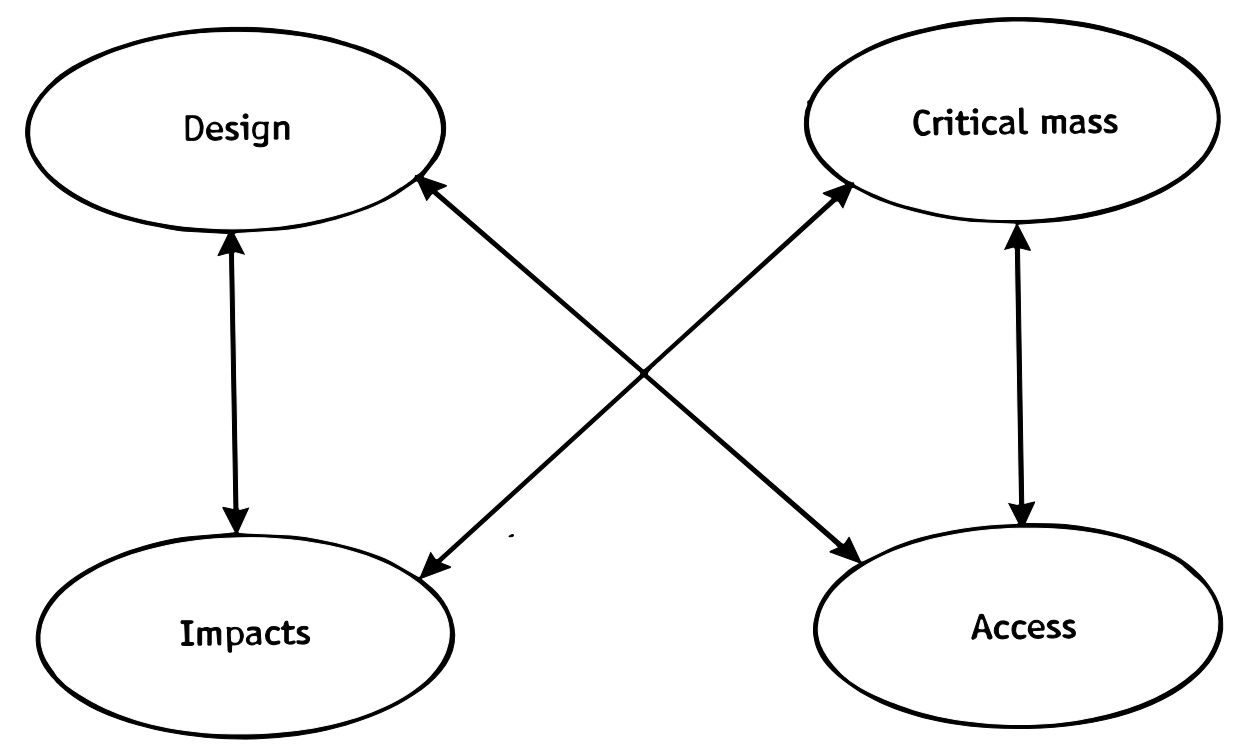

Figure 5: Patterson (2000) Tetrad Model of Evaluation of Community Computer Network (Patterson, 2002, p. 66, fig 4.1)

Patterson (2000) listed lessons learned from the evaluation efforts of BEV:

1. Interdisciplinary collaboration is key on obtaining a valid picture, no single discipline could supply the conceptual and methodological framework to create a robust picture of the substantive phenomena.

2. The evaluation process must begin before the technological intervention or implementation.

3. All members of the evaluation team must agree to the public dissemination of the results and findings.

4. The evaluation process must extend to compare one community to another, i.e. the unit of evaluation must be the community. There were not enough evaluation instances to compare or make 
predictions to create a general theory of community computer networking.

5. The purpose of the evaluation was to empower the community and be responsive to the community initiative

The discussion of evaluation framework by Patterson concluded that researchers from social sciences, hard sciences, engineering, urban planning, theater, anthropology, literature and almost any other discipline could offer important conceptualizations to the evaluation of community technology initiatives. Consequently, an effective evaluation model needed to provide room for researchers from many disciplines to contribute to the evaluation strategy and to learn from the model. Patterson (2000) concluded:

The methodological domain deals with the tools that researchers use to see empirically what is happening. Reliance on a single method of making observations is a recipe for a myopic vision of the substantive domain. An ideal evaluation program should incorporate the diversity of methodological approaches available. The validity of the evaluation increases as experts from many different disciplines bring their discipline-specific conceptualizations and methodologies to bear on the same problem. (p. 63)

America Connects Consortium Suggestions

America Connects Consortium recently issued a fact sheet with regard to evaluating community technology centers. This document states that the goals of 
evaluation should be relevant, realistic and directly tied to the purpose of the program. Also within this fact sheet, Education Development Corporation outlined several steps useful to evaluating community technology learning centers:

- Define the program and its goals. Goals need to be relevant to the needs of the community and realistic with respect to available resources.

- Identify the indicators of success. What impact should the program have on the community? Cite realistic evidence of this impact.

- Determine the method of evaluation. Will interviews, questionnaires, observations or a combination of methods give the best information?

- Collect and analyze the information. Determine how this information will be used to improve program offerings.

- Tailor findings to take into account the needs of funders while helping staff improve programming practices.

- Create a partnership with the evaluator to obtain a clear understanding of how programs are working and how they might be improved (America Connects Consortium, ACC Fact Sheet \#2).

Evaluations of Existing Programs

BEV's HistoryBase project leveraged the networked environment and the World Wide Web to automate the collection and integration of information to document the history and progress of the project. HistoryBase combined a 
database with a Web interface and a system of meta-tags to create a record of the events that occurred in BEV. Other researchers could analyze and evaluate the project from HistoryBase (Schmidt \& Cohill, 2000).

Penuel, Michalchik, Kim \& Shear (2001) published an evaluation of six community technology programs who were grantees of the U.S Department of Education's Community Technology Center program. Frechtling, Silverstein, Snow, \& Somers (2000) were responsible for case study evaluations of US Department of Commerce TOP (TIIAP) initiatives. J ohnson \&J ohnson Associates (2001) prepared an evaluation of TOP projects which were funded initially in 1996 and 1997 for three years. These evaluation reports were based on interviews with program staff at the technology programs. These people have a stake in ensuring that their programs could be labeled "successful" by the evaluators. Indeed, funders shaped not only the programs they fund, but also program evaluations by their reporting requirements. Evaluation framework and frequency depend heavily on funding and the requirements of individual funders (Penuel \& Kim, 2000). The PowerUP program initiated by America OnLine issued its first program evaluations in March 2002. This evaluation focused on outcomes for youth at the PowerUP funded sites.

The research community has begun to gain insights into how communication and information technologies might support development in underserved communities. However, many important questions remain about how community organizations might best use existing research and how additional data collection might enable programs to grow, innovate, and refine their 
technology initiatives. Moreover, Ba, Culp, Green, Henriquez, and Honey (2001) concluded:

Although community-based technology programs are expanding quickly, rigorous research documenting both effective program design and outcomes lag behind. Questions remain about the kinds of conceptual frameworks and practical tools that will genuinely help community organizations to determine whether their programmatic efforts are meeting their goals. We still have much more to learn about how underserved communities actually make use of the computer and Internet in their daily lives (p. 16)

This fact is uniquely illustrated by a request which appeared in the America Connects Consortium's listserv. The following email exemplifies the need for the development of frameworks for evaluation of community technology programs as well as definitions and measures of success:

I have been, recently, engaging in discussions about how best to measure the success of a nonprofit "Learning Community" web site, and what constitutes success. This is possibly an unanswerable question, as each web site is unique in its mission and goals. Is there anyone on this list that is aware of resources, or able to offer comment on this subject? (Glynn, July 7, 2001)

Characteristics of Effective Initiatives

Breeden, et al (1998) concluded that an effective program would have these characteristics: 
- Effective planning and design,

- Well-trained staff and volunteers,

- Thoughtful up-to-date curriculum,

- Inviting physical environment.,

- Expert support,

- Evaluation.

Cohill (1999) stated that an effective community networking project will have achieved a "critical mass" of network users, i.e. that point at which there are so many users that the applications and information become truly useful thus making a whole range of additional applications feasible. Ehrich and Kavanaugh (2000) indicated that BEV was effective because BEV and the accessibility of electronic communication played an important role in significant changes in public education throughout the county.

Penuel and Kim (2000) described effective centers as providing a variety of opportunities for individual learning as well as organizational learning. Centers defined as "effective" by these researchers were able to locate and use multiple forms of collaborative relationships within the organization and from the broader community to survive and thrive. Organizational support was needed for centers to function effectively while providing high quality learning opportunities, and retain qualified staff.

Bowden, Blythe \& Cohill (2000) stated "the true measure of success in the project will not be the number of consumers of information services and 
products, but will be the number of community producers in the proposed environment" (p. 17). These researchers add :

It (BEV) has never been seen as primarily a technology trial, like some fiber-to-the-home or gigabit testbed. While some new technologies have been tested in the BEV, the emphasis has always been on the provision of useful information to the end user (p. 21). Martin and Cohill (2000) reflected the same thinking in regard to Blacksburg Electronic Village:

An electronic village is not just a connection to the Internet. It is a group of geographically co-located individuals, interacting electronically with each other, with local content, and with the worldwide resources of the Internet. Where does that local content come from? Well, without a large staff whose only purpose would be to gather and post information, we had to rely largely on volunteers, and many of our early volunteer contributors were project champions. (p. 285)

In a computer-mediated discussion forum attended by leaders from international Telecottages, Fuchs (1998) asked participants “How do you know a Telecentre has succeeded?" Signs of success were noted, with the discussion listing the following as characteristics of successful centers:

- The growing number of users

- The growing business (start with basics then add more services for hire) 
- How the ICT (Information and Communications Technology) market is growing ( If, for example, e-mails are being utilized to the extent that there is demand for the growth of the market) and if local people grow links with international markets

- If there is a development, e.g. of a market for web-based content creation in the community, because others (entrepreneurs and NGOs) want either to develop their web pages or want their information on your web page

- If there is a growing demand for Telecentre services in the area to the extent that other agencies establish their Telecentres.

- If some entrepreneur develops a business around the servicing and maintenance of IT and ICTs in the area/ community

- If some entrepreneur sees the opportunity to develop and provide some software support in the area

- If an NGO or an entrepreneur in the community sees the need or possibility of providing training for ICTs in the area

- If some entrepreneur/ NGO sees the market to develop ICT networks and infrastructure in the area

- The final turnover of business of the Telecentre. (Chapter 10, paragraph 7)

Ward (2000) indicated a similar progression at Blacksburg with respect to business incubation. As community use of networked telecommunications grew, many new Internet- based businesses developed. This was an expected and hoped 
for outcome, but it also brought difficulties. Many residents became upset when their new privately supplied Internet service was not as robust as the service formerly provided through VA Tech. Ultimately, network congestion became such an issue at BEV that a local access switch had to be installed.

However, Paddy Moindrot from the telecottage in Wales responded to the question “How do you know a telecentre has succeeded?" as follows:

To survive is to succeed! Length of survival is in proportion to success. The most successful might be the longest survivors on the least funding. In the public eye, the most successful are the best self-publicists. Like getting on the cover of Rolling Stone! (Fuchs, 1998, Chapter 10, paragraph 7).

Perhaps sheer survival does indeed characterize the effective community technology center.

\section{Information Technology and Social Change}

Communications and Information Infrastructure

Maughan (2001) has defined the components of a robust model of communications and information infrastructure as:

1. Devices: e.g. Telephone handsets and headsets, computers, card swipes, fax machines, satellite uplinks or downlinks, videoconferencing cameras and monitors, LCD projectors;

2. Networks: Optical fiber, coaxial cable, twisted pair copper wire, servers, wireless transceivers, coders and decoders, hubs, bridges, switches; 
3. Skills: Knowledge and abilities to plan, install, maintain, and use components of the infrastructure;

4. Budget: The financial resources to acquire, operate, and maintain systems, including salary, capital, and reoccurring money;

5. Policies: Formal intellectual property, copyright and privacy laws, as well as informal guidelines, rules, and procedures on who, where, how, and when information can be accessed and used, and when and how equipment and software will be upgraded and/ or replaced, and what type of vendor agreements and partnerships will be established (p. 21).

Maughan (2001) described access as the ability of users to input or output information to be stored, retrieved, processed or transferred. Users might manipulate information differently, but they need to access correct information at the proper time. Users need information that pertains to their situation and do not need unnecessary information. Evaluation of the effectiveness of the communication and information system involves assessing a range of issues. Moreover, separating human, financial, and policy consideration from the technical system components may provide an excellent technical system but an inappropriate operational and strategic perception. The same may be true for community technology centers.

Referring again to Maughan (2001), mature communications and information systems exhibit a set of characteristics:

- A critical mass of each of the five elements above is evident.

- Elements are matched according to similar maturities, thereby the system is optimally efficient. 
- Size or complexity may be an indication of maturity, but small communications and information structures may be mature.

- An operational and maintenance plan has been negotiated and is in place

- A plan to respond to change is in place.

Social Informatics

According to Kling (2000a), "Social Informatics is the body of research that examines the design, uses, and consequences of information and communication technologies in ways that take into account their interaction with institutional and cultural contexts" (p. 245) (italics in original). Early research on the social implications of communication and information systems was largely deterministic. Researchers asked questions concerning the impact of an Information and Communication Technology (ICT) on society. Study questions took the form of "Will A or B occur when a given ICT is implemented?" According to Kling (2000b) the answer is not A or B but sometimes A, sometimes $\mathrm{B}$, and sometimes variations of $\mathrm{AB}$. In other words, "ICT, in practice, is socially shaped" (p. 219)(italics in original). Thus any local computing package is a combination of equipment, people, governance structures, and policies. The local computing package forms a socio-technical network. The more realistic perspective of the impacts of ICT required shifting to an understanding that the impacts of communications and information systems were socially created.

Kling (2000b) discussed socio-technical networks as highly intertwined complexes. While researchers commonly separate artifacts (generally called the 
"technology") from social contexts, the highly intertwined model suggested by Kling views the technology in use and the social world as not separate from each other, but as co-constituting each other.

Kling (2000b) characterized access to technology as having two components: 1. Technological access and 2. Social access. Technological access referred to the physical availability of suitable equipment and infrastructure, while social access referred to professional experience, economic resources, and technical skills. Most development efforts of CTCs assumed that if technical access were supplied, social access would follow. However, both Kling's highly intertwined social informatics model and Maughan's robust communication and information system model predicted that access was much more than simple technical access. Both researchers asserted that access to communication and information technology was dependent upon a complex set of social, political, economic and technical factors.

\section{Planning for Rural CTC's}

Since developing even a modest community technology center can entail significant resources, planning for effective programs is obligatory. Neighborhood Networks, CTCNet and the National Center for Small Communities (NCSC) have published planning guides which are available from the respective organizations. The Neighborhood Networks planning guide (1998) included a form for a business plan. However the Neighborhood Networks guides went on to say that there are so many flavors of Neighborhood Networks Centers that there was no one right way to write the business plan. 
CTCNet’s Start-up Manual (Stone, 2000) suggested a 12-month timeline for planning and opening a new community technology center. Suggestions were made for roles and tasks necessary for steering council members. CTCNet also discussed determining the focus of programs and important partnerships that should be cultivated (Stone, 2000). The National Center for Small Communities guide presented planning for community technology centers as part of a small community's strategy for embracing the Internet as a tool for improving communication and service delivery. NCSC (1999) directed readers to the CTCNet Start-up Manual for more specific planning information.

Individual practitioners have published guidelines for planning community technology programs. Odasz (1998) suggested that planning should start from the activity of writing a press release describing the new community technology center. Cohill (2000c) includes a succinct two-page set of guidelines for community networking projects and an even briefer one-page guide. Cohill advocated "planning lightly" when beginning a community networking project. This was taken to mean that planning must be flexible to accommodate rapid changes in technology, varying levels of sophistication in infrastructure, and changing community needs. Cohill (2000d) stated that planning too rigidly could be as detrimental as not planning thoroughly enough. In fact, according to Cohill, "Many of our most successful efforts were the result, not of complex, inches-thick planning documents, but of ear-to-the-ground abrupt changes of plan, just because of what we heard from the community" (p. 344). 
Planning to meet Rural Challenges

Little to address specific rural challenges was discussed in the available planning guides. The NCSC guide enumerated various solutions for overcoming the shortages of telecommunications infrastructure that plague many rural communities. National Center for Small Communities (NCSC) listed case studies of rural communities employing public access strategies:

- Mountain Association for Community Economic Development (MACED), eastern Kentucky

- KooteNet, Lincoln County, Montana

- Vermont Telecommunications Application Center (VTAC), Burlington, VT

- Grow Iowa Foundation, Inc six counties in Iowa

- Blacksburg Electronic Village, Blacksburg, VA

- Northern Hills Community Development, Inc, which coordinates Telecommunications Solutions for Rural Revitalization in the Black Hills of South Dakota (ch. 4, pp. 10-17).

Strategies employed by these initiatives may find application in other rural communities.

NCSC (1999) advocates strategic planning for telecommunications in rural communities. This may seem an obvious step, however, many rural communities did not realize the importance of planning for information infrastructure. According to NCSC, the following steps were involved: 
- Identify gaps in existing telecommunications infrastructure to pinpoint problem areas.

- Prioritize problems to address first.

- Identify common areas of concern to create opportunities for partnerships.

- Build broad-based support.

- Coordinate multiple strategies.

These steps could be summarized as 1 . Needs assessment; 2 . Goal prioritizing and setting; 3. Crafting and implementing an appropriate action plan (NCSC, 2000). According to NCSC (2000) “Community leaders can help bring telecommunications access to towns or cities by establishing a public-access site at a local school, library or community center."(ch. 1, p. 11)

NCSC (2000) regarded rural electric co-ops as having a stake in becoming the vendors of information services to their customer base. The National Rural Electric Cooperative Association consisted of 1000 electric co-ops in 46 states. As an example, Northwest Iowa Power Co-op was making huge investments in fiber-optic infrastructure throughout its service region. Additionally, when US West did not meet customer need for high-speed telecommunications capacity in Aberdeen, SD, Northern Electric Cooperative joined with J ames Valley Telephone Company to provide the service. The resultant Northern Valley Communications became a Competitive Local Exchange Carrier, LCEC, competing with US West. The communications system has been upgraded with an ADSL switch. The communications infrastructure allowed attracting a 3M plant and a Super 8 
Reservations Center to Aberdeen. Now a "smart park," wired for high- speed communications, will add another attraction for businesses. Obviously, proactive planning in communications and information infrastructure can assist rural communities in economic development.

These strategies may not be without controversy, however. When residents of Hawarden, Iowa were frustrated with poor cable service, they convinced the municipality to create a municipally owned cable/ communications utility as part of an upgrade to the existing electric utility. The Iowa Telecommunications Association challenged the municipality. The District court ruled in favor of Hawarden. The Iowa Supreme Court overturned the District Court ruling, but later re-heard the case and ruled in favor of the municipality (NCSC, 2000).

Ward published a guide for the technical aspect of planning a rural community technology project or a rural community network. According to Ward's (2000) outline for community technology planning, the following must be considered:

A. Services-- local Web pages, local chat service, Email lists, user email forwarding addressed, user email accounts, local network news discussions,

B. Local access-- public access terminals; modem pool; ISDN, cable modem, and DSL, town ethernet utility.

C. Providers-- local; remote; or do-it-yourself.

D. Support services-- for public access; for modem pool; network server; network connection. 
E. Equipment location.

F. Procurement and installation-- hardware, software, data lines ( pp. 274-276).

Obviously, differing opinions regarding planning for community technology initiatives exist.

Critical Factors for Developing Effective Community Technology Programs

Various authors have published lists of important factors extracted from their practice. Servon (1999) attributed success at community technology centers in the Pittsburgh, PA area to the following factors:

- leadership of community members,

- leadership from city government,

- partnerships with well-established institutions,

- support from local foundations,

- strong university presence,

- strong neighborhood organizations (p. 47).

Rose (1998) noted that Technology in Learning's most effective outreach efforts were through partnerships with existing organizations. Cohill (2000) stressed the importance of community partnerships: local government, public libraries, public school system, key business persons, local higher education, and active citizens. Penuel and Kim (2000) recognized the importance of partnerships. According to their research, partnering organizations should take responsibility for outreach and identifying potential participants. The community technology center provides extended learning experiences for the 
collaborative partner organization. Based on their findings, Penuel and Kim (2000) stressed the value of creating a network of individuals, organizations, and businesses to support the improvement of practices within community technology centers. Many promising practices in pedagogy (e. g. project-based learning), and organizational support already exist, but must be collected and disseminated. Penuel and Kim (2000) emphasized the need to invent a set of tools and resources for programs that do not yet exist. The knowledge from the experience of community technology practitioners must be collected and distributed across people, environments, and situations to improve practice. Much intelligence and wisdom in this area already exists but must be collected and distributed to those who need it in the field.

\section{The Case for Blended Methodology}

Patton (1990) discussed in depth the various strengths and weaknesses of both the logical positivist paradigm, which uses quantitative experimental methods to test hypothetical generalizations, and phenomenological inquiry which applies qualitative approaches to inductively understand human experience in context specific situations. Experimental designs are best adapted to situations where it is possible to limit program change and improvement so as not to interfere with the research design. However,

under real-world conditions where programs are subject to change and redirection, naturalistic inquiry replaces the fixed treatment/ outcome emphasis of the controlled experiment with a dynamic, process orientation. A dynamic evaluation is not tied to a 
single treatment and predetermined goals or outcomes but focuses on the actual operations and impacts of a process, program, or intervention over a period of time. (p. 42)

Qualitative methodology focuses on documenting process, discovering variations and exploring individual differences in experiences as well as outcomes. In contrast to the quantitative/ experimental research designs which require specification of main variables and a statement of specific research hypotheses before data collection, the qualitative/ inductive approach seeks to understand program activities and outcomes that emerge from experience within the setting. Theories about program processes and outcomes are grounded in direct program experience (Patton, 1990). The two methodologies are not mutually exclusive or diametrically opposed.

Indeed, there is often a flow from inductive approaches, to find out what the important questions and variables are (exploratory work), to deductive hypothesis testing aimed at confirming exploratory findings, then back again to inductive analysis to look for rival hypotheses and unanticipated or unmeasured factors (p. 46). Consequently, matching research methods to the purpose of a study and the questions asked is of primary concern (Patton, 2000).

The advantages of using quantitative variables and indicators are parsimony, precision, and ease of analysis. Where key program elements can be quantified with validity, reliability, and credibility, and where necessary statistical assumptions can be met (e.g. 
linearity, normality, and independence of measurement), then statistical portrayals can be powerful and succinct.

The advantage of qualitative portrayal of holistic settings and impacts is that greater attention can be given to nuance, setting, interdependencies, complexities, idiosyncrasies and context. (pp. 50-51)

Patton (2002) concludes by saying "The methods of qualitative inquiry now stand on their own as reasonable ways to find out what is happening in programs and other human settings" (p. 90).

\section{Grounded Theory}

Grounded theory was "discovered" and elucidated by Glaser and Strauss (1967). According to Kendall (1999) grounded theory can be traced to the Chicago School of Sociology and the development of symbolic interactionalism. Symbolic interactionalism was developed as a reaction against the functionalist theories that dominated sociological thought. Symbolic interactionalist theory was introduced as an alternative approach that viewed society as a fluid and dynamic process of varied and reciprocating interactions.

Basically, grounded theory does not begin with a theory or hypothesis. Grounded theory begins with the research situation. Within the research situation the researcher's purpose is to understand what is happening and how participants manage their roles. Observation, conversation, and interview are the data collection methods. Interestingly, the literature is considered a data source 
on the same level with data collected from study participants rather than being given a position of priority. As such, the literature may be used in comparison with data collected from the research situation (Dick, 2001).

According to Dick (2001), grounded theory differs from other research methodologies in that it is explicitly emergent. Since no hypothesis testing is involved, doing grounded theory well often involves unlearning some research practices that have been internalized through the educational process. Consequently, though this study did not seek to produce a theory, grounded theory methodology was considered useful for allowing critical factors to emerge from the research situations.

Kendall (1999) stated in simple terms that the purpose of grounded theory methodology is to generate theory through an ongoing process of comparative analysis of the collected data. Data analysis occurs simultaneously with data collection. Each new data set is coded and compared to previously collected data. Theoretical memos written throughout the data collection/ analysis phase would conceptualize properties of theoretical ideas and constructs. As similarities and differences emerge during the data collection/ coding/ analysis process, codes are clustered together to form categories. Saturation is reached when no new categories are generated from the data. Identification of a core concept and the interrelationships among categories form the basis for the grounded theory.

Glaser and Strauss (1999) described two types of coding, substantive (open) and theoretical. Strauss and Corbin (1990) described open, axial, and selective coding. 
Kendall (1999) used both the coding described by Glaser and that reported by Strauss and Corbin to analyze the same data set. Kendall (1999) concluded that axial coding introduced by Strauss and Corbin was satisfactory for description when the researcher was interested in thematic analysis and concept development. However, to generate theory:

it is necessary to move on to selective and theoretical coding to gain a more complex and abstract level of analysis to integrate the categories and produce a theory. This can best be done by not becoming wedded too early in what looks obvious and putting extensive time into doing conceptual description via axial coding. (p. 755)

Dick (2000) presented a practical explanation of grounded theory research. The process is explained visually below:

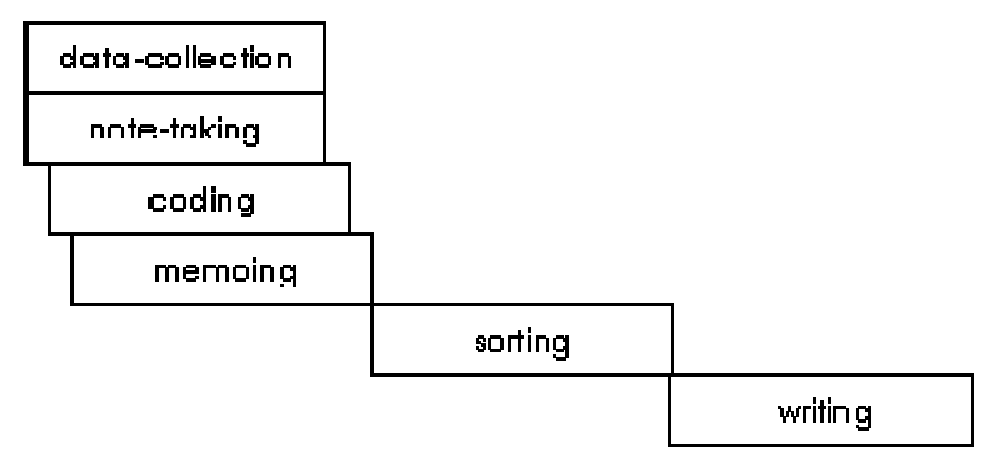

Figure 6: Grounded Theory Research Process as described by Dick (p.3) 


\section{Data Collection and Analysis}

Glaser and Strauss (1999) described the process of theoretical sampling used in grounded theory research. The researcher was encouraged to select study participants on the basis of theoretical relevance to the study rather than attempting to randomize the sample as in experimental-deductive studies. According to Glaser and Strauss, comparison groups should provide maximization or minimization of differences and similarities. Minimizing differences among comparison groups served to increase collection of similar data for any emerging category. Data similarities helped verify the existence of a category within the research situation, thereby strengthening the concept development. On the other hand, maximizing differences increased the probability that diversity would be noted and incorporated into the emerging themes and concepts.

\section{Summary of Review of Literature}

The digital divide phenomenon was predicted to be the cause of social upheaval and the establishment of a permanent underclass. Rural areas were reported to be at greater risk for suffering the consequences of the digital divide than urban locales. Community technology centers and community networks are two strategies employed to address the digital divide. Community technology centers and community networks have been launched in numerous locations worldwide. Planning and evaluation tools have been developed and are available. Individual writers and organizations describing their experiences have published lists of what factors are necessary to create successful community technology 
centers. However, none of these lists specifically target rural community

technology centers. Moreover, these suggestions are not based on research that compares more than one case.

Grounded theory methodology is based on ongoing comparative analysis of data from the research situation. The purpose of grounded theory research for this study was not theory generation, but rather thematic analysis and concept development from the data collected. As described by Dick (2001), the literature served as a source of data. Consequently, the grounded theory approach would be constructive for studying selected rural community technology centers in order for a substantive list or grouping of critical factors to emerge from the practices and history of the centers included in this study. Additionally, data collected from the literature could be compared with the data collected from the centers. The data would then be triangulated using another data collection tool. This would identify the critical factors for developing effective rural community technology centers by distilling wisdom from a variety of practitioners, which is the purpose of this research. 


\title{
C H A P T E R 3
}

\section{Method ol ogy}

\author{
Introduction
}

This chapter discusses the research design for this study. Development and pilot testing of the data collection instruments, inclusion criteria for study participants and the process for identifying potential rural community technology centers are presented. Data collection and analysis methods are addressed. A process diagram for ensuring data validity is included in the final section of this chapter.

\section{Purpose Statement}

The purpose of this research was to identify the critical factors for developing effective rural community technology centers.

\section{$\underline{\text { Research Questions }}$}

1. How is effectiveness measured in rural community technology centers?

2. What factors are critical for developing effective rural community technology centers?

3. What criteria should be used to measure critical factors? 


\section{Procedures}

\section{Review of Literature}

A review of the literature was conducted in the following areas: Community Technology Centers, rural Community Technology Centers including a survey of rural Community Technology Centers worldwide, effectiveness issues and measures, planning for rural Community Technology Centers, theories of information technology and social change, qualitative research methods and Grounded Theory methodology. Peer-reviewed material was available from scholarly journals in the areas of information and social change theories, qualitative research methods, and grounded theory methodology. References were obtained from the accepted scholarly research material located by searches through library catalogues and electronic databases. Literature pertaining to Community Technology Centers (CTC) was found in non-traditional places such as: The CTC Web site and Community Technology Center Network (CTCNet) newsletter and magazine, reports collected and published by Benton Foundation, Morino Institute, Children's Partnership, and National Center for Small Communities. Semi-scholarly studies published by Community Technology and Community Networking pioneers were available. Master's theses, doctoral dissertations and evaluations of programs funded by federal grants were also sources of information. America Connects Consortium published a comprehensive bibliography of Community Technology literature in 2001. Inclusion Criteria for Study Subjects The following criteria were required for subjects to participate in the study: 
1. The rural community technology center or rural community network must have been in existence for a minimum of two (2) years.

2. The area served by the center qualified as less urbanized, nonadjacent to a Standard Metropolitan Area (SMA) or rural adjacent or non-adjacent.

3. The person participating as the interviewee was a current paid or volunteer staff person at the rural community technology center.

4. If the subject was from a rural community network, the program made some provisions for public access through either a freestanding community technology center or a technology center within an existing community agency.

\section{Identification of Study Participants}

The theoretic sampling technique described by Glasser and Strauss (1999) was used. The study began by interviewing rural community technology centers staff identified in the Review of Literature. An appeal was made to the current 260 members of the Rural Telecommunications Congress to recommend potential study sites. The report by National Center for Small Communities (NCSC) (2002) was the source of a listing of 14 potential participants with contact persons. Individual sites reported in the Community Technology Review were also contacted. America Connects Consortium was contacted with a request to broadcast on the America Connects Consortium forum an invitation to participate in the study. Membership lists of the Association for Community Networks and 
the CTCNet were obtained from organizational Web sites. Finally, several personal contacts were asked to suggest potential participants. From these sources a list of potential study sites was created.

An initial phone contact was made to determine whether the technology center met inclusion criteria and whether potential study subjects would be willing to participate in the study. As the comparative analysis process proceeded, additional study participants were identified following the Glaser and Strauss (1999) strategy of maximizing and minimizing similarities and differences. Identification and selection of study participants from the list of potential study participants continued until saturation of categories was achieved. Saturation was achieved when no new categories were generated from interview data.

Although the goal of 15 to 20 participating centers was set initially, 26 centers meeting the inclusion criteria agreed to participate. Of these, 26 completed the telephone interview, but only 5 returned the quantitative survey.

Development of the Research Instruments

In order to collect data, two instruments were developed. The first, the Telephone Interview Protocol, consisted of open-ended interview questions. The second, the Rural Community Technology Center Survey, was comprised of opinion questions with Likert scale responses. Research cited in the Review of Literature and the Research Questions developed for this research were used to guide the development of questions for both the Telephone Interview Protocol and the Rural Community Technology Center Survey.

Questions for both instruments were based on information from literature sources. The suggestions in the literature were tabulated and reviewed for 
repeating themes. Each area identified in the literature became the basis for a question on the Telephone Interview Protocol. Additional questions were designed to probe for areas not already identified by other questions. All questions related back to the Research Questions guiding this research.

Literature sources, as well as the suggestions found in the case studies conducted by NCSC (2002) were used to guide formulation of questions in both the Telephone Interview Protocol and the Rural Community Technology Center Survey.

Based on Maughan's (2002) model of a robust telecommunication system and Kling's (2001) theory of social informatics, critical factors were anticipated to include a wide range of technical, social, economic, and policy issues. Earlier writers had alluded to this fact. Breeden, et al (1998) concluded that an effective CTC program would exhibit: (1) Effective planning and design, (2) Well-trained staff and volunteers, (3) Thoughtful, up-to-date curriculum, (4) Inviting physical environment, (5) Expert support, (6) Evaluation. Cohill (2000) mentioned a "critical mass" of users as being important for an effective community network. Patterson (2000) stated that existing communications models were incapable of explaining the Blacksburg Electronic Village (BEV) phenomenon and noted that after a technology has diffused through any culture, the technology is socially shaped. Patterson offered the Tetrad model of evaluation for BEV. Kavanaugh (2000) pointed out that Blacksburg Electronic Village was effective because of participating in significant changes in public education throughout rural Montgomery County, VA. However, Cohill (2000) stated that BEV's most effective initiatives were the result of listening to the needs of the community and that 
barriers to success were found to be educational problems, rather than technical issues.

The National Center for Small Communities (1999) reported that the steps for building an effective community technology initiative were: (1) Identifying gaps in telecommunications infrastructure, (2) Prioritizing problems to address, (3) Building broad based support, (4) Developing partnerships and (5) Coordinating multiple strategies. While certainly not related to a rural area, Sevron \&Nelson's work in Pittsburgh, PA (1999) noted the following as factors for success: (1) Leadership of community members, (2) Leadership of city officials, (3) Partnerships with well-established organizations, (4) Support from local foundations, (5) Strong university presence and (6) Strong neighborhood organizations.

These suggestions from the literature were analyzed using the Center for Disease Control EZ-Text (Carey et al, 1998). The resulting categories became the basis for the Telephone Interview Protocol questions.

Pilot Testing of Instruments

Both the Telephone Interview Protocol and the Rural Community Technology Center Survey were pilot-tested. Pilot testing followed the method outlined by Dillman (2002) which included the following stages:

1. Review by knowledgeable colleagues. This stage ensured that all the necessary questions were included and that answers to questions could be compared to data obtained from the literature. The feedback group consisted of graduate faculty members who were 
familiar with both the research topic and the methodology of qualitative analysis.

2. Evaluation of cognitive and motivational qualities. This purpose of this stage was to guarantee that the wording would be understood and interpreted similarly by subjects. Several persons from the researcher's place of work read the instruments and were interviewed by the researcher. Each person was asked to explain as completely as possible what they understood each question to be asking. The group consisted of persons from the housekeeping staff, the administrative staff and management.

3. Pilot study with small group. This step made certain that the response categories on the Likert scale distributed across the scale rather than being concentrated in one or two categories and that useful information would be obtained from the open-ended questions. This group was comprised of persons from the researchers place of work and included parents of children in afterschool programs, housekeeping staff, administrative staff and management.

A copy of each data-collection instrument is included in the Appendix.

\section{Data collection}

Individual centers were initially contacted by telephone with the request to participate in the study. The components of the study were outlined completely. Center directors, coordinators, managers, instructors, or volunteers with onsite 
experience were sought as study participants. An appointment to administer the interview by telephone was requested. All potential subjects contacted seemed interested in discussing their programs. One subject, a county Extension Agent felt that he could not discuss his program without first contacting his supervisor. Three potential subjects scheduled appointments for the interview but were unavailable at the interview time. Twenty-six interviews were completed.

Subjects were asked if they would allow the interview to be tape-recorded. Twenty-three interviews were taped. Two participants declined to be taped and one interview was not taped due to equipment malfunction. Participants were supplied with a copy of the interview questions prior to the actual interview. Participants could elect to receive a summary of the results if they so desired.

Interviews followed the semi-structured questions in the Telephone Interview Protocol. The questions were meant to start conversation on a given topic. Additional questions or prompts were printed on the interviewer's protocol sheet and were used to probe more deeply into the question's topic or to stimulate further conversation. Each interview was designed to last 15-20 minutes. Few of the subjects restricted themselves to the time limit. Most seemed excited to discuss their centers.

Following the suggestion published by Dick (2000), notes were made during the interviews. All taped interviews were transcribed. Interview tapes were reviewed to verify and augment notes. Notes from interviews and interview transcripts became the raw data for analysis. 


\section{Likert Scale Questions}

After the qualitative interviews had been coded and analyzed, and the codes placed into thematic groupings, participating centers were again contacted by telephone. Subjects who previously responded to the telephone interview were requested to conclude their participation in the study by completing the Rural Community Technology Center Survey. This portion of the study required only 5-10 minutes. Subjects were allowed to take the survey via email or facsimile. While the interview data was considered primary, the purpose of this data collection step was to allow triangulation with the qualitative data collected through the interview process. No attempt was be made to generalize results from the Rural Community Technology Center Survey for a larger population.

Unfortunately, very few subjects returned the survey. The researcher had anticipated a high return rate based on the personal relationships developed during the interviews. Telephone conversations with personnel from the centers indicated that staff changes and various program closings contributed to the low rate of return. Some subjects were simply not available to take the survey due to illness, vacations and other personal reasons. A total of six surveys were returned which represented $23 \%$ of the subjects interviewed.

Analysis of Data

Analysis of data followed the plan described by Dick (2000). Data analysis occurred simultaneously with data collection. The answers to the interview questions and the notes made during the interview were coded in an ongoing process. As coding was carried out, memos were made. These memos comprised a separate set of notes consisting of ideas that were generated during the coding, 
review, and comparison steps. Coded responses were grouped into similar clusters. Clusters of codes formed thematic groups. Data collection and analysis continued until the codes were saturated. Saturation was achieved when no new codes were generated from the data. Each individual code was considered to be a factor. When codes were grouped into thematic groups, the groups were termed "critical factors." Memos written during coding and categorization were used to build and enhance the concepts of how the factors worked together to make an effective rural community technology center.

\section{Coding Process}

Coding progressed according to the method outlined by Carey et al (1998) and illustrated in Figure 7 below:

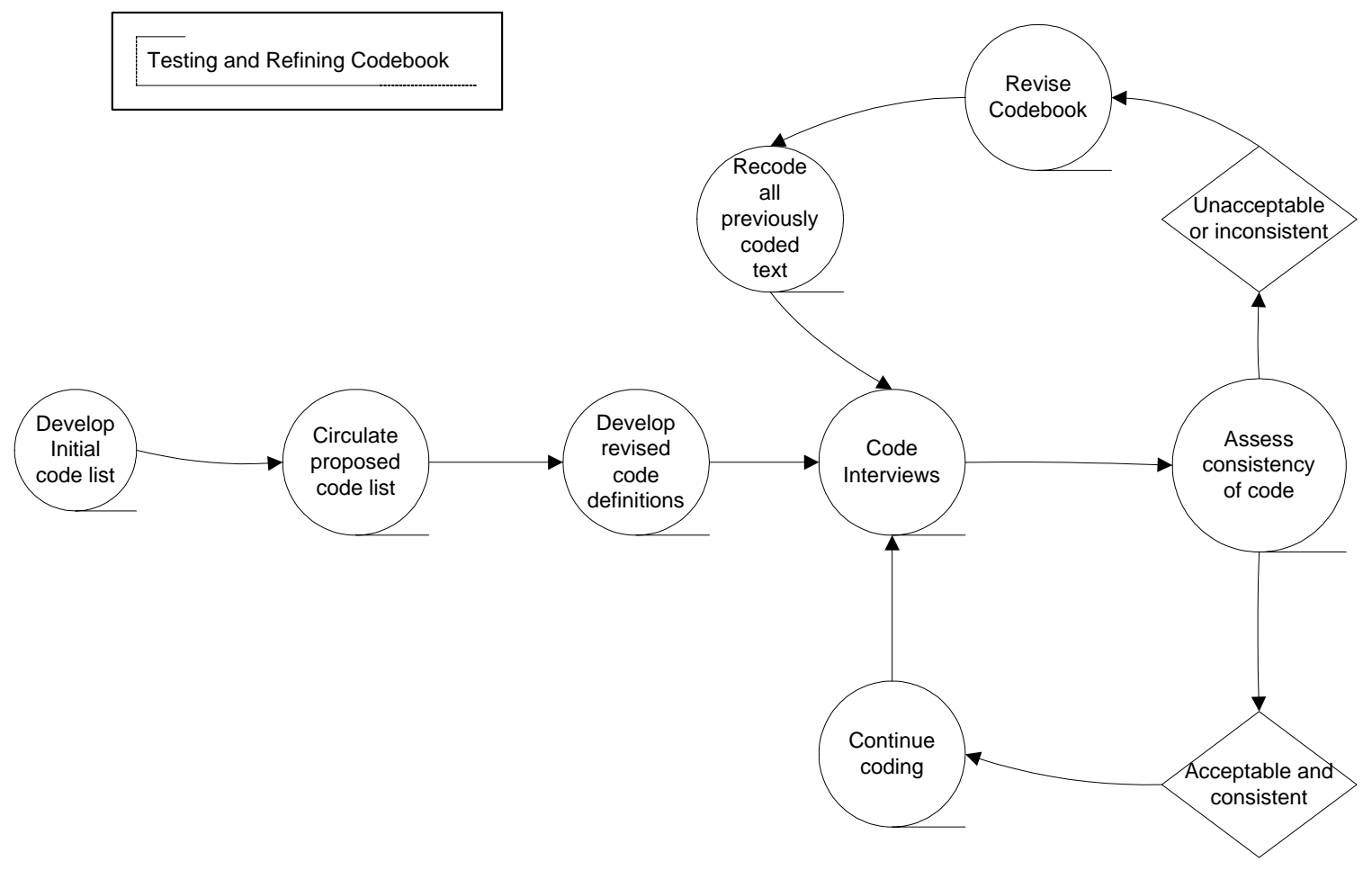

Figure 7: Schematic of Codebook Testing Process Flow 
Developing and Refining the Codebook

The codes used to analyze the raw data were developed as the data were analyzed. The base of the codebook was derived from the fourteen case studies reported by NCSC (2002). Each case study was read by the researcher with the intent of identifying factors which were identified in the case study as important. A list of 23 codes was derived from the case studies and placed into the codebook table of EZ-Text.

After each interview was transcribed and segmented into the EZ-Text analysis tool, responses were read and codes assigned to the ideas expressed by the subject. New codes were added to the codebook as new ideas were expressed. When new codes emerged from the data and were incorporated into the codebook, the researcher re-read all interviews such that the new codes could be assigned where necessary. This became an iterative process until no new codes emerged from the data. The final codebook consisted of 120 codes. Each interview was read and coded a minimum of four times.

\section{Assessing Code Consistency}

To ensure consistency of data coding an independent coder was engaged. The independent coder was supplied with the raw data in the form of transcribed conversations in segmented electronic format, interviewer notes, and full taped interviews. The tapes were only to be reviewed when addition clarification was necessary.

The independent coder was requested to read the data, then code the data using and augmenting the existing codebook if necessary. The coded data from 
both the original coding and the independent coding were compared for consistency. The secondary coder found no instances requiring augmenting the codebook. Only rarely did the secondary coder add already existing codes to the raw data. This occurred 11 times in the secondary coding. Since the entire body of raw data yielded 1301 coding instances, the 11 occurrences of adding a defined code represented less that $1 \%$ variation in code assignment. In no cases did the secondary coder recommend removing an assigned code from the data.

Survey Data

Quantitative data were collected from the Rural Community Technology Center Survey. The primary purpose for collecting data from the survey was to triangulate and validate the results of the analysis of the qualitative data. Unfortunately, a low rate of return (23\%) limited the usefulness of the survey data. However, no survey results were inconsistent with the interview data. After both the qualitative and quantitative data sets were analyzed, conclusions and inferences that address the problem statement were made. Results were summarized and recommendations made for further research. 


\section{Research Flow Diagram}

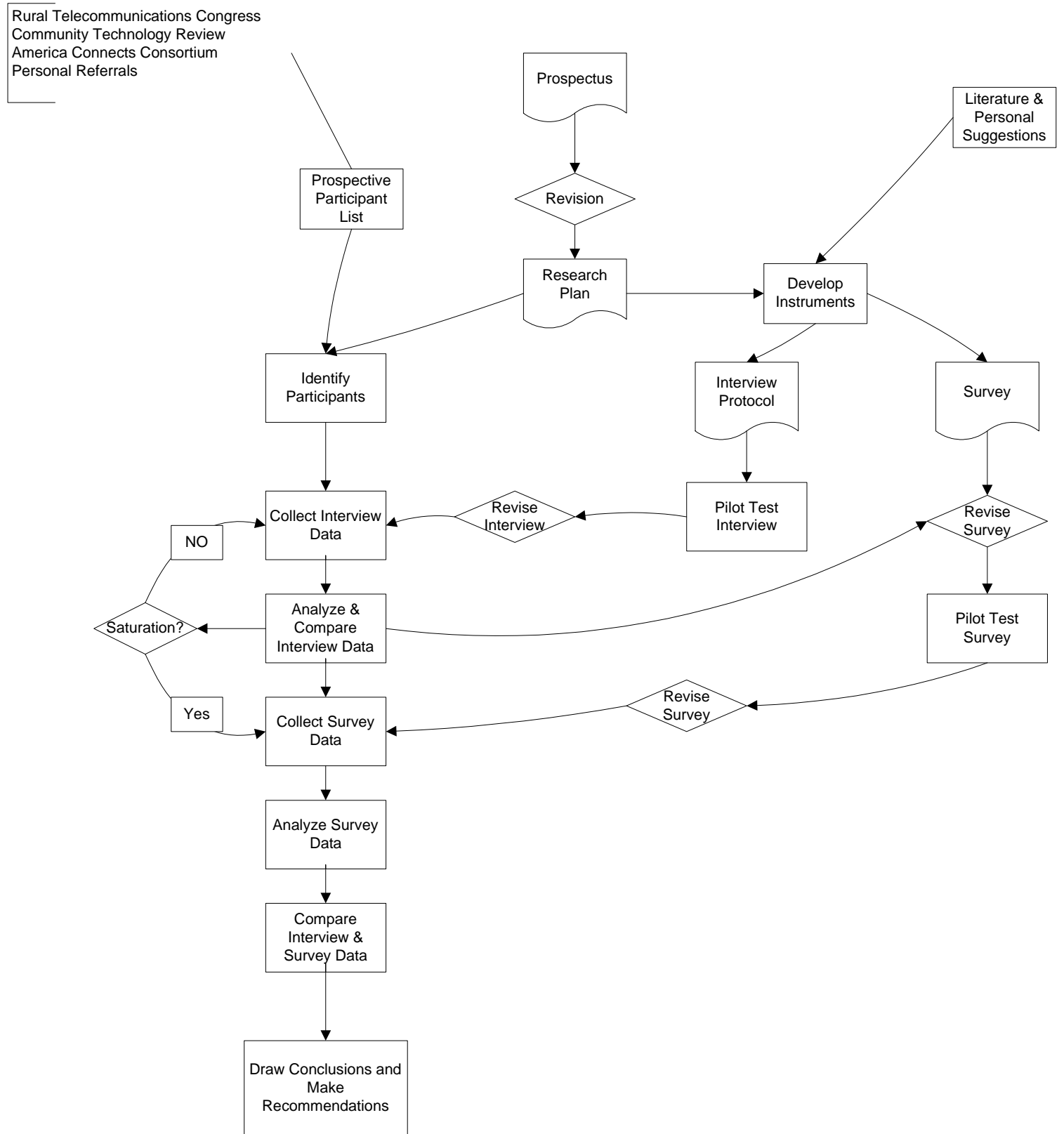

Figure 8: Research Process Flow Diagram 


\section{H A P T E R 4}

\section{Res u l t s}

\section{Introduction}

This chapter describes the study sites, the data-collecting processes and the results of data analysis with respect to the study questions. The unique features of rural community technology centers are discussed at the end of the section covering Study Question 2. Implications of the study results are discussed in the final section of this chapter.

\section{Procedures}

An initial list of potential subjects was built from the membership lists of CTCNet and the membership of the Association for Community Networks. From this list of over 800 potential subjects, 120 sites were identified that met the inclusion criteria for being rural. Attempts were made to contact each of the locations to schedule an interview at a convenient time.

Inclusion Criteria for Study Subjects

The following criteria were required for subjects to participant in the study:

1. The rural community technology center or rural community network must have been in existence for a minimum of two (2) years. 
2. The area served by the center qualified as less urbanized, nonadjacent to a SMA or rural adjacent or non-adjacent.

3. The person participating as the interviewee was a current paid or volunteer staff person at the rural community technology center.

4. If a rural community network, the program made some provisions for public access through either a freestanding community technology center or a technology center within an existing community agency.

Qualitative Data

A maximum of three attempts was made to contact each potential subject to schedule an interview at a time convenient to the subject. Over $50 \%(>60)$ of the telephone numbers on the initial list of 120 were either to programs no longer in existence, wrong numbers or disconnected numbers. From this initial contact, a list of 26 interviewees scheduled times for interviews. Table 2 describes the sites included in the study.

\section{Table 2:Description of Sites Included in Study}

\begin{tabular}{llll}
\hline $\begin{array}{l}\text { Subject } \\
\text { Identifier }\end{array}$ & Location & Subject & Description of Site \\
\hline 61 & Decorah, IA & Librarian & $\begin{array}{l}\text { Site was housed in public library. It had } \\
\text { been in operation at least 4 years }\end{array}$ \\
\hline 35 & York County, & Network & $\begin{array}{l}\text { A community network. Met criteria of } \\
\text { rural, adjacent, but might also be called } \\
\text { suburban. Library serves as public access } \\
\text { site. }\end{array}$ \\
\hline
\end{tabular}




\section{Table 2: (continued). Description of Sites Included in Study}

\begin{tabular}{|c|c|c|c|}
\hline 96 & Central PA & $\begin{array}{l}\text { Activities } \\
\text { Coordinator }\end{array}$ & $\begin{array}{l}\text { Center was part of community center in } \\
\text { Section } 8 \text { (HUD subsidized) housing } \\
\text { project. CTC operating since 1996, } \\
\text { community center has been operating for } \\
20 \text { years. CTC started with funds from } \\
\text { local church. }\end{array}$ \\
\hline 45 & Arkansas & $\begin{array}{l}\text { Technology } \\
\text { Coordinator }\end{array}$ & $\begin{array}{l}\text { Part of a multi-service center which had } \\
\text { been serving community for } 25 \text { years. } \\
\text { RCTC in existence } 3 \text { years }\end{array}$ \\
\hline 86 & Western NY & $\begin{array}{l}\text { Technology } \\
\text { coordinator }\end{array}$ & $\begin{array}{l}\text { RCTC was a partnership with public school } \\
\text { district. Teaching lab housed in school }\end{array}$ \\
\hline 89 & Rural Ohio & Director & Center with focus on Arts \\
\hline 103 & $\begin{array}{l}\text { Marble Falls, } \\
\text { Texas }\end{array}$ & $\begin{array}{l}\text { Technology } \\
\text { Director }\end{array}$ & $\begin{array}{l}\text { Area is rural, but becoming a bedroom } \\
\text { community for Austin. }\end{array}$ \\
\hline 115 & $\begin{array}{l}\text { Eastern } \\
\text { Washington }\end{array}$ & Librarian & Center is part of a local public library \\
\hline 31 & $\begin{array}{l}\text { Rural } \\
\text { Vermont }\end{array}$ & Staff person & $\begin{array}{l}\text { Community Network is only ISP for area. } \\
\text { Located in a museum. Public access site } \\
\text { available also. }\end{array}$ \\
\hline 56 & $\begin{array}{l}\text { Hawaii-large } \\
\text { island }\end{array}$ & $\begin{array}{l}\text { Technology } \\
\text { Coordinator }\end{array}$ & $\begin{array}{l}\text { A Boys and Girls club located on the large } \\
\text { island of Hawaii. The center itself is in the } \\
\text { plantation house of an early sugar cane } \\
\text { plantation. }\end{array}$ \\
\hline 53 & $\begin{array}{l}\text { Southwestern } \\
\text { Delaware }\end{array}$ & $\begin{array}{l}\text { Program } \\
\text { Coordinator }\end{array}$ & $\begin{array}{l}\text { A state-of-the-art Boys and Girls Club } \\
\text { which also serves as a community center to } \\
\text { area. }\end{array}$ \\
\hline 76 & $\begin{array}{l}\text { South-central } \\
\text { Minnesota }\end{array}$ & $\begin{array}{l}\text { Technology } \\
\text { Coordinator }\end{array}$ & $\begin{array}{l}\text { A project of the county Extension Service. } \\
\text { Teaching lab in local public school. }\end{array}$ \\
\hline 110 & $\begin{array}{l}\text { Northern } \\
\text { Vermont }\end{array}$ & Volunteer & $\begin{array}{l}\text { Though there is an adult (volunteer) } \\
\text { coordinator, this free-standing center is } \\
\text { run by participant input. Participants are } \\
\text { primarily children and youth. Partners } \\
\text { with } 4 \text {-H. }\end{array}$ \\
\hline 42 & $\begin{array}{l}\text { Santa Cruz, } \\
\text { Arizona }\end{array}$ & $\begin{array}{l}\text { Program } \\
\text { Director }\end{array}$ & $\begin{array}{l}\text { Boys and Girls Club on Mexican border. } \\
\text { Many non-English speaking residents. } \\
\text { Located next to elementary school, the } \\
\text { center is a stop for the high school and } \\
\text { middle school buses. }\end{array}$ \\
\hline
\end{tabular}




\section{Table 2: (continued). Description of Sites Included in Study}

\begin{tabular}{|c|c|c|c|}
\hline 6 & $\begin{array}{l}\text { North } \\
\text { Carolina } \\
\text { Sandhills } \\
\text { region }\end{array}$ & $\begin{array}{l}\text { Executive } \\
\text { Director }\end{array}$ & $\begin{array}{l}\text { Community Network with public access } \\
\text { sites. A Community Development } \\
\text { Corporation which runs after-school } \\
\text { programs and educational programs to } \\
\text { increase public awareness and values for } \\
\text { technology. }\end{array}$ \\
\hline 122 & $\begin{array}{l}\text { North- } \\
\text { central West } \\
\text { Virginia }\end{array}$ & Librarian & $\begin{array}{l}\text { This small public library was one of the } \\
\text { first to offer public Internet access in } 1994 .\end{array}$ \\
\hline 66 & $\begin{array}{l}\text { Eastern } \\
\text { Kentucky }\end{array}$ & $\begin{array}{l}\text { Project } \\
\text { Director }\end{array}$ & $\begin{array}{l}\text { A multi-county program under the control } \\
\text { of local community action groups, some } \\
\text { groups chose to keep their kiosks available } \\
\text { after the federal grant was finished. }\end{array}$ \\
\hline 59 & Illinois & $\begin{array}{l}\text { Program } \\
\text { Director }\end{array}$ & $\begin{array}{l}\text { Transitional living center for homeless } \\
\text { veterans is helping residents learn new } \\
\text { skills and get in touch with estranged } \\
\text { family members. }\end{array}$ \\
\hline 68 & $\begin{array}{l}\text { Eastern } \\
\text { Kentucky }\end{array}$ & $\begin{array}{l}\text { Program } \\
\text { Director }\end{array}$ & $\begin{array}{l}\text { A project within a local healthcare } \\
\text { organization. Original goals were reducing } \\
\text { a staggering drug abuse problem and other } \\
\text { unhealthy choices. }\end{array}$ \\
\hline 63 & $\begin{array}{l}\text { Western } \\
\text { Kentucky }\end{array}$ & $\begin{array}{l}\text { Program } \\
\text { Coordinator }\end{array}$ & $\begin{array}{l}\text { Located in Housing Authority complex this } \\
\text { Boys and Girls Club is the only after-school } \\
\text { program in the region. The Center also } \\
\text { serves as a community center for many } \\
\text { organizations. }\end{array}$ \\
\hline 40 & $\begin{array}{l}\text { Bethel, } \\
\text { Alaska }\end{array}$ & $\begin{array}{l}\text { Program } \\
\text { Coordinator }\end{array}$ & $\begin{array}{l}\text { This small coastal town is the hub of } 62 \\
\text { villages. Substance abuse and other } \\
\text { negative behaviors abound. This center is } \\
\text { a stable, caring place for many children } \\
\text { and youth. }\end{array}$ \\
\hline 101 & $\begin{array}{l}\text { Pine Ridge } \\
\text { Reservation }\end{array}$ & $\begin{array}{l}\text { Technology } \\
\text { Coordinator }\end{array}$ & $\begin{array}{l}\text { This center which serves Lakota people was } \\
\text { described by the Technology Coordinator } \\
\text { as "shamedest place". }\end{array}$ \\
\hline 120 & $\begin{array}{l}\text { Wisconsin } \\
\text { Rapids, } \\
\text { Wisconsin } \\
\end{array}$ & $\begin{array}{l}\text { Technology } \\
\text { Coordinator }\end{array}$ & $\begin{array}{l}\text { This central Wisconsin Boys and Girls Club } \\
\text { serves many Hmong who have immigrated } \\
\text { from southeast Asia. }\end{array}$ \\
\hline 95 & $\begin{array}{l}\text { Bloomsburg, } \\
\text { Pennsylvania }\end{array}$ & $\begin{array}{l}\text { One of } \\
\text { founders of } \\
\text { original } \\
\text { project }\end{array}$ & $\begin{array}{l}\text { Bloomsburg was site of an early } \\
\text { Community Network which has passed out } \\
\text { of existence. Commercial ISP's have filled } \\
\text { the need. Now the community is } \\
\text { implementing a technology-based business } \\
\text { incubator. }\end{array}$ \\
\hline
\end{tabular}




\section{Table 2: (continued). Description of Sites Included in Study}

\begin{tabular}{|c|c|c|c|}
\hline 112 & $\begin{array}{l}\text { Southwestern } \\
\text { Virginia }\end{array}$ & Teacher & $\begin{array}{l}\text { Primary school obtained a } 21^{\text {st }} \text { Century } \\
\text { Community Learning Center grant and } \\
\text { offers training to community at the school. }\end{array}$ \\
\hline 7 & $\begin{array}{l}\text { Eastern } \\
\text { North } \\
\text { Carolina }\end{array}$ & $\begin{array}{l}\text { Program } \\
\text { Director }\end{array}$ & $\begin{array}{l}\text { This program serves the multi-racial } \\
\text { Lumbee region near Pembroke State } \\
\text { University. }\end{array}$ \\
\hline
\end{tabular}

Interviews were conducted via telephone. Subjects gave verbal consent to be interviewed. Most interviewees allowed the interviews to be audio taped. If, however, the subject did not wish to be audio taped, the interview was conducted without audio taping. Of the 26 interviews, 23 were taped. Two subjects did not wish to be taped and with one interview the taping equipment malfunctioned. The researcher took hand written notes during all interviews and transcribed the notes immediately after the conclusion of the interview. All audio taped interviews were transcribed with the intent of capturing all colloquial language. Transcribed interviews and notes formed the body of raw data. Each interview was segmented by question number and coded using EZ-Text (Carey et al, 1998). As new factors emerged, codes were added to the codebook. The raw data were re-coded until no new codes became apparent. Codes were originally organized by question number and analyzed for occurrences. After the initial analysis by question number, the codes were grouped in a thematic network of factors.

Organization of Qualitative Data

Each interview question was designed to investigate particular aspects of the community technology center or community network participating in the 
study. Table 3 lists each question with its research purpose and related Research

Question.

\section{Table 3:Interview Questions with Relationship to Research Questions}

\begin{tabular}{|c|c|c|c|}
\hline $\begin{array}{l}\text { Question } \\
\text { Number }\end{array}$ & Question & Purpose & $\begin{array}{l}\text { Research } \\
\text { Question }\end{array}$ \\
\hline Q1 & $\begin{array}{l}\text { How would you describe the area } \\
\text { where your center is located? }\end{array}$ & $\begin{array}{l}\text { Demographics, geographic } \\
\text { location, economic } \\
\text { situation }\end{array}$ & 2 \\
\hline Q2 & $\begin{array}{l}\text { Please describe the interior of your } \\
\text { center. Include the general size, } \\
\text { number of computers, overall look. }\end{array}$ & $\begin{array}{l}\text { Setting, size, unique } \\
\text { interior features. Put } \\
\text { subject at ease. }\end{array}$ & 2 \\
\hline Q3 & $\begin{array}{l}\text { How, would you say, does the } \\
\text { Community Technology Center } \\
\text { address problems in your community? }\end{array}$ & $\begin{array}{l}\text { Mission, goals and } \\
\text { objectives }\end{array}$ & 2 \\
\hline $\mathrm{Q} 4$ & $\begin{array}{l}\text { During a normal week at your center } \\
\text { who might participate in activities at } \\
\text { your center? }\end{array}$ & Population served & 2 \\
\hline Q5 & $\begin{array}{l}\text { How do people get to and from your } \\
\text { center? Do adults bring children? If } \\
\text { so, what do the children do? How do } \\
\text { people get home? }\end{array}$ & $\begin{array}{l}\text { Transportation and child } \\
\text { care }\end{array}$ & 2 \\
\hline Q6 & $\begin{array}{l}\text { Describe the partnerships with other } \\
\text { organizations that have been } \\
\text { important to the development of your } \\
\text { center. }\end{array}$ & $\begin{array}{l}\text { Planning, organization } \\
\text { and collaborations }\end{array}$ & 2 \\
\hline Q7 & $\begin{array}{l}\text { How are major decisions made at your } \\
\text { center? }\end{array}$ & Organizational structure & 2 \\
\hline Q8 & $\begin{array}{l}\text { Thinking about the people who have } \\
\text { been important in the development of } \\
\text { your center, who are these people and } \\
\text { how have they been important? }\end{array}$ & $\begin{array}{l}\text { Planning, key persons, } \\
\text { "evangelists" }\end{array}$ & 2 \\
\hline Q9 & $\begin{array}{l}\text { Explain the technical issues that your } \\
\text { center has had to deal with to become } \\
\text { effective. How did you solve these } \\
\text { problems? }\end{array}$ & $\begin{array}{l}\text { Hardware and software } \\
\text { issues, } \\
\text { telecommunications } \\
\text { infrastructure }\end{array}$ & 2 \\
\hline Q10 & $\begin{array}{l}\text { How has your center been funded } \\
\text { during its history? How do you plan } \\
\text { to fund its operations in the future? }\end{array}$ & Planning, funding & 2 \\
\hline Q11 & $\begin{array}{l}\text { What has contributed to the } \\
\text { effectiveness of your center? What } \\
\text { barriers had to be overcome? }\end{array}$ & $\begin{array}{l}\text { Important factors for } \\
\text { developing effective } \\
\text { centers }\end{array}$ & 2 \\
\hline
\end{tabular}




\section{Table 3: (continued). Interview Questions with Relationship to Research}

\section{Questions}

\begin{tabular}{llll}
\hline Q12 & $\begin{array}{l}\text { If someone asked if your center is } \\
\text { successful or effective, what would } \\
\text { you say to prove that it is? }\end{array}$ & $\begin{array}{l}\text { Current effectiveness } \\
\text { measures }\end{array}$ & 1 \\
\hline Q13 & $\begin{array}{l}\text { Based on your own personal } \\
\text { experience what would you say is the } \\
\text { best way to measure any center's } \\
\text { effectiveness? }\end{array}$ & $\begin{array}{l}\text { Alternative effectiveness } \\
\text { measures }\end{array}$ & 3 \\
\hline Q14 & $\begin{array}{l}\text { In your opinion, what makes your } \\
\text { center special? }\end{array}$ & $\begin{array}{l}\text { Unique features or factors } \\
\text { not addressed in previous } \\
\text { questions }\end{array}$ & 2 \\
\hline Q15 & $\begin{array}{l}\text { Is there anything else that has made } \\
\text { your center effective? }\end{array}$ & $\begin{array}{l}\text { Second chance to pick up } \\
\text { on features or factors } \\
\text { contributing to } \\
\text { effectiveness }\end{array}$ & 2 \\
\hline
\end{tabular}

The great value of qualitative investigation is its depth or richness. Thus, while each question was designed with the purpose of obtaining certain information, the researcher often discovered pertinent information about the center when the subject was discussing some seemingly unrelated topic. For example, while asking about partnerships (Q6), the researcher might find that a Boys and Girls Club served senior citizens in the late morning or a local church had contributed resources to a community center in a HUD subsidized housing complex.

Although qualitative data permit a researcher to probe below the obvious to uncover information not directly related to the interview question, organization and analysis of the data can be problematic. While the temptation was to analyze responses according to each question's purpose, a more meaningful analysis resulted from building an organizing scheme of codes. 
Quantitative Data

After all interviews were transcribed and coded, attempts were made to contact each of the 26 study subjects by telephone. Subjects who could be contacted were asked to complete the Rural Community Technology Center Survey. Results were tabulated with the intent of being used as a triangulation tool to check the results from the interviews. A low return rate caused survey data to be of little value.

\section{$\underline{\text { Research Question } 1}$}

\section{How is effectiveness measured in rural community technology centers?}

When asked how effectiveness could be demonstrated for their centers, subjects offered a variety of responses. Figure 9 illustrates all responses which were given by more than one subject $(n>1)$. While evaluation by attendance was most often cited as evidence of effectiveness, other significant measures were also named: Variety of programs, personal narratives, site visits, content available to participants that would otherwise not be available, changes in crime statistics-, and improvement in scholastic achievement. Financial support from the local community, other support from the local community, and support from businesses were also mentioned as indicators of success. Being constantly self-evaluating was also listed as a factor for developing successful centers. Two youth- oriented centers responded, “J ust ask the kids" or "I'd tell them to come see for theirselves [sic]." 


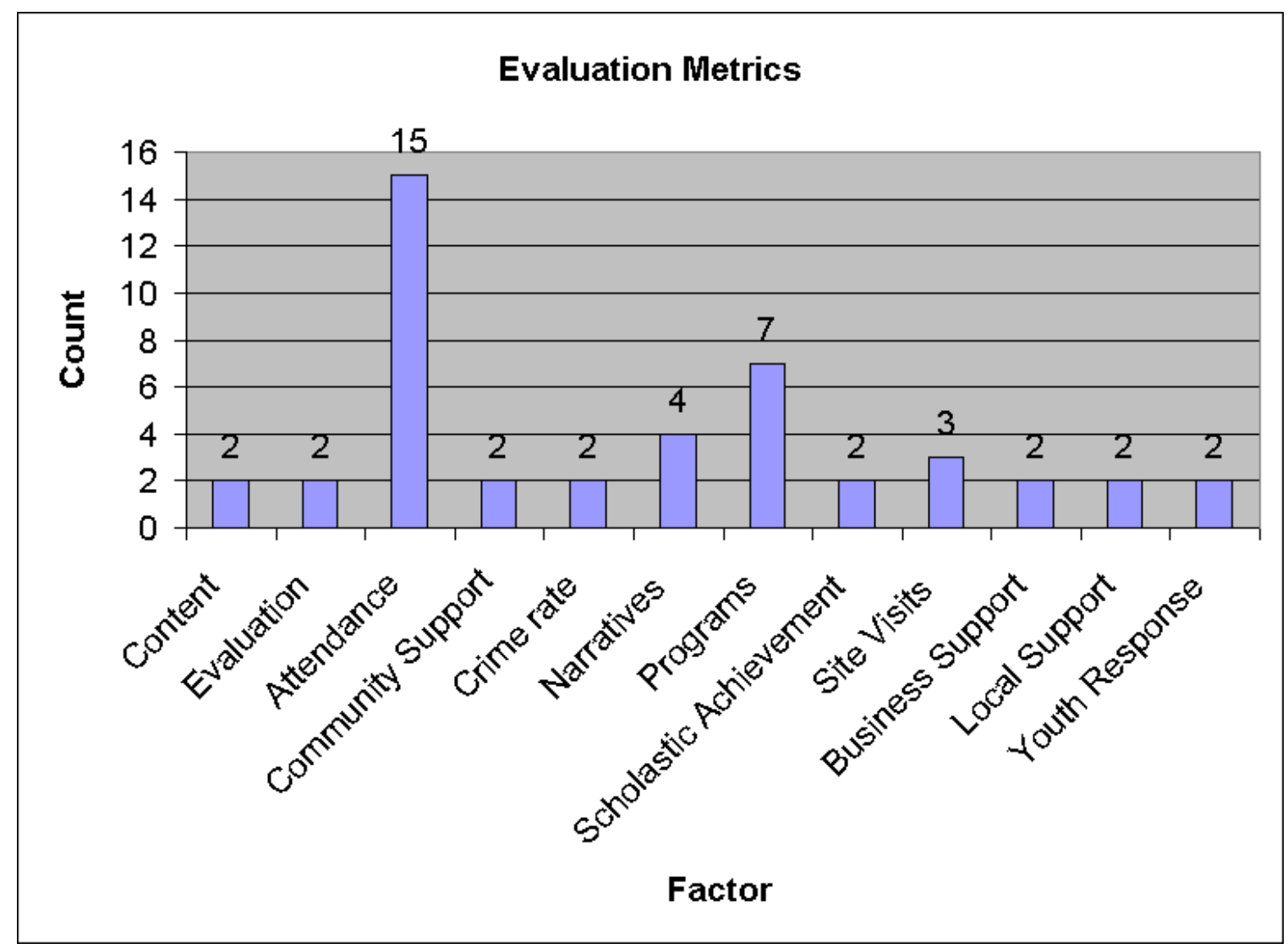

Figure 9: Study subject responses to Research Question $1(n>1)$

A number of unique $(n=1)$ answers were also given as evidence of effectiveness. One community network cited technical reliability, up-to-date equipment and the fact that there was no access to technology in the area until it was established as substantiation of its success. Another community network using libraries as public access sites responded that its history of financial sustainability without reliance on grants was evidence of effectiveness. Sheer 
longevity demonstrated success, another subject noted. A multi-county program in eastern Kentucky noted the leadership development that resulted from the project was evidence of effectiveness. A center focused on youth in Alaska described changes in behavior of the youth as evidence of its positive impact. ‘We don't have the fights between younger kids and we don't have passed-out teens in theyard." From the island of Hawaii came one of the most poignant indicators of success.

One of my biggest successes I seen [sic], I think I can always remember, I asked a kid one year what was she going to be when she grew up? And she tells me she's going to go on welfare. Uh, because that's her model of the world that she sees everyday. And then the next year, after she hangs out for a while, I remembered that I made that kind of my mission, in the back of my head, you know to, like to, hopefully to have her change her mind. So the next year I ask her and she told me she was going to be a teacher.

In economically distressed communities and dysfunctional families, an individual having positive goals for the future can be a better indicator of success than a pre- and post-test. 


\section{Research Question 2}

What factors are critical for developing effective rural community technology

$$
\text { centers? }
$$

Research question 2 yielded the most complex set of factors contributing to the development of the rural technology centers. The purpose of the study was to discover which factors, both technical and human, were critical for developing centers and programs that were effective. During the coding and re-coding process as no new codes emerged, an organizational structure for factors became apparent. All codes could be organized into eleven groups with a twelfth category called “Unique Features.” This organization is illustrated in Figure 10: 


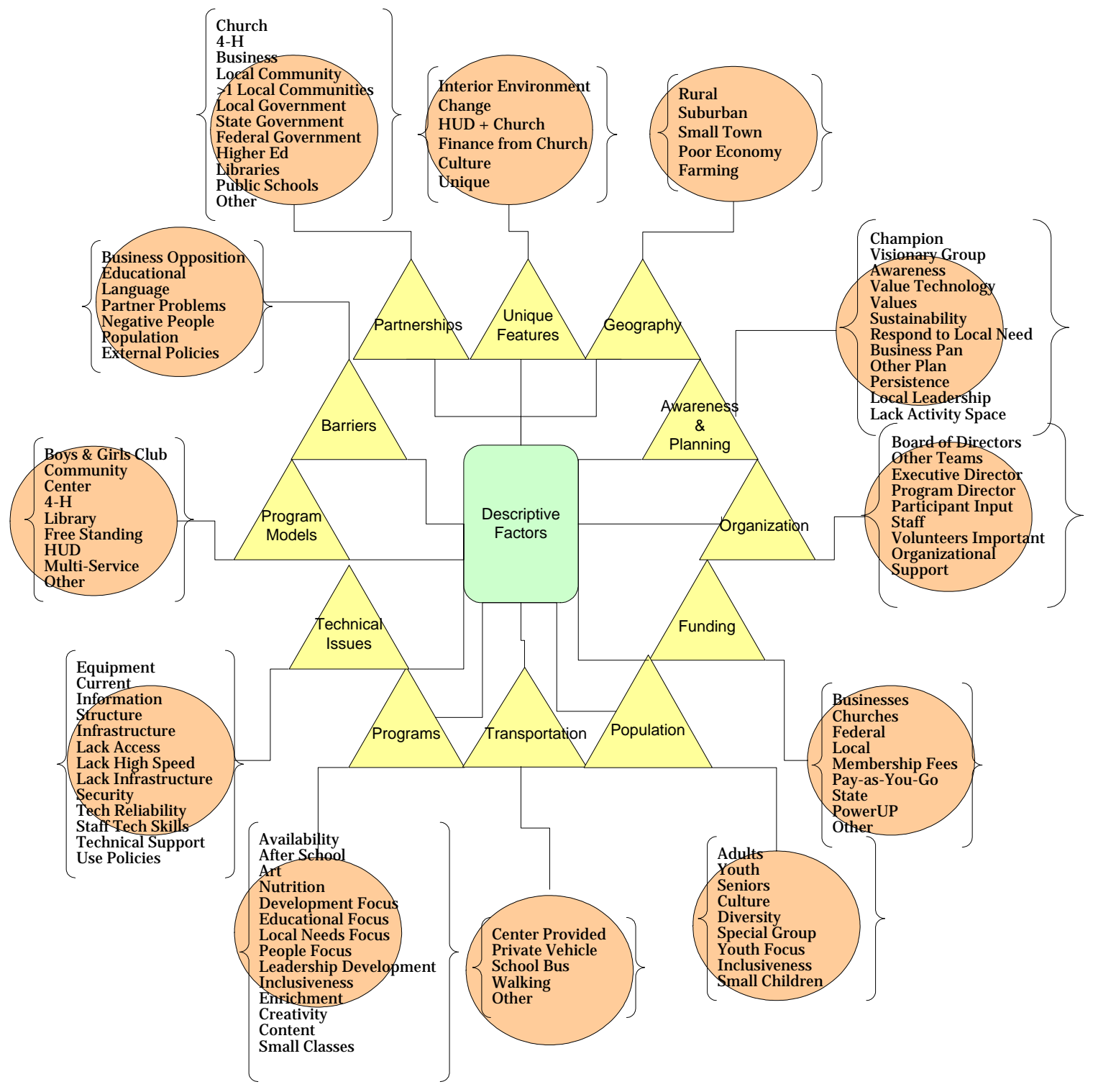

Figure 10: Clustering of factors into thematic groupings

Some codes, e.g. those occurring in the Technical Issues or Transportation categories, were only related to one specific area. However, a few codes, e.g. "Other" (meaning Other Partnerships), were situated in multiple areas. Other Partnerships became obvious in the Program Models, Partnerships and Funding 
groupings. Analysis of each group of responses will begin at the upper right yellow triangle and proceed in a clockwise direction.

\section{Geographic Factors}

The actual purpose of Interview Question 1(Q1) was to determine whether or not the subject viewed the location as rural. Additionally, this question served the purpose of initiating a dialogue and setting a pleasant conversational tone for the interview. Even this simple question was revealing. Eighteen respondents described their area as rural in Q1. Throughout all interview questions, 21 of the 26 respondents described themselves as rural. In Hawaii, the first sentence was “it's the boonies!” The researcher interpreted that response as RURAL. Interestingly, though Q1 was seeking geographical information, the second highest response $(\mathrm{n}=12)$ was a statement of economic disadvantage. Throughout all interviews, a poor economy was noted 21 times. Because terms such as "poverty stricken" were used, the researcher inferred that the negative economic situation was obviously important to respondents. Agriculture, farming or gardening were mentioned only 5 times in all interviews, which demonstrates that most of the rural communities represented by this study have very little active agricultural base or that agriculture simply wasn't important to the subject. Additionally, 10 subjects identified their location as a small town. Results are illustrated by Figure 11 below: 


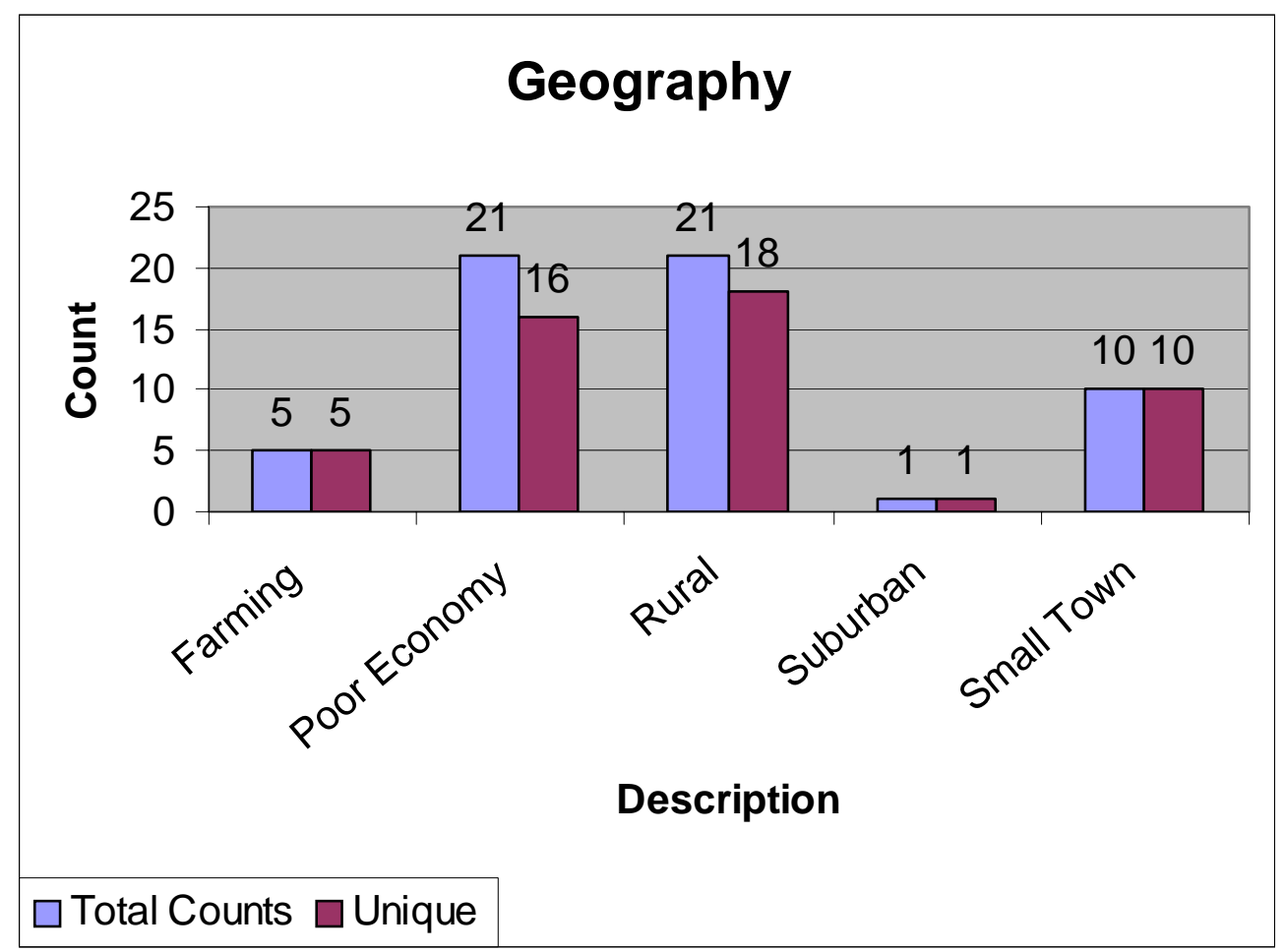

Figure 11: Geographic factors related to rural Community

Technology Centers

Awareness and Planning

The Awareness and Planning theme related to the early steps in developing the technology programs. Having a champion or "evangelist" was most often cited as important to the early stages of development of the center ( $n=19,16$ unique). In contrast, only one subject noted the importance of a visionary group. Awareness of the need for the project or awareness of technology was also described as being important ( $n=13,12$ unique). Five subjects related a connection between awareness of the project or the need for the project and the presence of a champion who "preached" the message about technology. Other important factors were persistence ( $n=11,8$ unique), planning in general (Business Planning + Other Planning $=8$ ) and planning with the idea of sustainability $(n=8)$. Less often cited 
were: responding to local needs $(n=7)$, and support of local leadership $(n=6)$. One respondent summed it up as “Um, I think I've pretty much said it all. It's just team work and having a plan and persistence. And trying new things." Results are presented graphically in Figure 12.

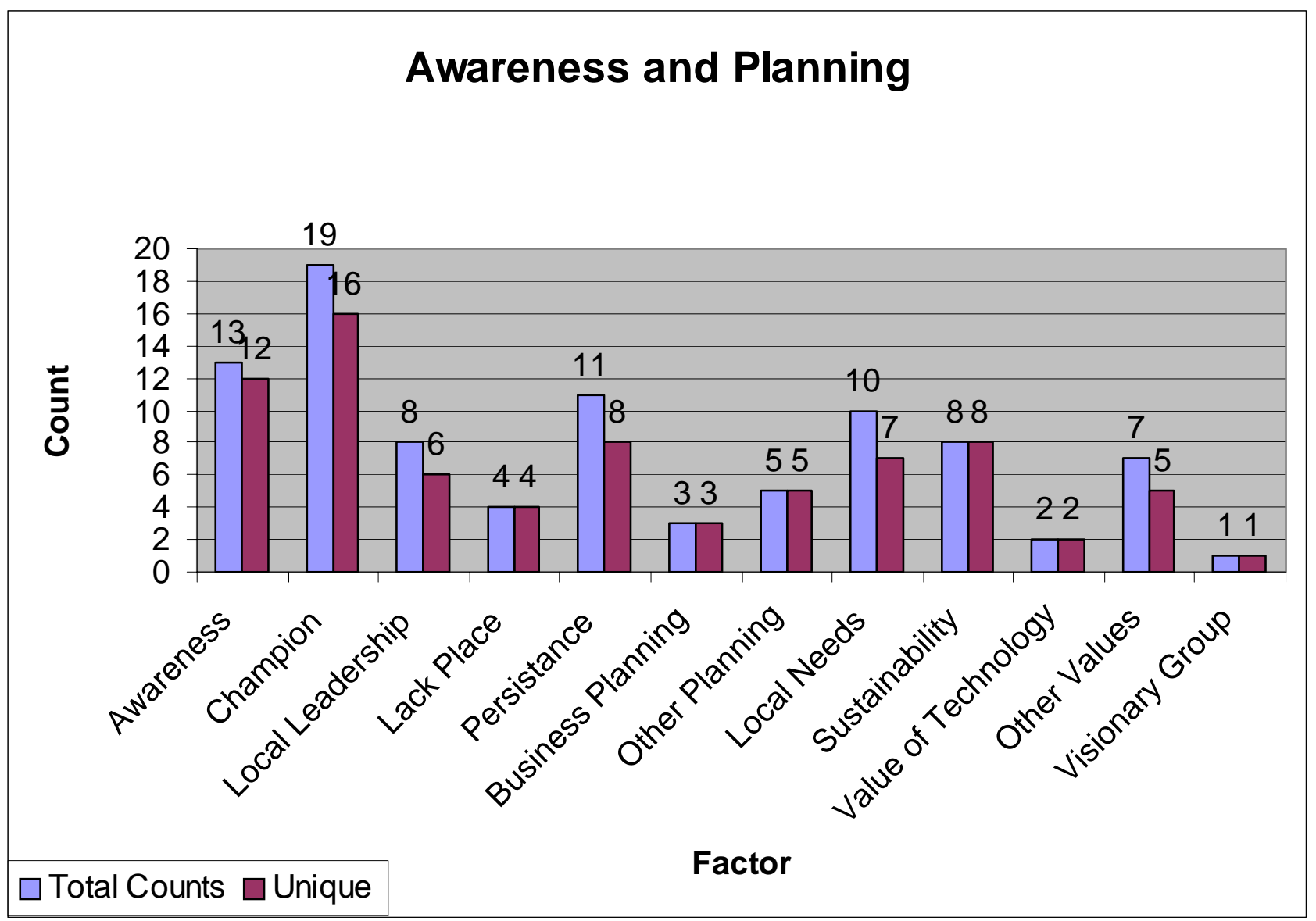

Figure 12: Counts of Factors in the Awareness and Planning

Thematic Group 
Organization

This group of factors related to how the center functioned as an organization. Often the subject revealed information about the organizational structure while speaking about other topics. Throughout all interview questions, either paid or volunteer staff were cited most frequently $(n=32)$ as the critical factor. If the numbers were adjusted for unique values only, the board of directors became the most prominent feature $(n=17)$. An executive director, participant input and volunteers were also regarded as important characteristics. Organizational support from other agencies was cited by four subjects. Six subjects related that teams other than a board of directors were important in the decision making process.

As 16 interviewees mentioned the importance of staff persons for a total of 32 counts, the question of how the counts were distributed arose. The question was whether the large number of total counts came from only one or two organizations. An additional question was whether any specific type of organization had cited staff as important multiple times. One subject alluded to staff four times; three subjects mentioned staff 3 times in all interviews; six interviewees mentioned staff twice and three subjects referred to staff once. The conclusion was that staff was important to centers across the spectrum, rather than only a few centers or one type of center. Figure 13 is a graphic representation of the factors in relating to the organization of the rural community technology center. 


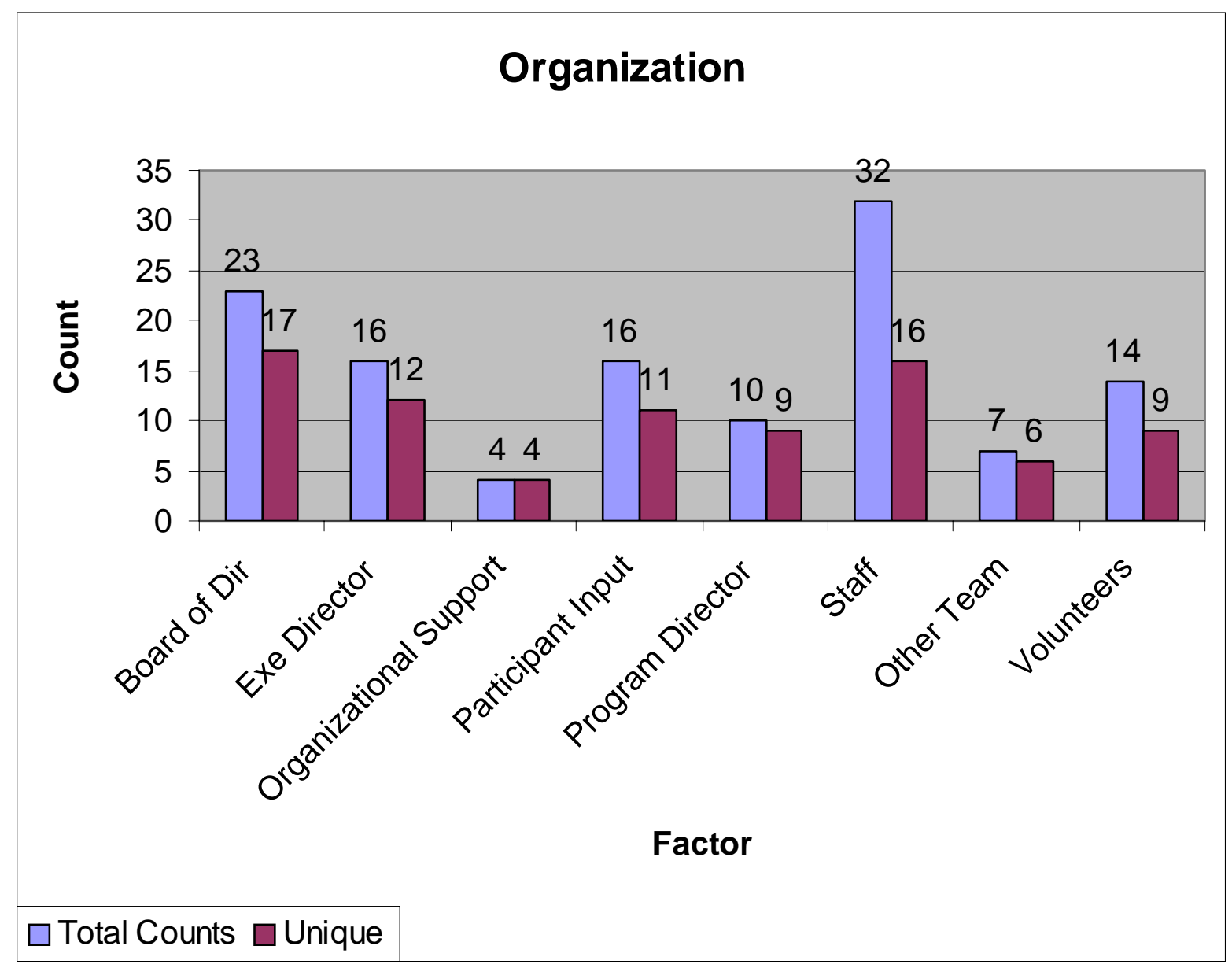

Figure 13: Organizational Structure Factors

Funding

Funding issues are always of concern to not-for-profit organizations and agencies. Rural Community Technology Centers and Community Networks were no exception. The centers represented by this study had developed an interesting array of funding styles. Funding types are graphically represented in Figure 14. 


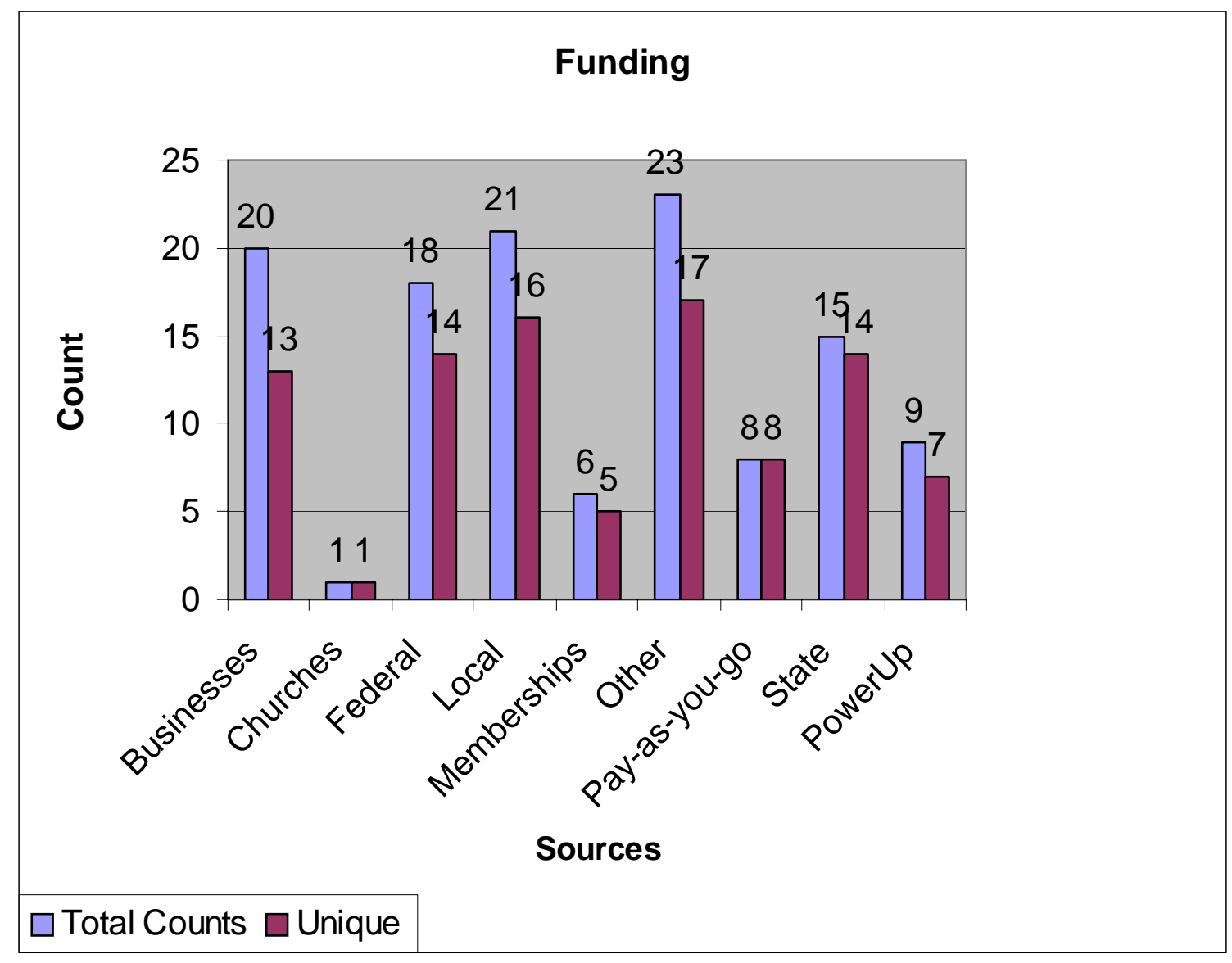

Figure 14: Funding Sources used by Rural Community Technology Centers and Networks

The "Other" factor includes private funding (except PowerUp), foundation grants, and personal contributions not including membership fees. The number of responses indicated that some creative mixed- bag funding mechanisms $(n=23,17$ unique) were essential for effective centers. Local fund raising ( $n=21,16$ unique) efforts seemed to be more important than either federal ( $n=18,14$ unique) or state grants ( $n=15,14$ unique). Eight of the centers used some form of "pay as you go" financing $(n=8)$. PowerUP, the funding and support mechanism established by 
AOL-Time Warner was utilized by a number of centers ( $n=9,7$ unique), particularly Boys and Girls Clubs. Some of the centers charged membership fees ( $n=6,5$ unique) to contribute to their budgets. The one center that received financial support from a local church was a surprise because the center was at a HUD subsidized housing complex. One would not have expected a center in a federal housing project to receive funding from a religious group. Rural community technology centers appeared to be creative in designing funding streams, rather than following a formula.

Populations Served by the Centers

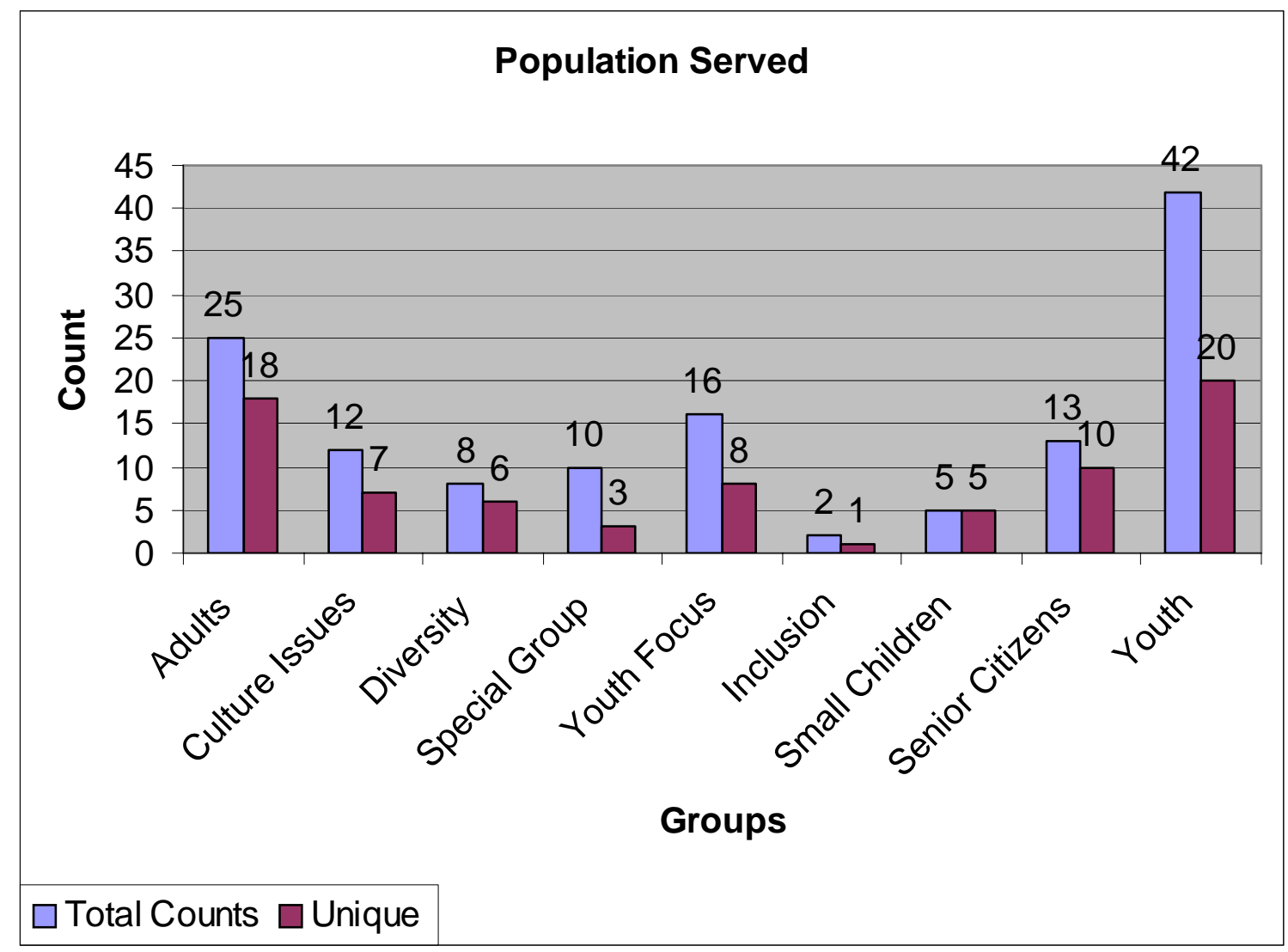

Figure 15: Populations Served by Rural Community Technology Centers and Networks 
Populations served by the sites included in this study are represented in Figure 15. Youth were the population most often served by the rural CTC's $(n=42$, 20 unique). However, 16 centers which reported servingyouth also served adults. Five centers serving adults made provision for children while adults were participating in programs. Ten of the centers that served youth also offered programs for senior citizens. Four centers whose fundamental mission was to serve youth, e.g. Boys and Girls Clubs, also offered classes for seniors. The one center that focused on a very specific population, a residential facility for homeless male veterans, also served $4-\mathrm{H}$ club members by making the 4 - $\mathrm{H}$ youth computer mentors to the men at the center. Effective rural centers seemed to understand the importance of making services available to as broad an audience as possible.

Cultural issues and diversity have become important to rural community technology programs. Hmong people from Southeast Asia have settled in significant numbers in south-central Minnesota. Individual centers discussed offering programs to Hmong, Hispanic, Native American and Native Alaskan people. Rural areas are no longer monocultures and effective centers have learned to serve diverse groups. One community network cited inclusiveness of all sectors: business, education, non-profit and community, as important to its effectiveness.

\section{Transportation}

Since transportation can be a problem in rural areas where homes are widely separated, the researcher asked subjects about how participants were able to travel to the center. Private vehicle was the most common form of transportation ( $n=15)$. Participants often walked to the center $(n=12)$. In afterschool programs and summer programs targetingyouth, the local school district 
made provisions for transporting students from school to the centers ( $n=13,11$ unique). Five centers provided transportation for their participants and in four cases there were other provisions for transportation. In the conversations with the subjects, transportation did not seem to be a critical issue at most sites. Figure 16 graphically represents transportation methods.

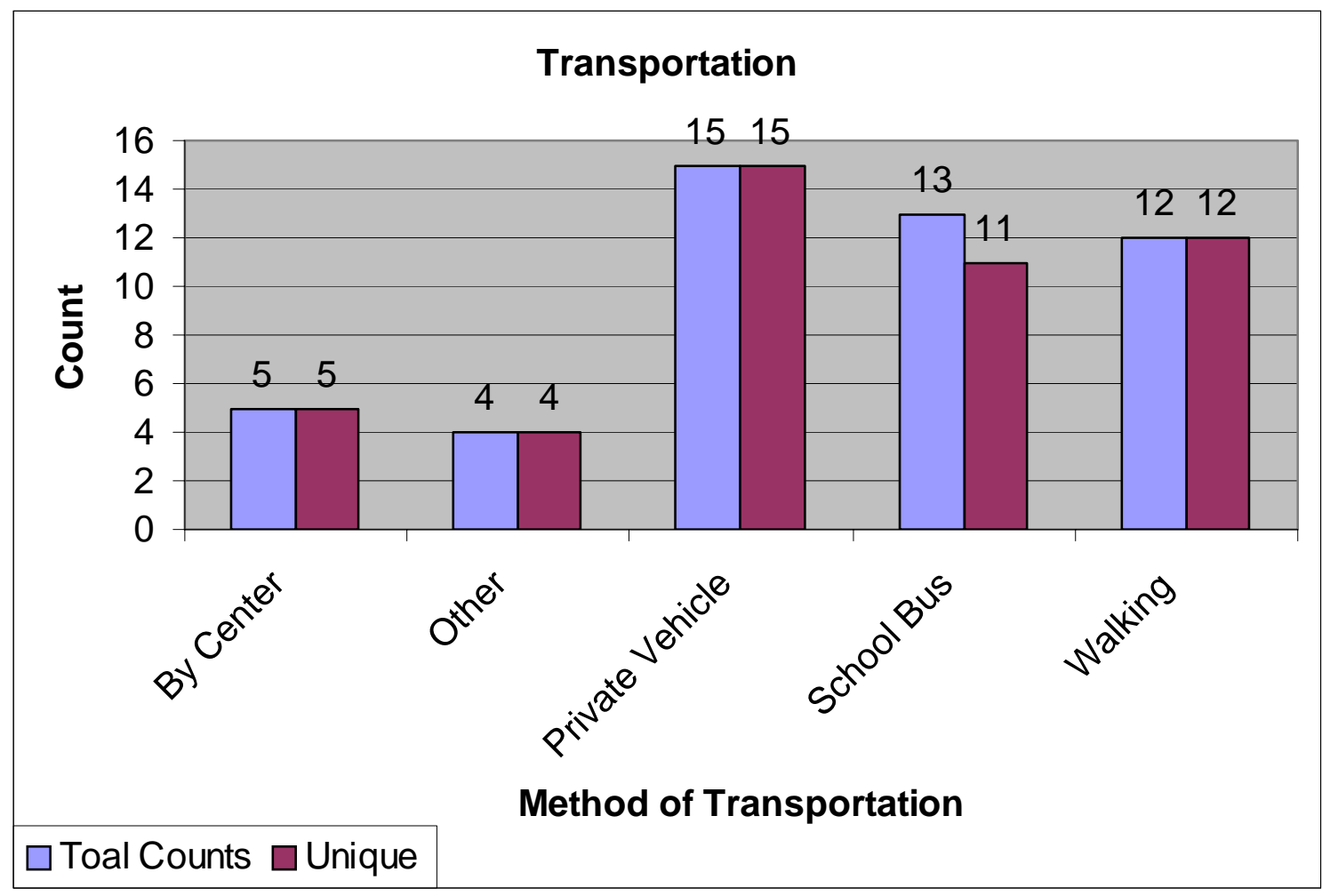

Figure 16: Transportation to and from Centers

Programs

Subjects had much to say about programs and program offerings at their centers. Focusing on education ( $\mathrm{n}=28,21$ unique) and on people ( $\mathrm{n}=21,13$ unique) were prevalent themes as were focusing on local needs ( $n=26,13$ unique) and economic development ( $\mathrm{n}=19,14$ unique). The content of available programs and 
relevance of accessible information was considered to be important ( $\mathrm{n}=27,17$ unique). Three sites regarded both education and responding to local needs as important. Five centers discussed their response to local need and their focus on people. Educational focus and economic development were themes for ten subjects. Twelve subjects discussed their educational focus and focus on people or personal development. Interestingly, seven centers mentioned economic development, educational focus, and people as their issues. Thus education, economic development and personal development were major program areas for many rural community technology programs.

The minor program themes that emerged were interesting. Three sites discussed art- related programs. In fact, the person being interviewed at a site in rural Ohio had to hurry at the end of the interview because the chain saw artist was scheduled to arrive shortly to do a presentation for the after-school students.

One subject cited creativity and "thinking out of the box" in program selection as important. Another subject pointed to small classes as important to its participants. In Alaska, the center included nutrition and gardening in its programming because the children and youth were from families where substance abuse was prevalent and the children were not feed nutritious, regular meals. Programs from the eastern Kentucky multi-county project noted that leadership development was a critical part of its programming. Figure 17 illustrates the relationship of factors associated with programming. 


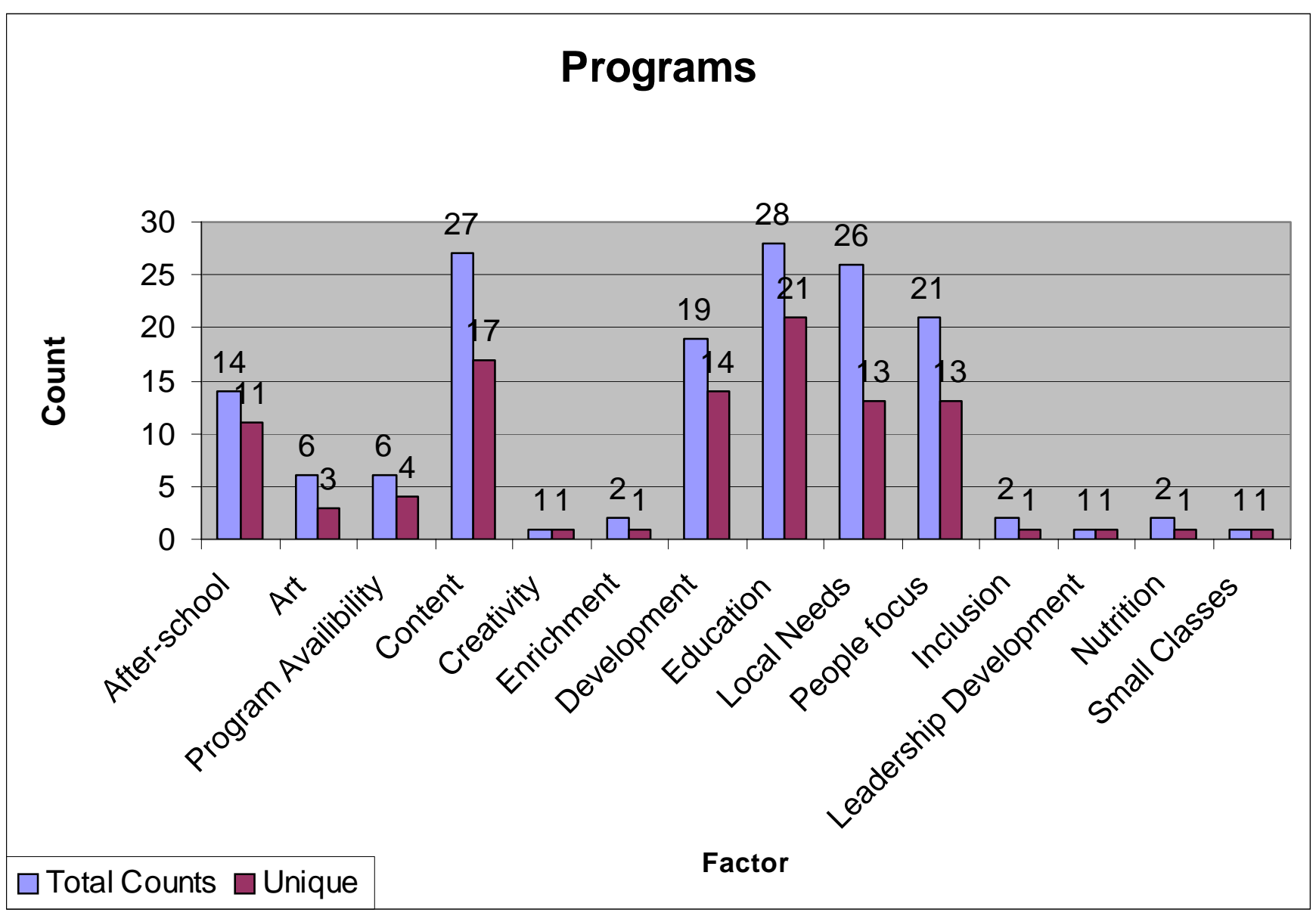

Figure 17: Factors Influencing Effective Programming

Technical Issues

Nearly all of the rural community technology centers interviewed in this study experienced technical issues that had to be overcome. Obtaining up to date, reliable equipment and the availability of technical support appeared as the major issues for centers to address. Technical support ( $\mathrm{n}=24,20$ unique) and technical literacy of staff persons $(n=3)$ were mentioned by many of the interviewees as problems encountered during development. Another major issue was obtaining up-to-date equipment ( $\mathrm{n}=21,13$ unique). Standardized operating systems and 
other features were much more readily maintained and allowed new users to consistently participate in programs without experiencing frustration. Staying current with hardware and software systems contributed to ongoing interest in centers ( $n=9,7$ unique). Effective centers transitioned from being places where people learned basic computer skills to laboratories for individuals to test new applications before they made purchases for their homes or businesses. Technical factors are related in Figure 18.

One center in northern Vermont did, however, use older, donated equipment to teach youth computer building, repair and maintenance skills. The person being interviewed related that several of youth who attended the center had been able to develop small businesses servicing computers since there were no other sources of such service available in their area.

Since all centers in this study were in rural areas, A) Information infrastructure ( $n=9,7$ unique) and B) Lack of infrastructure $(n=13)$ were problems for many developing centers ( $\mathrm{A}$ union $\mathrm{B}=18$ unique). Having high-speed Internet access was considered very desirable for enhancing the learners' experience with information technology $(n=6)$. Lack of access to technology $(n=18,12$ unique) was a general problem to be overcome by the centers. Libraries, schools and healthcare providers were able to use E-Rate to obtain affordable high-speed Internet access. Cable modem or DSL were used by centers not eligible for E-Rate. Where cable modem and DSL were not available centers used satellite for their high-speed access. 


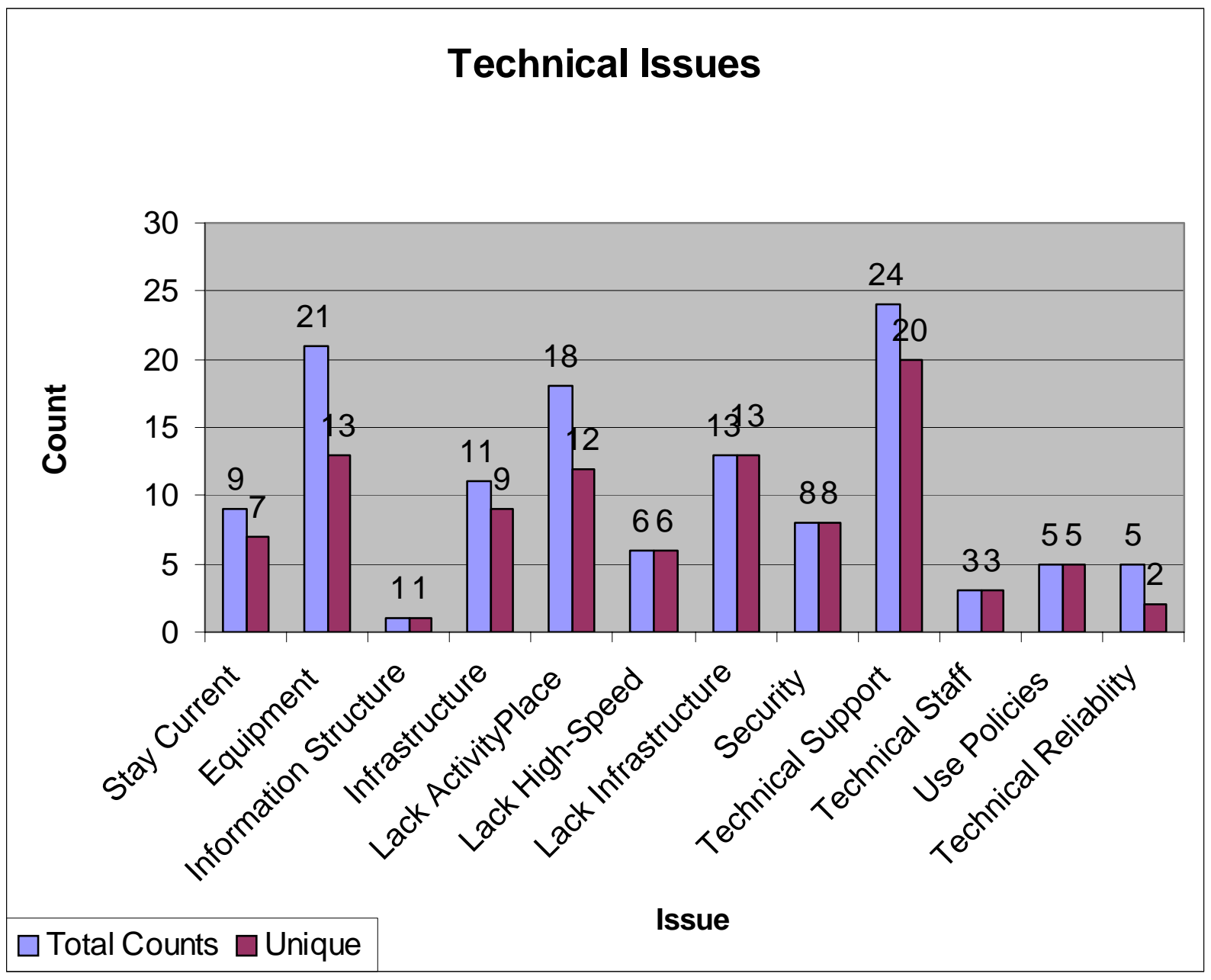

Figure 18: Technical Factors Affecting Rural Community

Technology Programs

Policies for appropriate usage of the technology, particularly content available through the Internet was a less frequent, but nonetheless significant issue. Since youth programs were often part of a center's offerings this issue was frequently encountered by staff. Most centers relied on filtering software, but the center in northern Vermont had posted a list of "stupid sites" which had been compiled by the youth attending the center. Peer pressure and peer intervention were the use policy at that site. 
Finally, computer security had to be established. Keeping viruses and other malicious content out of systems and preventing inadvertent system changes were addressed using standard operating system methods.

Program Models

There was no one model upon which the centers based their programs. Creativity in local programs was the major theme. Seven sites were Boys and Girls Clubs and seven served as community centers. Three centers served as Boys and Girls Clubs and community centers. Two centers were located in HUD subsidized housing complexes. One of the centers in a HUD housing complex was also a community center and a Boys and Girls Club. Making the very most of facilities and resources was a recurring message from the study subjects. None of the centers interviewed were free-standing technology centers. One of the community centers also called itself a multi-service center which housed many community services.

Seven of the study subjects used a partnership with 4-H Clubs as part of their strategy. While 4-H has traditionally been thought of as an agricultural program operating under the umbrella of the Extension Service, many 4-H programs have "technology teams" which engage in community service projects. The technology center at the Transitional Living Center for homeless veterans in Illinois was successful because the local $4-\mathrm{H}$ technology team maintained the center and its network. In northern Vermont the volunteer adult overseeing the technology center spoke with pride about his technology team which had competed at both the state and national level. 
Rural libraries were another major theme for community technology centers. In interviews, eighteen references were made to partnerships with libraries with ten subjects having public access sites at local libraries. Rural libraries have made the transition from book repositories to information centers, and have embraced information technology as integral to library offerings to the public.

The category Other Partnerships (P-OTH, $\mathrm{n}=32,23$ unique) could be misleading. This category encompasses both novel program models and general partnerships of the rural CTC's. A few of those novel models are noteworthy. One of the centers included in the study was housed in a museum. A program in eastern Kentucky placed Internet kiosks in places where people naturally gathered. This included country stores so that residents could buy bread and milk and check their email. In a third case, the community technology centers were a component of a broader strategy of a Community Development Corporation. Program Models are illustrated in Figure 19.

The three community networks included in the study have very different characteristics. In east-central Vermont the community network remains the sole Internet service provider and described itself as "the only game in town." In northcentral Pennsylvania the community network has ceased to exist because commercial businesses have filled the ISP needs of the community. The founding group is now developing a technology-based business center. In eastern Virginia the community network has developed into a community Internet portal where local businesses can advertise and local community organizations can keep citizens informed about services and activities. The study subject from eastern Virginia 
used the recent hurricane as an example. Damage from the storm was extensive and the community network became the main "nerve center" for coordinating aid and rebuilding.

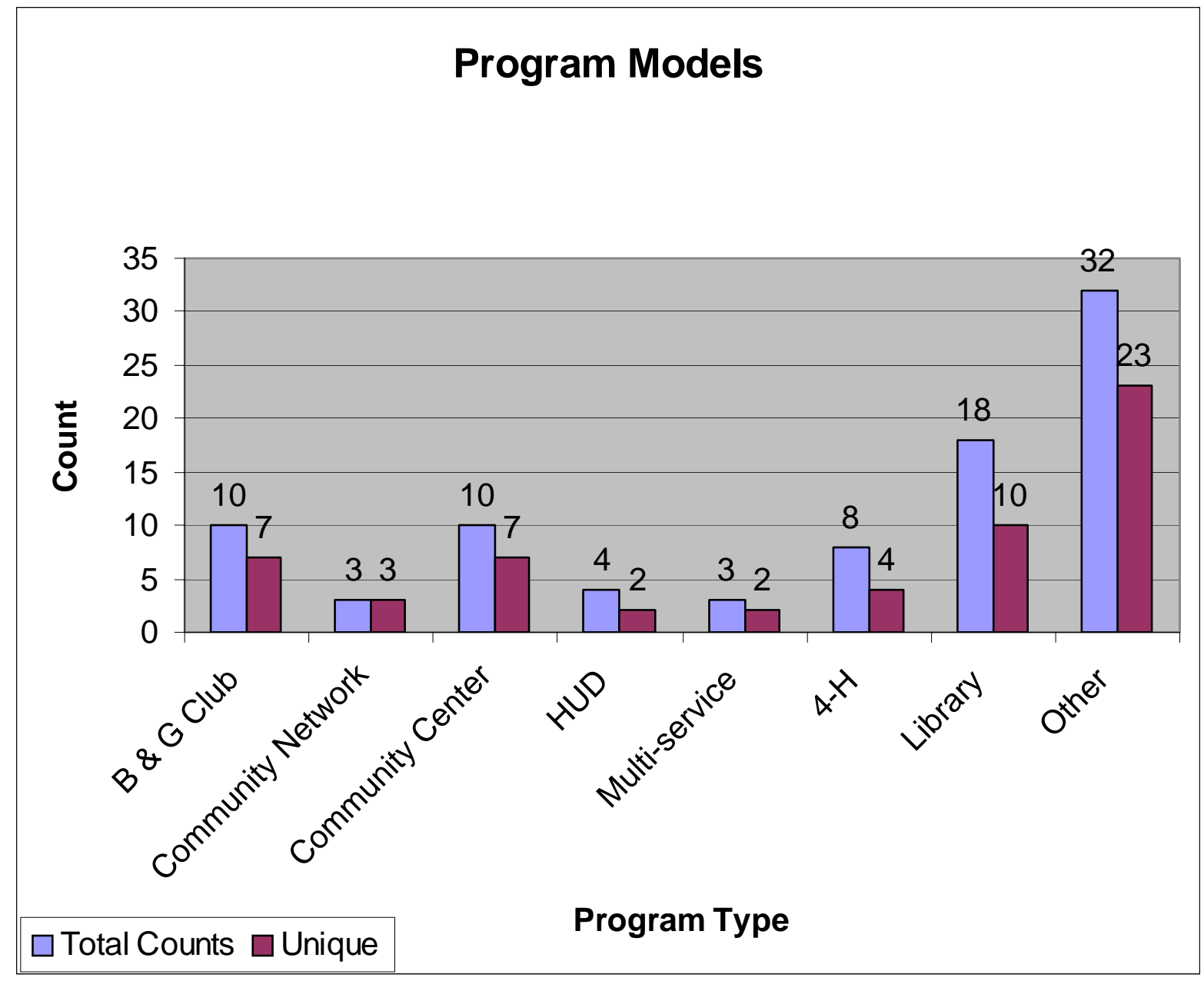

Figure 19: Program Models Employed by Rural Community

Technology Programs

Barriers

All subjects in this study discussed barriers or problems that had to be overcome in order for the technology centers to become effective. Technical issues have been discussed in an earlier section. Financial issues were a major concern 
( $\mathrm{n}=10,8$ unique) as financial concerns are important to any community-based non-profit organization. A more thorough treatment of financial concerns is under the section on funding above. Other barriers tended to be human factors.

Negative people ( $n=9,6$ unique) were encountered in the development of effective centers. This included nay-sayers, transient people and lack of local leadership capacity. Low population density, out migration and isolated people were also major themes ( $n=8,7$ unique). Not being able to build or maintain important partnerships proved problematic for some centers $(n=3)$.

Governmental policies or policies of large corporations were obstacles for some projects $(n=4)$. In three cases the business sector was oppositional either because the value of the "new-fangled" information technology was not appreciated or because local business felt that governmental agencies or non-profit organizations should not be involved with what was primarily a commercial enterprise. During initial contacts with former community networks, the researcher found that community networks had either passed out of existence because the business sector had begun to provide Internet service or become local information portals. Only one community network included in the study remained as the only ISP in a region. In fact, some of the model community networking projects, La Plaza, Dillonet and Bloomsburg Community Network had passed out of existence and were replaced by for profit ISPs.

More minor issues encountered by centers were educational problems e.g. lack of understanding of instructional methods or lack of availability of adequate curricula for participants. Two centers pointed out language barriers that had to be overcome. In Arizona nearly all participants were native Spanish speakers, but 
staff were Anglos. The large Hmong refugee settlement in south-central Minnesota was a challenge to the community technology center because of language and cultural differences.

Figure 20 displays the barriers that had to be overcome at study sites.

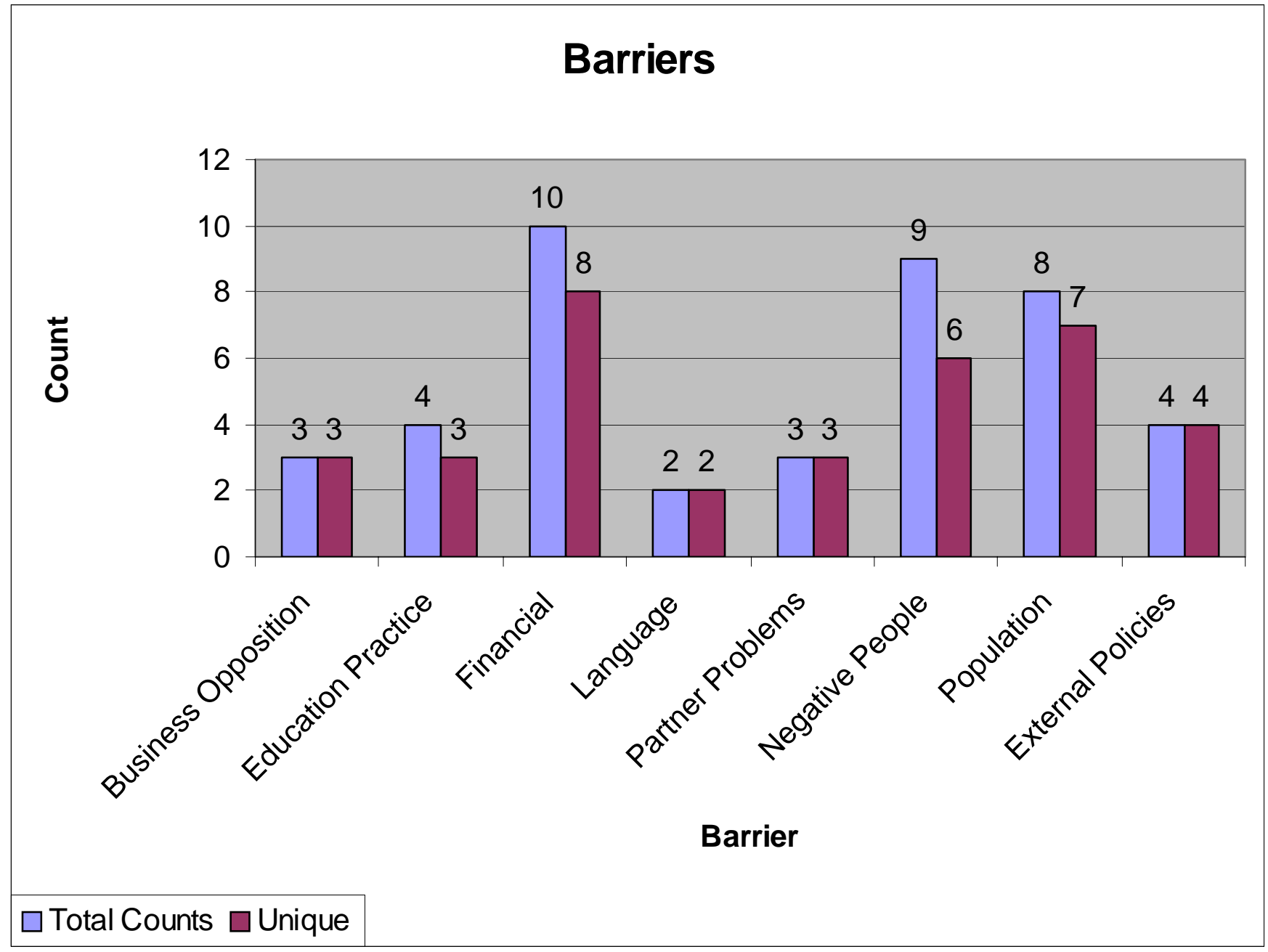

Figure 20: Barriers to Developing Effective Rural CTC's 
Partnerships

Partnerships with other organizations emerged as a major theme among the centers studied. More individual references were made to partnerships than any other factor. The total of all references to partnerships was 233, more than any other group of factors. Partnerships included many different organizations and agencies. The most frequently cited partnerships were with local schools ( $\mathrm{n}=37,20$ unique) and with the local community people ( $\mathrm{n}=36,23$ unique). Partnerships with multiple groups were the norm rather than the exception. All six centers reporting partnerships with churches ( $n=8,6$ unique) also reported other partnerships. Fourteen of the centers describing partnerships with the local community also mentioned partnerships with local government. Five of the centers reporting partnerships with both local community and local government also spoke about partnerships with an institution of higher education. Eight centers described partnerships with the local school districts and with higher education. Of the eight centers reporting partnerships with both local schools and higher education, four also noted other partnerships were important in their development. Eight centers indicated partnerships with both businesses and local schools. Seven of those with partnerships with both business and local schools also had other important partnerships. Clearly, this discussion of important partnerships can go on and on. Without a doubt, creating multiple partnerships was a critical factor for developing effective rural community technology centers. Figure 21 displays the Partnership data. 


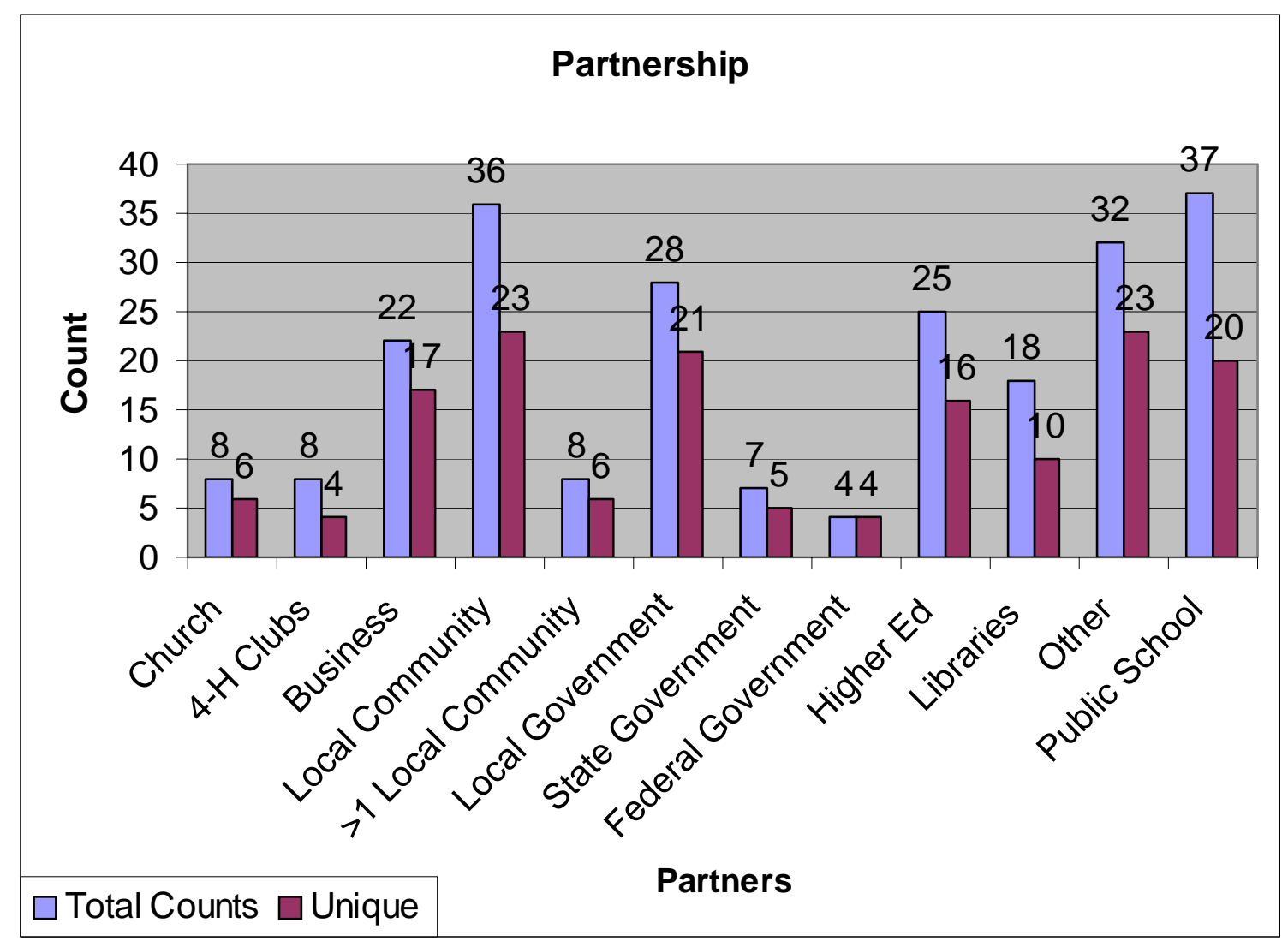

Figure 21: Partnerships Developed by Rural CTC's

\section{Unique Features}

Oftentimes the last grouping is the catchall for everything that did not fit in any other category. In this study the "Unique Features” classification might easily be the most interesting and revealing grouping.

This study uncovered an uncanny assortment of interior décor in centers. In a HUD-subsidized housing complex, a three-bedroom apartment had been converted into a learning center. In the living room was a large table for doing crafts or having meetings. The kitchen was used to teach better shopping and cooking skills. One bedroom had become a library with a children's section, 
another bedroom had become the computer lab with four up-to-date computers with DSL hook-up to the Internet. According to the interviewee, everyone knew that the center was for residents of the complex, but the wider community had trouble learning that the center was available to them also. This center, though in HUD-subsidized housing, was actually founded with help from a local church. This fact was interesting since federally funded projects have historically not made alliances with religious onganizations.

On the large island of Hawaii, the center was housed in a 1900's plantation house of a former sugar cane plantation. The main room had formerly been the big parlor of the plantation house. "There's a fireplace, but we don't use it," said the respondent. This center was proud of the fact that they had air-conditioning. The center had a comfortable lounge area that had sofas and big chairs. It was the homework lounge. Teens liked the environment, "It's cool, very cool."

In northern Vermont, near the Canadian border, the center was a 19201930's garage. The workbenches have become benches for tearing down and rebuilding computers. "Uh, and then I have um, the old remnants of a garage, which is stepping back into history, it's like into the 1930s," said the coordinator of the center. He also added that it was the only heated place where youth could congregate in the harsh winter weather. The center's coordinator had been a highenergy, type A personality in Silicon Valley, CA until he suffered a stroke. The stroke had very subtly affected his speech, so he relied on peer mediation to maintain discipline and respect for the center's equipment. High school age youth were expected to help middle school students with their projects. "I serve middle school and high school and in the winter it's quite a competition between the two 
groups, and in order for the high school kids to participate, they have to agree to have projects and work for the middle school kids. That's, and um, otherwise, the high school kids would take over." This gentleman was not an educator, but had intuitively applied sound educational practices of project-based learning and peer mentoring. "I'm looking to serve the younger kids, and then guide them into being proper high school kids, you know. The high school kids are basically graduates and they get to hang out just because they've paid their dues."

In rural Ohio, the center was in what had been a 1930's machine shop. The pulleys and other heavy equipment were left in place as part of the décor. This center focused its programs on technology and art. The youth had actually shown and sold their works to a wide audience. This subject was also the coordinator who was waiting the arrival of the chainsaw artist to introduce the young people to chainsaw sculpture. The researcher was somewhat bemused thinking how the children in her own programs might respond with chainsaws in hand. The interviewee assured her, however, that when given responsibility, the participants behaved responsibly and safely.

In rural Illinois, the computer center was a former motel. The overall population served was homeless veterans. Each resident had his own private space in a room, but community activities and the computer center were in the former lobby and main desk area.

The multi-county project in eastern Kentucky established action teams in each community that participated in the project. Action teams had the responsibility of placing the Internet kiosks at assessable sites within each community. While there was a large central computer laboratory used as a 
training facility, the kiosks often were placed in country stores. The residents could buy bread and milk and also check their email. This project also trained 4- $\mathrm{H}$ club members as "Cyberguides" to help community people learn the basics of computer use. When the federal grant that originally funded the project had ended, most storeowners chose to maintain the kiosks at their own expense. They felt that the extra business brought in by the kiosk was worth the cost of the phone line and Internet service.

Another community technology project in Kentucky was organized at a public health facility. The rationale for the project centered on the staggering drug and alcohol abuse problem plaguing the area. The purpose of the computing center was to deliver information about drug, alcohol and other unhealthy behaviors and to encourage self-esteem and new skills. The rural myth of the idyllic country community has been smashed by substance abuse, unemployment, and out migration. This and other centers included in this study were attempting in various ways to mitigate this reality.

A new graduate of the Computer Science program at Columbia wanted to get some real world experience. The young man, a native of India, had recently received his master's degree and was working in an unusual setting. "How would I describe it? This place is about 12,000 population, uh, one of poorest places of the state. South Dakota. We don't have much resources or anything. It is Indian Reservation-Pine Ridge." Since the young man had grown up in India he was not unaware of conditions of poverty. However, he described the setting as "shamedest place I ever see." 
Because culture was an important issue for many centers, the researcher found many instances were cultural issues were addressed in programs. In Arkansas the technology center had been in existence for three years. However, the technology focus had been incorporated into an overall community development strategy which had been operating for over 25 years. This predominately African-American community had built housing to replace substandard dwellings and was providing childcare for their people who were entering the work force. After-school enrichment and childcare were also made available. The African-American churches had played an important role in the development and implementation of the overall community development strategy.

The Executive Director of the Community Development Corporation in North Carolina spoke at length about the work of the CDC which also sponsored the community technology centers.

Well, it's pretty rural. It is and I think that even when we begin to talk about, um rural technology centers, um and rural community technology centers we have to almost think and speak honestly about what our challenges and opportunities and barriers as related to those entities in communities were. One-um because and if you know this area you know this is where literacy, or the rate of illiteracy is extremely high. Um that connects in my thinking um the racialethnic presence. Predominately people of color um in terms of African-American and American Indian population. Growing in terms of Hispanic presence while it's just been embraced with the um documentation of the land's census taking. Um there's been an 
explosion of Latino-Hispanic population and presence in this community. So that's due to the fact that it's rural and that labor has been relied upon to do the swine, hog farm, the turkey-poultry industry, even the lettuce growing, you know the sweet potato, the farming has slipped away from being family farming to now commercial farming, sigh. But those are just some of the agri-reality um that are present but dwindling. So the illiteracy piece. It's one of the challenges [facing] people to even desire to move to another level around embracing community technology. And the learning around it. Then theyoung people are geared up to do it because of course um you know the state of North Carolina is one where we talk about education, you know "leave no child behind;" education being one of the foremost areas of progress. And concern. So young people tend to have it but their parents-- don't. They have an interest and would willingly participate in community computer learning centers, but their parents are more reluctant to do so. Again one of the contributing factors being the illiteracy um rate and reality but then the absence of a community value for technology. Or learning in general. I think that's a part of, even in terms of encouraging success or encouraging effectiveness. Um, in rural communities around this um digital technology approach. It's all about focusing on mind set shifts. All about inculcating new values. It is all about creating different kinds of opportunities um or access to the knowledge of different opportunities that haven't been present before. And that's 
what we focus on here. I mean I think it's important to um for the notion of community technology centers to grow out of the community development corporation movement here. Because you know CDC's grew out of, they were a component of the anti-poverty [initiatives].

In Alaska, the technology center was in a town of 5500 which is the hub of 62 small outlying villages. Small aircraft is the only method of transportation into the town. Over $80 \%$ of the participants at the center are Native Alaskan. Clearly, cultural issues—or issues of cultural clash-must be faced by the center. Native Alaskans have a very high rate of substance abuse and "passed-out teens" was a problem. The center has seen an improvement in this behavior among its participants.

Sewing machines for making native-inspired crafts and native dance classes are as much a part of the center as are computers and a homework center. The outlying villages are too small to support a local school, thus a boarding school has been established in the town. There is also a juvenile detention center. The center is able to have some positive impact on theyoung people from both of these institutions, according to the subject. Gardening and nutrition are integrated into the program because the local children are often neglected. The interviewee described very popular bread making classes. The children and youth make bread dough and form the dough into native-inspired sculpture. The sculptures are baked and then the young people get to eat their work. The children learn to cultivate and enjoy eating vegetables grown in the long days of the arctic spring 
and summer. The computer center allows the youth to contact and interact with other youth from native cultures.

Finally, response to change was pointed out by centers as being very important. While some interviewees stated having a strategy for the development of the center was important, others felt that flexibility and the ability to change was more important. "I think one of the things that has contributed to effectiveness is that drive to be flexible, to change to meet the changing needs of the community." Another center summed it up as "I'm thinking here. Um, I think I've pretty much said it all. It's just team work and having a plan and persistence. And trying new things. Um, that really, not really trying to stay stuck on anything, not say that it has to be this way or that way. You know, just staying flexible. Yeah. I think that would be it in a nutshell."

\section{$\underline{\text { Research Question } 3}$}

What criteria should be used to measure critical factors?

In Research Question 3 the researcher was looking for alternative metrics for evaluating the effectiveness of a rural community technology center. Research Question 3 was the core of Interview question Q13. Subjects replied with discussions pointing to many evaluation metrics. Figure 22 charts the responses given for Interview question Q13: 


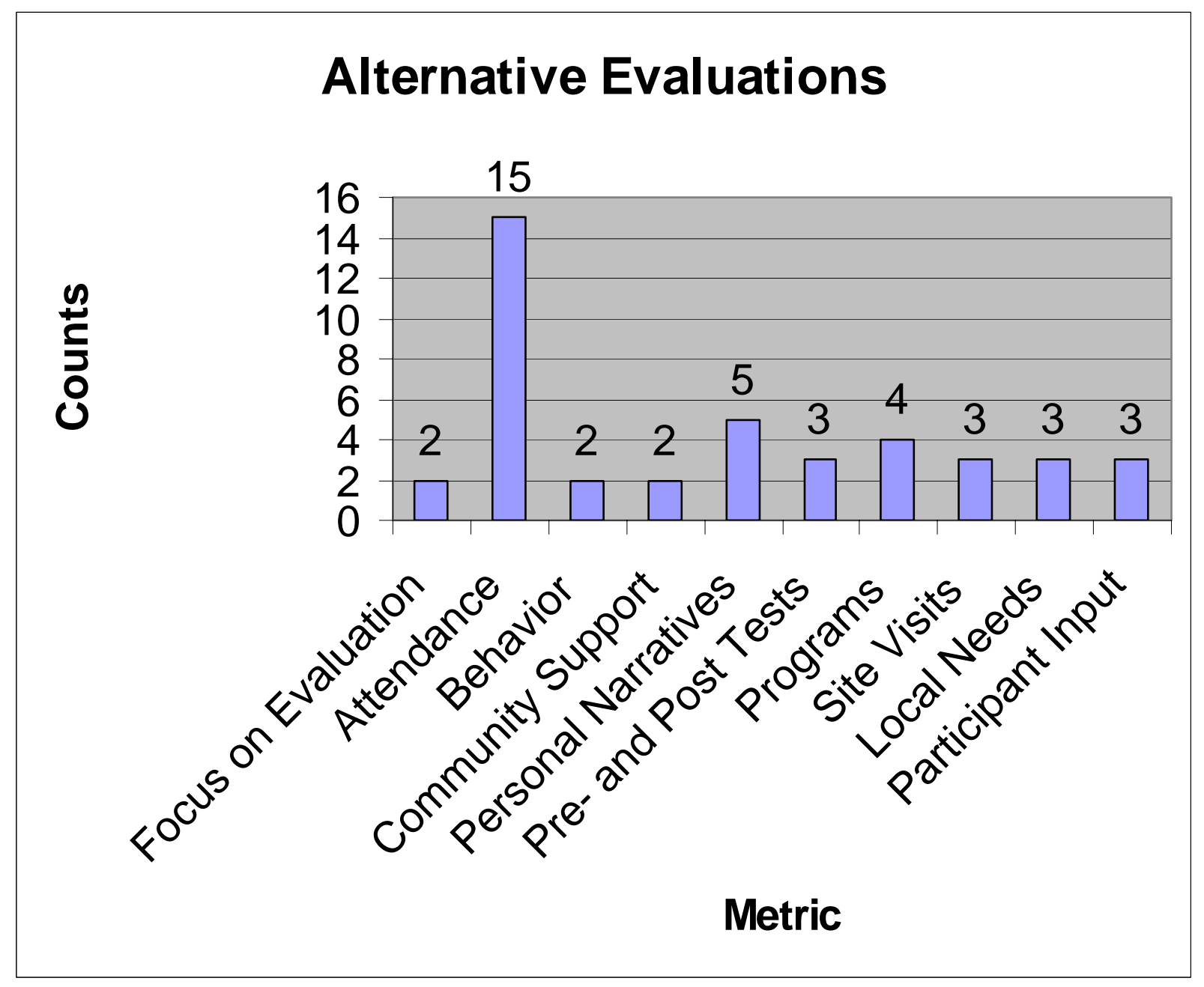

Figure 22: Alternate Evaluation Metrics Discussed by Subjects

As in Research Question 1 attendance or participation ( $\mathrm{n}=15$ ) was the most often-cited evaluation metric. Subjects were aware that participants "vote with their feet" and would not attend programs that were not considered valuable or effective. Evaluation by personal narratives $(n=5)$ was also considered important. A rural community technology center that offered a wide variety of programs was considered effective $(n=4)$. Community support $(n=2)$, participant input $(n=3)$ and focusing on local needs $(\mathrm{n}=3)$ were also important metrics. Evaluation by 
positive changes in participant behavior $(n=2)$ was also mentioned. One could arguably consider improved behavior and leadership capacity to be related to individuals and be subsets of personal narratives. If so, evaluation by personal narratives would show a higher value on the chart.

Three subjects felt that some form of pre- and post-tests $(n=3)$ would be good program evaluations. Three subjects thought that site visits $(n=3)$ would yield informative evaluations. One center mentioned both pre- and post-tests and site visits. Two centers $(\mathrm{n}=2)$ noted that evaluation and reflection on evaluation with the idea of improving programs were vital to building effectiveness. Both centers referring to the importance of evaluation also pointed to evaluation visits as good metric.

Notable metrics

In discussing alternative metrics, some of the responses given by only one subject were noteworthy. All Boys and Girls Clubs have access to a survey entitled "Commitment Quality." Clubs can ask community people, visitors from other areas, or board members to evaluate the club using this survey. The tool is "walkthrough" evaluation instrument that visitors are asked to complete. Results are used to improve the overall quality of the club. Since only one of the Boys And Girls Clubs referred to that evaluation tool, the researcher inferred that few were actually using it.

The volunteer coordinator at the site in northern Vermont made the point that attendance itself was not a useful measure in itself. He emphasized that one had to look at how many participants were engaged in a positive manner. “Um, I'll tell ya, I would go and I would go there after school and see how many kids are 
there, having fun, um, just that's that's [sic] the measure." His emphasis was on not simply attending, but having fun. "And that's my measure. Nobody is forced to come here. Um, and that's all I do is look in and see if kids are having fun and that it's appropriate for their age, and you know, if it's noisy, it's fine."

The manager of the community network serving York County, Virginia gave two broad categories for evaluating community networks. "Uh, communications and uh, economics. Within those two broad categories you come up with lots of sub elements. But those two broad categories have got to be there for a community network, or it's not mature."

Three of the interviewees alluded to measuring the centers success at focusing on local needs. The librarian at a site in rural eastern Washington summed it as

Um, that doesn't necessarily mark a success, just because people are coming in to use it. Are they getting their needs met? That's a different kind of question. And that's where your success lies. Being able to access their email to their expectations? Were they able to compose a resume to their expectations? Were they able to acquire additional skills in Excel that they've not had previously? Um, do they come back again? That's one mark. I've had a number of people come in repeatedly.

That same principle was mirrored by the site coordinator in central Pennsylvania, “Um, I think you have to talk to the people that you serve. And get 
their opinion, sometimes you might not agree with their answers, but you get a good idea."

For community networks, York County's coordinator thought that sustainability was an important measure of effectiveness. "Well two things, physically, during it's first 3-5 years, does it become self-sustaining, and two, does it attract businesses? And if it does, then it will be physically self-sustaining."

The Executive Director of the CDC in southeastern North Carolina said that metrics should look beyond the obvious attendance numbers to changes in values.

I think there has to be some um opportunity to ask people what affect this has had on their lives. Um, to determine if there has been a shift in the value, a shift in the knowledge. Um qualitatively and quantitatively. Figure out if peoples' lives have been changed because of the involvement. I'm big on um photographs and pictures and. I like to document that way. We've got tons and tons and tons of picture stuff around.

Perhaps pictures are worth thousands of words. This subject certainly thought that to be true.

Overlapping Evaluation Metrics

Research Questions 1 and 3 pertained to evaluation of rural Community Technology Centers and what measures might be used for evaluating the effectiveness of centers. Subjects discussed many evaluation metrics, some of which were insightful and creative. There was a good deal of overlap in the 
responses to Research Questions 1 and 3. Responses and overlapping of responses are represented schematically below in Figure 23:

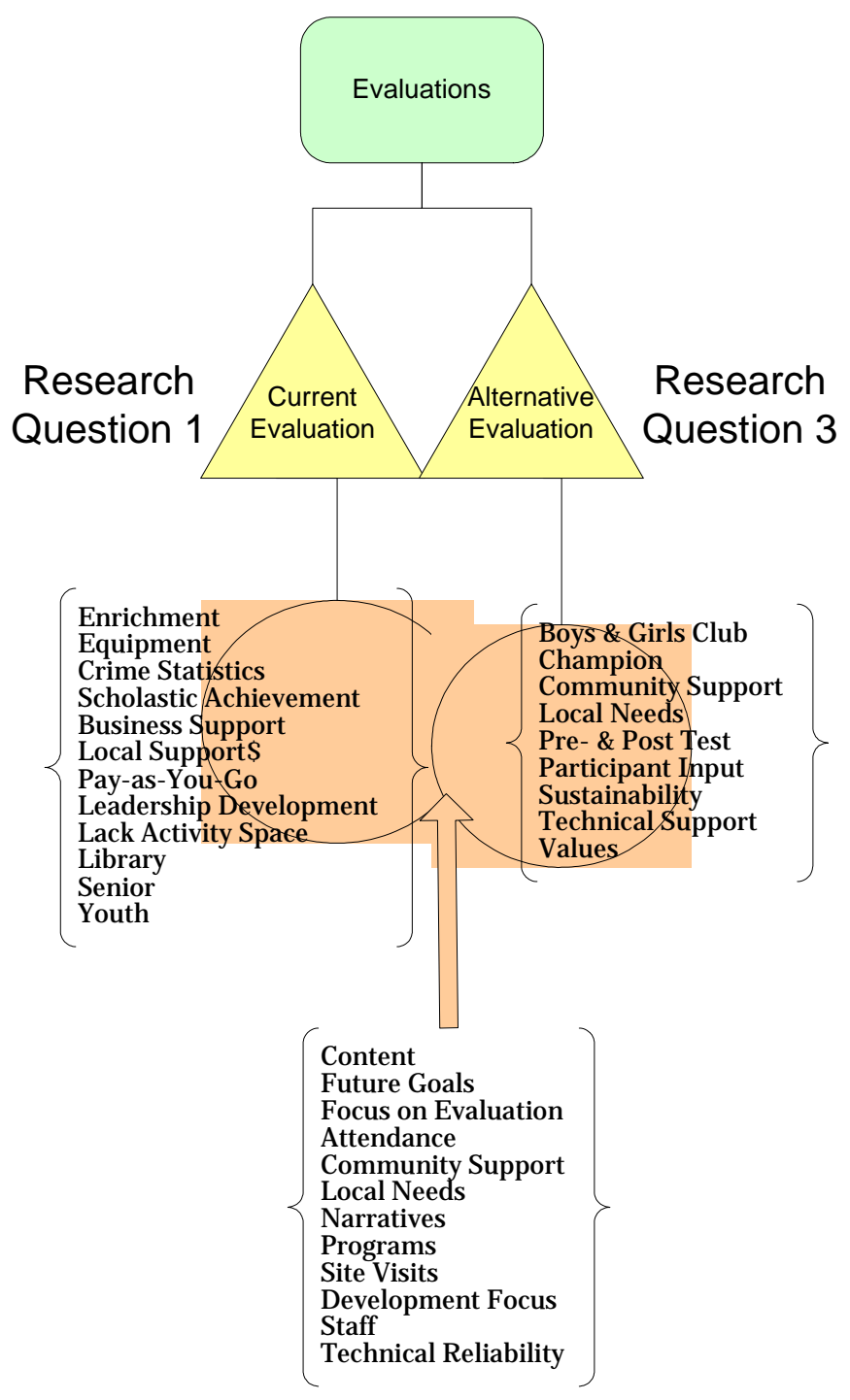

Figure 23: Schematic Representation of Evaluation Metrics

Suggested in Research Questions 1 and 2

Thinking that the overlapping codes might be interesting, their relative incidences are represented in Figure 24. 


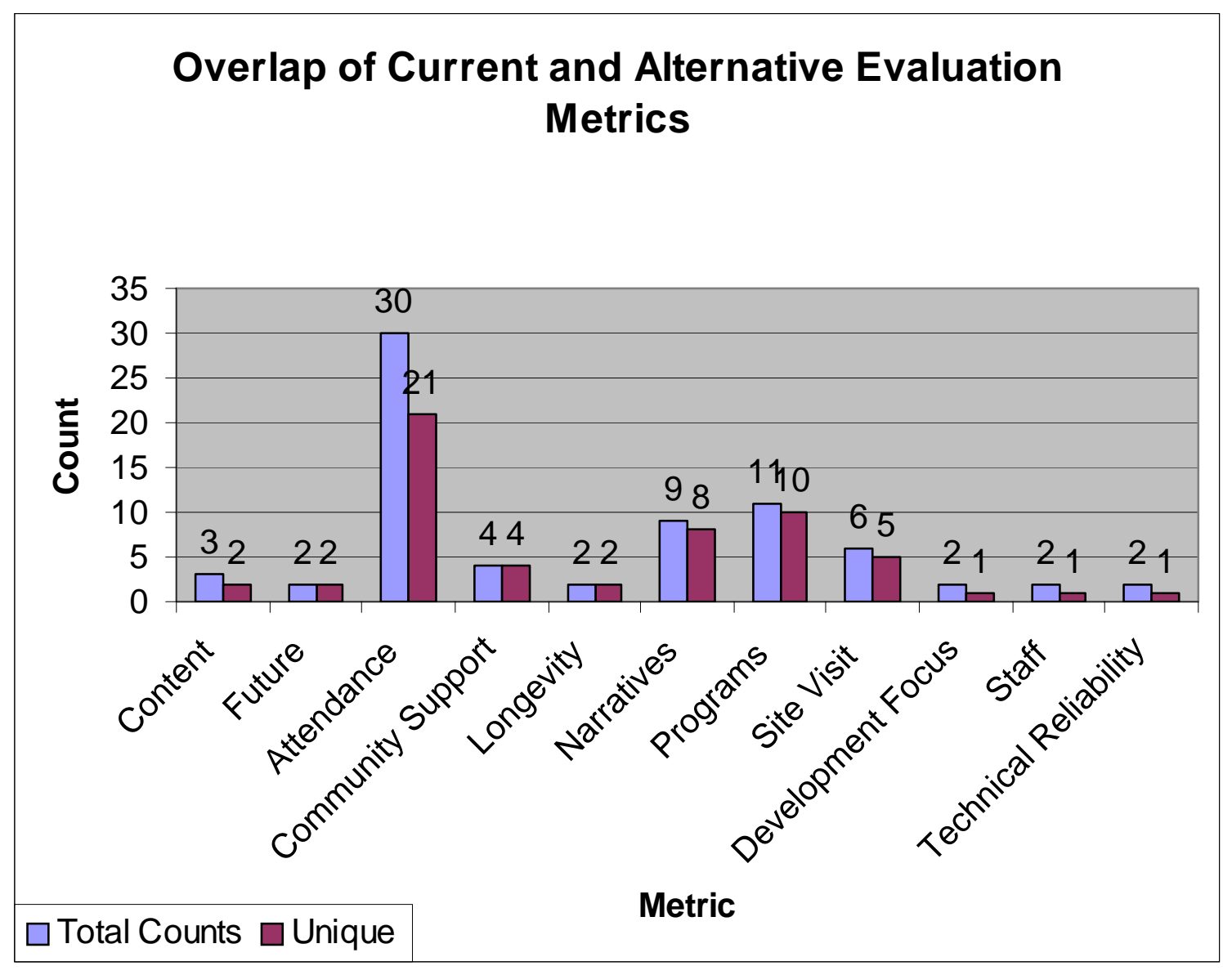

Figure 24: Relative Incidences of Evaluation Metrics Discussed in both Research Questions 1 and 2

As in the results pertaining to Research Question 1, attendance numbers ( $n=30,21$ unique) were most often cited as evidence of effectiveness. Programs and program participation ( $\mathrm{n}=11,10$ unique) were considered important also. One subject noted that even a dropout rate might imply effectiveness rather than lack of success, "We do have a lot of adults enroll in the classes and I think have to come to the class until they learn what they want and then they may stop because they've gotten enough out of it to fit their personal need." The technology coordinator at the Boys and Girls Club on the Mexico-Arizona border observed that not just 
programs, but the products of the programs would be an important measure of effectiveness.

We have, like my computer has a big hard drive with a member's project folder and it's full. I always try to get them to save everything they do no matter how small so they just always have it. I would show them the projects that were done. And some of them are resumes, uh, kids that did their senior projects are stored in there, like I said, those Powerpoint projects. Stuff like that. A lot of them are doing this music program. It's called the MTV music generator. It's pretty easy to put together a song. They really like that. They can actually put it on a regular CD. They can play it at home on their stereo. Stuff like that.

Personal narratives ( $n=9,8$ unique) and having future plans or goals were appreciated as strong indicators of effectiveness.

Some kids, we have conversations with kids, the teenage girls were saying oh, you know they're 14 or 15, I want to have a baby at 14 and 15. And it's like, do you understand what that means? You will have no more life of your own. And so now these same kids, we've shown them films and put the reality to them, they've decided um, maybe when I'm 30 we're gonna have kids. And some kids that said they were going to quit school when they were 16. They're still in school. And other kids who thought you know they didn't even have a chance to go to college, I guess they really couldn't see a future for 
themselves. Down here they couldn't see the possibilities. One of them is at OU (Ohio University) right now, one graduated last year, another one is going to Hocking College to get the basics, and then he wants to go to NewYork City to go to NYU in film. Um, other kids are applying now to see what qualifications they need. J ulliard, and you know schools all over the place.

Narratives and future plans such as these speak forcefully about the effectiveness of rural community technology centers.

Site visits ( $\mathrm{n}=6,5$ unique) were favored by some interview subjects. "Invite them to come on board and find out more about it," a subject from southeastern North Carolina put the idea in plain words. From Arkansas came an equally simple statement, "I'd tell them to come see for theirself [sic]. That's all you can tell them, is to come see for yourself, and then tell them a little bit about what has been accomplished through it." Clearly these subjects believed that there was more to understanding positive impacts than numbers or narratives.

Community support and community leadership capacity building were measures observed as important by centers. According to the northern Vermont interviewee,

Um, I think that being a small town um, success is measured by um, support from the community, in that we get write ups in the local paper, we get uh, visits from the big city TV stations at least twice a year. Um, we get donations from local industries, we're the Maple capitol of Vermont. I'd say the world or US, the maple producer 
always gives us maple products when we travel to the conferences because you know kids love maple syrup in 2 oz. Bottles. And maple syrup is candy, you know.

In Kentucky, communities not only supported the community technology project, but also were able to use what they learned to further the use of computer technology in their own communities:

This many years later that it's still going and there are still laptops out there being lent and there's still kiosks being run and there's new developments. I think that's really important too, like this Internet project that we had nothing to do with that. The community themselves secured the funding. They got it set up, they did all the staffing, they hired technical support. So I think it shows that we were able to build capacity in that community. And so that they are able to make new developments, um you know, kind of run with it on their own. Instead of having to have an outside group take on the administrative work. So even though at the beginning we had to do it they were able to learn through our experience and able to take it on themselves.

\section{General Observations and Comments}

Rural community technology centers and community networks existed in many "flavors." Some served extremely remote areas, others were located in communities that were transitioning into distant suburbs of larger cities. All 
effective centers and networks were located in small town settings and were the result of multiple partnerships with other organizations and agencies. Partnerships with local school districts, community groups, local government, and higher education were significant, but other partnerships were equally important and often very creative.

"Rural" and "poverty" were closely connected for many of the study subjects. Economic development issues were often part of the overall strategy of the rural community technology centers. Unfortunately, many of the brightest graduates of programs associated with the community technology centers needed to re-locate to other areas to rely on their technology skills for income.

Many community networks have either gone out of existence or become online repositories of local information. Few remain active with the focus of providing Internet and local network access to rural residents.

Many of the study subjects discussed "champions" who had been pivotal in the early stages of the center's development. However, quite a few of the subjects talked with the energy and enthusiasm of social evangelists themselves.

While the majority of centers relied on attendance numbers as measures of success, the study subjects were personally more interested in personal narratives, brighter futures and changed values as effectiveness metrics. Unfortunately these are more difficult to collect in a small community-based organization with limited resources. Most resources were targeted at implementing programs. One subject discussed having lots of photographic records that had been collected.

Determining how to operate programs and best tell their story was a problem for rural community-based programs. 


\section{Implications of the Research}

Practical implications

The results of this research implicate that many factors are critical for developing effective rural community technology initiatives. The areas needing attention, effort and planning are summarized below:

- Groups wishing to develop effective rural community technology centers or programs should realize the value of partnerships and work to build partnerships with local groups and local government. Effective community technology centers relied on cultivating multiple partnerships.

- In the planning phase of the center, a local champion or evangelist for the program would be an asset. Raising general awareness of the project and the need for the project was a critical factor for developing an effective program. Local leadership and responding to local needs are important elements to consider. Persistence also is an essential factor in developing a rural community technology center. From the beginning, planning for sustainability will help ensure a successful program.

- The findings of this study indicate that a traditional organizational structure with a board of directors and an executive director is effective. However, including the center as part of a larger community organization was strategic for thriving programs. The researcher found no free standing centers serving rural communities; 
all were incorporated into other organizations. Staff persons were indicated to be the most valuable asset in actual program implementation

- Creative mix-bagged funding mechanisms are employed by successful rural community technology centers. Federal and state grants were incorporated into the funding strategy, but local fund raising and business support were equally vital to the development of effective centers. The creative character of the funding was confirmed by "Other" being the most often cited source.

- Serving as many different groups as feasible was a feature of successful rural community technology centers. Planning for full inclusion and making room for diversity and cultural differences was essential. Rural areas are no longer monocultures.

- Transportation issues were addressed in various ways. Most programs found that participants were able to use private vehicles. Youth- serving organizations often used the school bus system to transport students from school to after school programs with parents picking students up later. However no centers commented as to whether they felt that they were reaching all of their targeted participants or whether potential participants might be hampered by lack of transportation.

- The content of programs was critical. Programs should be peopleoriented, educational, and focused on both local needs and development. Many special focus programs were popular. Art, 
native culture, and nutrition were unique features of after school programs.

- Securing technical support for the computers and network was an important issue. Staying current with equipment and applications was vital. High-speed connections were essential for ensuring a positive experience for participants. Overcoming infrastructure shortcomings required creativity, but was not impossible.

- Rural community technology centers were not developed on a consistent model. Boys and Girls Clubs most nearly followed a set pattern, but they also served auxiliary purposes in the community. Most centers served multiple functions as community assets.

- Centers had barriers to overcome, most notably barriers associated with financial issues, negative people, low population density, isolation and out migration.

- Thriving centers incorporated unique features into their centers. Unique features were found in the interior décor. Culturally related factors added to the uniqueness.

Theoretical Implications

The findings in this research fits well into Maughan's (2001) model of a robust communication system. Separating human, financial, and policy considerations from the technical system components may provide an excellent technical system but an inappropriate operational and strategic perception results when human factors are not taken into consideration. The majority of critical factors necessary for developing effective rural were indeed human factors. 
Centers had far fewer technical factors than human factors that needed to be addressed.

Kling's (2000b) discussion of social informatics stated that any local computing package is a highly intertwined socio-technical system. Separating technical components or artifacts from social context and social shaping cannot give a complete understanding of community technology centers. The current research upholds this view. All centers included in this study were examples of highly intertwined socio-technical systems. 


\section{H A P T E R 5}

\section{Summary, Conclusions and Recommendations for further Research}

\section{Introduction}

This summary begins with a focus on the findings with respect to the three original research questions. Some observations not directly related to the research questions that nevertheless appeared significant will be discussed. The strength of the qualitative data will be discussed along with the possibility of alternative interpretations. Practical implications for developing effective rural community technology centers are identified. Findings are related to Maughan's model of a mature communications system and Kling's Social Informatics conception. Finally, recommendations for further study will be given.

\section{Purpose Statement}

The purpose of this research was to identify the critical factors for developing effective rural community technology centers. 


\section{$\underline{\text { Research Question } 1}$}

How is effectiveness measured in rural community technology centers?

While attendance was cited as the most often employed method for tracking effectiveness, many subjects offered methods that each felt would be more revealing. Personal narratives and narratives about future goals were deemed more informative than sheer numbers of participants. J uvenile crime statistics and school improvement were thought to be more telling than attendance numbers for centers servingyouth. Support, both financial and otherwise, from the local community and the local business community were considered important. This implied that in the rural community, local community groups and local businesses would not invest in programs that were not effective. One center operated by a local community development corporation related that they kept an abundance of photographs to document the center's history and effectiveness.

Several subjects discussed site visits as good methods for measuring their effectiveness. As one spunky young lady stated, 'I'd tell them to come see for theirselves [sic]." Many centers offered a variety of activities, and seeing participants engaged in these activities was considered solid evidence of effectiveness.

Subjects seemed to have a keen sense of the value of effectiveness data other than sign-in attendance sheets. Several stated that they routinely did participant surveys to evaluate individual programs. Many offered anecdotal evidence of changes in personal narratives of individual participants. Additionally, many understood a strong correlation between community support, community 
partnerships and effectiveness. Unfortunately for centers with slim resources, documenting these personal narratives required more resources than were always available. Evaluations built into the technical systems could be cost effective, but were not widely used.

\section{Research Question 2}

What factors are critical for developing effective rural community technology

\section{centers?}

Research Question 2 yielded the most complex set of results. Developing effective rural community technology centers and community networks was dependent on a large network of factors. Social, political and financial factors appeared to be more significant than technical factors. References to partnerships were made more often in interviews than to any other group of factors. Subjects had an implicit understanding of the value of partnerships and the futility of trying to develop their centers without multiple partnerships. The "barn-raising" metaphor appeared to hold true for rural community technology initiatives.

The researcher expected that institutions of higher learning would be important in developing effective centers, due to higher education's expertise with computers and networking. Unexpectedly however, public schools were the most often cited partners with references to community groups and local government at a slightly lower frequency. An unexpected partnership resource was with 4-H clubs. The 4-H clubs have made technology expertise a priority with some states having both regional and statewide technology teams. 
During the coding process, 120 codes emerged. After multiple codings by both the primary researcher and the secondary coder, no new codes became apparent. Codes were rather easily arranged into thematic groups. A few codes were placed in multiple groups while others were clearly related to only one specific group. Figure 25 diagrams the researchers construction of the relationships of factors for developing effective rural community technology centers: 


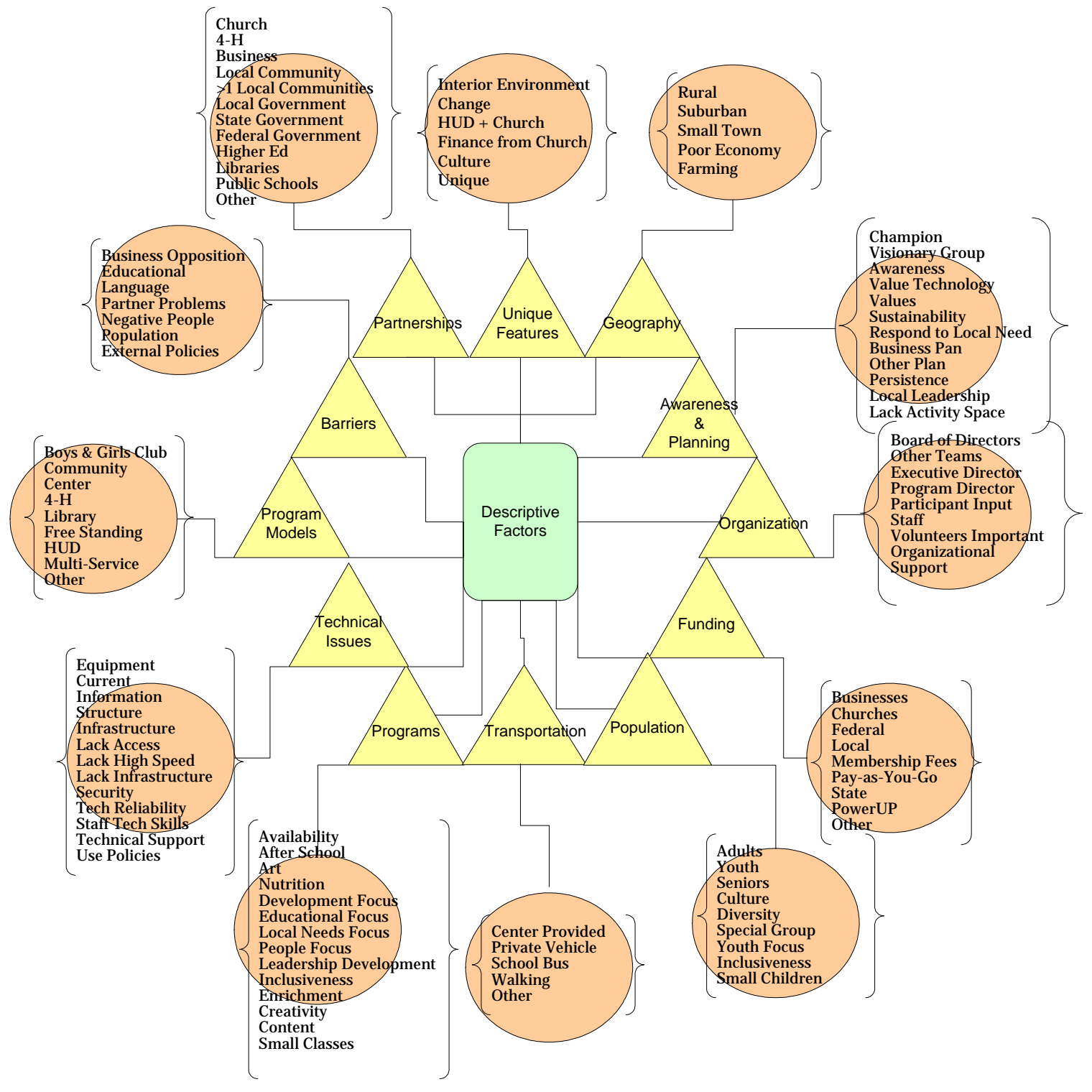

Figure 25: Relationship of Thematic Groupings

\section{Summary of Thematic Groups}

\section{Partnerships}

\section{As stated earlier, subjects made more individual references to partnerships}

than to any other group of factors. Partnerships included all sectors of the 
community: public schools, higher education, local community groups, businesses, state and federal agencies, libraries, 4-H Clubs, Boys and Girls Clubs, churches, tribal government, community development corporations, and others. Effective centers cultivated ongoing partnerships with all partners that might receive benefit from the collaboration.

\section{Geography}

All centers included in this study met the criteria for being rural. Only one community was not described as rural by the study subject. That community was described as being in transition from rural to suburban because it had becomea "bedroom community" for the greater Hampton Roads metropolitan region. Interviewees most often also linked economic distress with their description of the community. Few of the subjects interviewed mentioned farming or agriculture as currently adding any substantive value to the economy.

\section{Awareness and Planning}

Raising awareness of the need for the project and planning the project was regarded as important to the development of each project. For the project to have one or two champions or evangelists was the most often cited critical factor. Building awareness of the project and of the benefits of utilizing technology emerged as the second most essential factor. Persistence, planning in general and planning for sustainability also appeared as critical factors. Much to the researcher's chagrin, responding to local needs and buy-in by local leadership was found to be important, but not referenced as frequently as a having a champion, building awareness, or planning and persistence. 


\section{Organization}

In discussing how centers were governed, there was much commonality. Nearly all centers had the usual structure of board of directors with an executive director. Some centers also had a program director. However, the staff was mentioned most often as the crucial factor in the organization. Volunteer input, participant input and organizational support from other agencies appeared to be important factors for centers, but fell behind staff, board of directors and executive director in frequency of reference.

\section{Funding}

As would be expected, funding was a concern for all centers. Effective centers had created unique, mixed-bag funding mechanisms which relied on individualized packages of state and federal grants, corporate and private grants, contributions from individuals, local fund-raising and donations, membership fees and business activities. The category with the greatest number of references, "Other" was an indication of the resourcefulness of effective centers

\section{Population Served}

Effective rural centers seemed to understand the importance of making services available to as broad an audience as possible. In general, youth were most often cited as participants. However, rural centers nearly always offered some services to various groups. Boys and Girls Clubs offered services for adults and senior citizens in the morning hours. A HUD subsidized housing complex in Pennsylvania made services and classes available to the wider community. The facility serving homeless veterans engaged 4 - $\mathrm{H}$ members for hardware and 
software support. 4-H Clubs have targeted computer technology as essential to rural residents. Thus many states have 4-H Technology Teams as well as animal, horticultural and land judging teams.

Cultural issues and diversity have become important to rural community technology programs. Rural areas are no longer monocultures and effective centers have learned to serve diverse groups. Subjects mentioned that learning to serve participants within the participants' cultural context was important to effectiveness.

\section{Transportation}

The researcher included investigating transportation issues based on her own experience with technology-based programs targeting low income residents of isolated rural areas. Surprisingly, the centers seemed to have this aspect under control without much trouble. The most employed transportation method was private vehicle. School buses transported many youth from school to their programs. Participants often walked home from programs. Transportation, where provided by the center, was on a very limited basis. In most instances transportation was handled by the individual participants.

\section{Programs}

Subjects had much to say about their programs. The major themes in programming were: education, personal development, local needs and economic development. Most centers and community networks offered programs entailing more than one of the major themes. None of the centers included in the study were simply places where individuals could just drop in and use the computers. 
Libraries most nearly functioned as drop in centers, but they offered educational programs and support in basic computer and Internet skills. Genealogy was a popular research subject at libraries.

Interesting minor themes also emerged in the programming group. Art and music components appeared at three centers. Nutrition and gardening were covered in Alaska. Leadership development was an intentional part of the overall program in eastern Kentucky. Subjects noted that creativity in program offerings was a factor for success.

Technical Issues

Technical issues encountered by centers were not unusual. Obtaining technical support was the most prevalent problem. Maintaining up to date equipment and software was also difficult. Funders have not yet come to the understanding that technology is an ongoing operating expense like electricity and telephone rather than a capital expense.

Infrastructure and access to high-speed Internet were expected to be issues. Centers had addressed these issues in various ways. Schools, libraries and health care agencies had made use of E-Rate to obtain T1 connectivity. Two centers had satellite Internet access. PowerUP had aided Boys and Girls Clubs and some other centers in setting up their networks and obtaining Internet service.

\section{Program Models}

There was no one model upon which the centers based their programs. Creativity in local programs was the major theme. Centers included in this study were Boys and Girls Clubs, community centers, HUD subsidized housing 
complexes, libraries, youth centers and one museum. Many of the sites served more than one function in the community. Making the very most of facilities and resources was a recurring message from the study subjects.

Of the three community networks participating in the study, only one was still functioning as a community network and ISP. One community network had become a web-based community information center. The third had ceased to exist, but the founding group of citizens had embarked on developing a new technology based business incubation center.

\section{Barriers}

All centers experienced barriers which had to be surmounted in order for the centers to be effective. Financial and technical problems are described above as separate themes. Other barriers encountered were human factors. Nay sayers, transient people and lack of local leadership capacity were problems for some subjects. Low population density, out migration and isolated people were also major themes. Language was described as a problem for centers serving diverse populations. Not being able to build or maintain important partnerships proved problematic for some centers.

\section{Unique Features}

The unique features of the centers in this study were a credit to the ingenuity of rural communities to utilize resources. Effective centers were found in old machine shops and garages, former plantation houses, an old motel, a healthcare facility, libraries, a museum, and country stores. One center had brand new, state of the art youth and community facilities because a local high income, 
gated retirement community had been invited to make personal donations.

Flexibility, creativity, individuality, and uniqueness were major themes in developing effective rural community technology programs.

\section{$\underline{\text { Research Question } 3}$}

What criteria should be used to measure critical factors?

Research Questions 1 and 3 pertained to evaluation of rural Community Technology Centers and what measures might be used for evaluating the effectiveness of centers. Subjects discussed many evaluation metrics, some of which were insightful and creative. There was a good deal of overlap in the responses to study questions 1 and 3. Responses and overlapping of responses are represented in the Figure 26: 


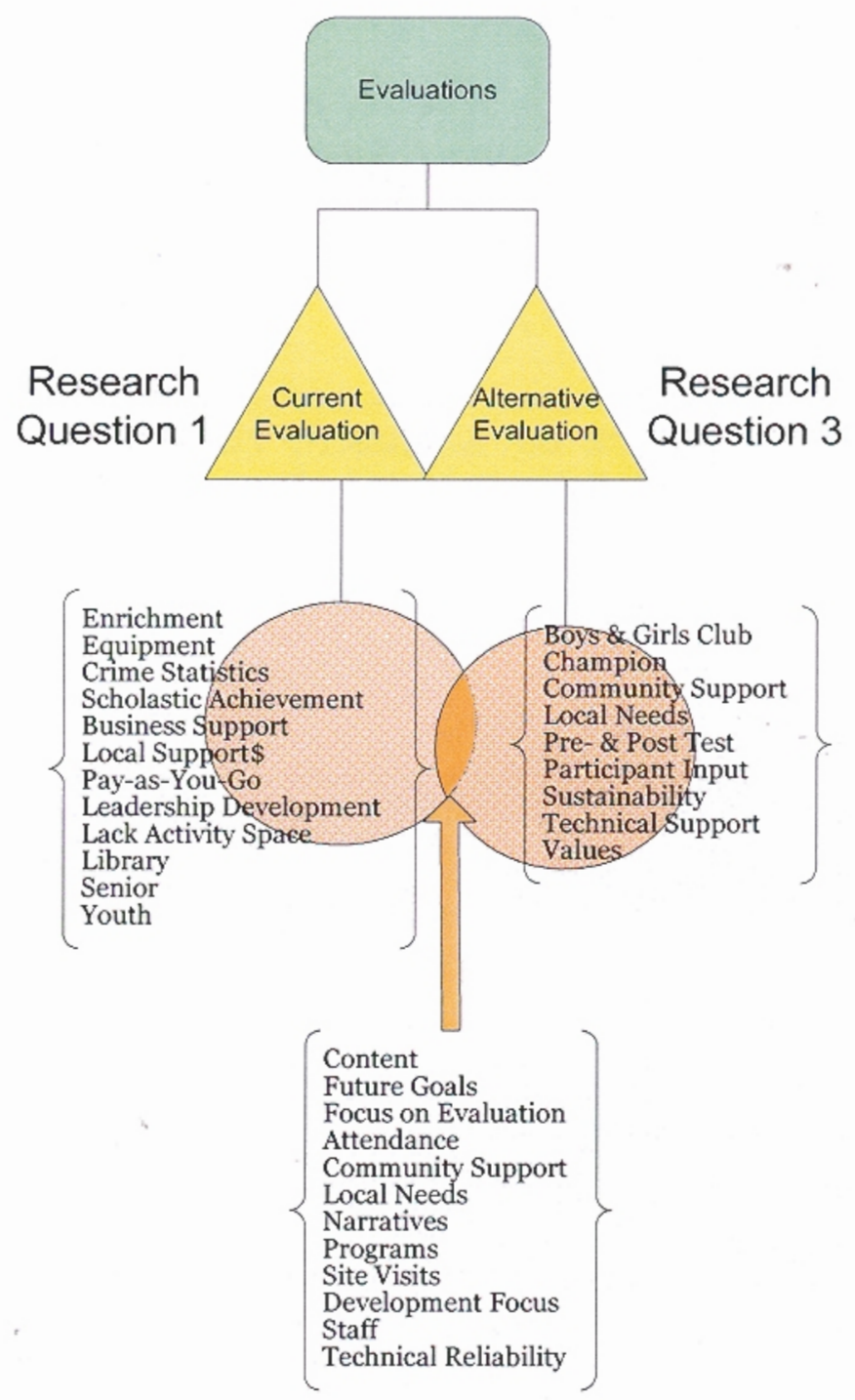

Figure 26: Evaluation Metrics

As in Study Question 1, attendance numbers were mentioned most often as an evaluation measure. Personal narratives and site visits were also considered good methods for documenting effectiveness. Boys and Girls Clubs have a "Community Quality" survey available for their use. Clubs can request community 
persons, parents, visitors or board members to make use of this tool while visiting the club. Results are used to improve the quality of the programs.

For children's programs, behavior of the children was noted as an important metric of effectiveness. One subject pointed to engagement by participants, rather than mere attendance as being more significant for evaluating success. Other interviewees felt that participants needed to be asked about their experience with the center. Instead of just attending, it was important to knowif the person's needs were met. One study subject even hinted that a high dropout rate might be indicative of effectiveness because in adult classes, participants enroll and attend long enough to learn what they needed, then stop because their immediate need was met. Few of those interviewed were professional educators. However, most understood intuitively about evaluation and many had insightful information about how rural community technology centers and networks might be evaluated.

\section{Strength of Qualitative Data}

The researcher was concerned as to how convincing the qualitative data collected in this study would be when the results were presented for review. Thus a survey instrument was developed as a triangulation tool. However, once the interviews were coded, the results appeared very strong. In fact, the qualitative data emerged much clearer than the survey data. Spotty returns for the surveys and a small sample size rendered the survey data of little value.

Using widely available software tools, Microsoft Access and Excel, the researcher was able to quantify occurrences of codes. In most instances codes were counted as total instances and as unique instances. In the interview a subject could 
make reference to a given factor in more than one question. In total counts, each reference would be counted as one occurrence of the code. In unique counts one subject could make reference to a given factor in response to several questions. However, in that scenario the code counted as one unique instance regardless of the number of times any one subject mentioned the factor. Codes were always unique for a given subject's response to a single question, regardless of the number of references made in the response to that question.

\section{Alternative Interpretations of Data}

The very nature of qualitative investigation allows for alternative interpretations of data. This was most obvious in the placement of codes into larger thematic groups. A number of alternative organizational structures for the data were tested. The researcher chose the classification system that appeared to accommodate the greatest number of codes with least amount of overlapping. Overlapping of coding groups did, however, occur.

The process of developing a set of questions for a semi-structures interview process presupposes a grouping system. In order to minimize this presupposition, the researcher began the coding process using nine brief case studies which were published in a non-scholarly community development periodical. These case studies were more showcases than scholarly case studies. However, they were analyzed for recurring themes. The results of this analysis formed the basis of the Interview Questions and the codebook used to analyze the raw data. Codes were added throughout the interview coding process until no new codes emerged. All 
interviews were read and coded a minimum of four times: three times by the primary coder and at least once by the secondary coder.

One might argue that a code cannot "emerge" without the coder having a presupposed code in mind. How can a researcher see a code that has not been presumed? While this is true, this researcher can also argue that no research, quantitative or qualitative, can be undertaken without some presumed outcome. A null hypothesis for a quantitative study cannot be based on random statements. The null hypothesis itself is a test statement to facilitate investigating a presumed outcome.

\section{Implications of the Research Findings}

Practical Implications

The results of this research implicate that many factors are critical for developing effective rural community technology initiatives. The areas needing attention, effort and planning are summarized below.

1. Groups wishing to develop effective rural community technology centers or programs should realize the value of partnerships and work to build partnerships with local groups and local government. Effective community technology centers relied on cultivating multiple partnerships.

2. In the planning phase of the center, a local champion or evangelist for the program would be an asset. Raising general awareness of the project and the need for the project is a critical factor for developing an effective program. Local leadership and responding to local needs 
are important elements to consider. Persistence also is an essential factor in developing a rural community technology center. From the beginning, planning for sustainability will help ensure a successful program.

3. The findings of this study indicate that a traditional organizational structure with a board of directors and an executive director is effective. However, including the center as part of a larger community organization was strategic for thriving programs. The researcher found no free- standing centers serving rural communities, all were incorporated into other organizations. Staff persons were indicated to be the most valuable asset in actual program implementation

4. Creative mix-bagged funding mechanisms are employed by successful rural community technology centers. Federal and state grants were incorporated into the funding strategy, but local fund raising and business support were equally vital to the development of effective centers. The creative character of the funding was confirmed by "Other" being the most often cited source.

5. Serving as many different groups as feasible was a feature of successful rural community technology centers. Planning for full inclusion and making room for diversity and cultural differences was essential. Rural areas are no longer monocultures.

- Subjects did not perceive transportation to be a critical issue. Transportation issues were addressed in various ways. Most 
programs found that participants were able to use private vehicles. Youth- serving organizations often used the school bus system to transport students from school to after school programs with parents picking students up later. However no centers commented as to whether they felt that they were reaching all of their targeted participants or whether potential participants might be hampered by lack of transportation.

6. The content of programs was critical. Programs should be peopleoriented, educational, and focused on both local needs and development. Many special focus programs were popular. Art, native culture, and nutrition were unique features of after school programs.

7. Securing technical support for the computers and network was an important issue. Staying current with equipment and applications was vital. High-speed connections were essential for ensuring a positive experience for participants. Overcoming infrastructure shortcomings required creativity, but was not impossible.

8. Rural community technology centers were not developed on a consistent model. Boys and Girls Clubs most nearly followed a set pattern, but they also served auxiliary purposes in the community. Most centers served multiple functions as community assets. 4-H Clubs made a significant contribution to developing effective rural community technology centers. 
9. Centers had barriers to overcome, most notably barriers associated with financial issues, negative people, low population density, isolation and out migration.

10. Thriving centers incorporated unique features into their centers. Unique features were found in the interior décor. Culturally related factors added to the uniqueness. Uniqueness and creativity were reported in programs, funding, and staffing.

Theoretical Implications

The findings in this research fits well into Maughan's (2001) model of a robust communication system. Separating human, financial, and policy considerations from the technical system components may provide an excellent technical system but an inappropriate operational and strategic perception results when human factors are not taken into consideration. The majority of critical factors necessary for developing effective rural were indeed human factors. Centers had far fewer technical factors than human factors that needed to be addressed.

Kling's (2000b) discussion of social informatics stated that any local computing package is a highly intertwined socio-technical system. Separating technical components or artifacts from social context and social shaping cannot give a complete understanding of community technology centers. This research upholds Kling's view. All centers included in this study were examples of highly intertwined socio-technical systems. 


\section{Recommendations for further Study}

Based on the findings of this study, the following areas for further study are recommended:

1. The transportation issue and determining the percentage of targeted participants actually being served were areas that appeared in discussions with colleagues. These issues warrant further investigation.

2. Major partners of rural community technology centers and community networks might be interviewed with the same interview protocol to determine if the critical factors are similar from each partner's point of view.

3. A study might be designed to test whether the critical factors for developing effective community technology centers identified in the present research might extend to other types of programs serving rural communities.

4. Results of the present study imply that some factors for developing effective centers were more important than others. An interesting set of questions could be generated to determine whether those results have statistical significance.

5. Finally, since unique features emerged as a thematic group for developing effective community technology projects, an interesting study could be designed to look at the quality of uniqueness in rural community programs. 
Rural Technology Centers

165

\section{R E F E R E N C E S}

About ACENet. (2000). Retrieved November 16, 2002 from

http:// www.acenetworks.org/ frames/ framesabout.htm.

Alkalimat, A., \&Williams, K. (2001). Social capital and cyberpower in the African American community, in L. Keeble \&B. Loader, (Eds). (2001). Community Informatics: Community development through the use of information and communications technologies, London: Routledge.

America Connects Consortium. (2001). About ACC. Retrieved October 30, 2002 from http:// www.americaconnects.net/ acc/

Ba, H., Culp, K., Green, L., Henriquez, A., \&Honey, M. (2001). Effective technology use in low-income communities: Research review for the America Connects Consortium. CCT Report prepared for The America Connects Consortium.

Bowden, P., Blythe, E., and \&Cohill, A. (2000). A brief history of Blacksburg Electronic Village. In A. M. Cohill \&A. L. Kavanaugh, (Eds), Community networks: Lessons from Blacksburg, Virginia, 2nd edition (pp. 15- 31). Boston: Artech House.

Breeden, L., Cisler, S., Guilfoy, V., Roberts, M., \& Stone, A., (1998). Computer and communications use in low income communities: Models for the Neighborhood Transformation and Family Development program. Prepared for Annie E. Casey Foundation. 
Carey, J ., Wenzel, P., Reilly, C., Sheridan, J., Steinberg, J ., \&Harbison, K. (1998). CDC EZ-Text: Software for collection, management and analysis of semi-structured qualitative databases (Version 3.06c). Atlanta: Developed by Conwal Incorporated for the Centers for Disease Control and Prevention.

Casalegno, F. (2000). Community dynamics and the BEV senior citizens group. In A. M. Cohill \&A. L. Kavanaugh, (Eds), Community networks: Lessons from Blacksburg, Virginia, 2nd edition (pp. 99-121). Boston: Artech House.

Chandler, D. (2000, October 10). Program is bridging the digital divide. Boston Globe. Retrieved October 5, 2000 from http:// www.boston.com/dailyglobe2/279/metro/Program_is_bridging_comput er_divideP.shtml

Chow, C., Ellis, J . \&Walker, G. (2000). CTCNet Evaluation Toolkit. Assembled by CTCNet Evaluation Team.

Chow, C., Ellis, J ., Mark, J ., \& Wise, B. (1998). Impact of CTCNet Affiliates: Findings from a national survey of users of community technology centers. Report by EDC available from CTCNet.

Cisler, S. (2000). Global CN 2000: First global congress on community networking; "the human face in Internet", report from conference held November 2-4, 2000. Retrieved November 11, 2000 from http:// home.inreach.com/ cisler/ cn2000.htm 
Cohill, A. (1999). Keys to success, in Blacksburg electronic village community network briefing book, pp 26-38.

Cohill, A. (2000a). The architecture of a community network. In A. M. Cohill \&A. L. Kavanaugh, (Eds), Community networks: Lessons from Blacksburg, Virginia, 2nd edition (pp. 33-57). Boston: Artech House.

Cohill, A. (2000b). The future of community networks. In A. M. Cohill \&A. L. Kavanaugh, (Eds), Community networks: Lessons from Blacksburg, Virginia, 2nd edition (pp. 357-380). Boston: Artech House.

Cohill, A. (2000c). Success factors of the Blacksburg Electronic Village. In A. M. Cohill \&A. L. Kavanaugh, (Eds), Community networks: Lessons from Blacksburg, Virginia, 2nd edition (pp. 335-356). Boston: Artech House.

Cohill, A. (2000d). Welcome to Blacksburg. In A. M. Cohill \&A. L. Kavanaugh, (Eds), Community networks: Lessons from Blacksburg, Virginia, 2nd edition (pp. 114). Boston: Artech House.

Cohill, A., \& Kavanaugh, A. (Eds). (2000). Community networks: Lessons from Blacksburg, Virginia, 2nd edition. Boston: Artech House.

CTCNet. (n.d). General History. Retrieved August 18, 2002 from http:// www.ctcnet.org/ history.html

Darling, J . (1999). Cambria County, PA's civic action network. Community technology review, Summer-Fall, p. 41. 
Dick, B. (2000). Grounded theory: a thumbnail sketch. Retrieved J une 27, 2002 from http:// www.scu.edu.au/ schools/gcm/ar/ arp/grounded.html

Dillman, D. (2000). Mail and Internet surveys: The tailored design method. New York: J ohn Wiley \& Sons.

Dutton, W. (1999). The web of technology and people: Challenges for economic and social research. Prometheus 17(1), 5-16.

Ehrich, R. \& Kavanaugh, A. (2000). Managing the evolution of a virtual school. In A. M. Cohill \&A. L. Kavanaugh, (Eds), Community networks: Lessons from Blacksburg, Virginia, 2nd edition (pp. 143-169). Boston: Artech House.

Ehrich, R., Lisanti, M., \& McCreaery, F. (2000). Networking families into schools. In A. M. Cohill \&A. L. Kavanaugh, (Eds), Community networks: Lessons from Blacksburg, Virginia, 2nd edition (pp. 123-141). Boston: Artech House.

Flora, C., Flora, J ., Spears, J ., \& Swanson, L. (1992). Rural communities: Legacy and change. Boulder, CO: Westview Press.

Forbes, B. (1999). Technology and communication policy: At the rural crossroads, Community Technology Review, Summer-Fall, pp. 36-37.

Fuchs, R.P. (1998). Little engines that did: Case histories from the global telecentre movement. IDRC Study/ Acacia Initiative Retrieved October 16, 2000 from http:// www.idrc.ca/ acacia/ engine/ eng_ 11.htm 
Glaser, B \& Strauss, F. (1999). The Discovery of Grounded Theory: Strategies for qualitative research. New York: Aldine De Gruyter.

Glynn, J . (2001) email appearing on America Connects Consortium listserv online forum J uly 7, 2001.

Grisham, D. (2000). Connecting theoretical conceptions of reading practice: a longitudinal study of elementary school teachers. Reading Psychology 21, 145170.

Harvey, A. (1999). Immediate issues concerning telecommunications in Indian country, Community Technology Review, Summer-Fall, p. 35.

Haywood, T. (1995). Info-rich--info-poor: Access and exchange in the global information society. London: Bower Saur.

Heid, J . (1999). No back roads: An Internet documentary. Retrieved October 29, 2002 from http:// www.nobackroads.com/ dillon/dillon.html

J ohnson \&J ohnson Associates. (2001). Technology Opportunities Program 1996 and 1997 Projects. Report prepared for U.S. department of Commerce, National Telecommunications and Information Administration under order number 56SBTK065162.

Kavanaugh, A., Cohill, A., \& Patterson, S. (2000). The use and impact of the Blacksburg Electronic Village. In A. M. Cohill \&A. L. Kavanaugh, (Eds). Community 
networks: Lessons from Blacksburg, Virginia, 2nd edition (pp. 77-98). Boston: ArtechHouse.

Kendall, J . (1999). Axial coding and the grounded theory controversy. Western J ournal of Nursing Research 21, 743-757.

Kling, R. (2000a). Social informatics: A new perspective on social research about information and communications technologies. Prometheus 18(3), 245-264.

Kling, R. (2000b). Learning about information technologies and social change: The contribution of social informatics. The Information Society 16, 217-232.

La Plaza Website Archives. (2002). retrieved August 18, 2002 from http://www.laplaza.org

Lawrence, E. (1996). Telematics-enabled development in rural areas: An analysis of theory and applications. Unpublised masters thesis, Dalhousie University, Halifax, Nova Scotia.

Lazarus, W. \& Francisco, M. (2000). Online content for low-income and underserved Americans: The digital divide's new frontier. Santa Monica, CA: The Children's Partnership.

Manohar, K. (2001). Will technology trickle down to rural America? A NetAction report, Retrieved August 18, 2002 from http:// www.netaction.org/ alt-tech/ alttech.pdf 
Mark, J ., Cornebise, J ., \&Wahl, E. (1997). Community Technology Centers: Impact on individual participants and their communities. Newton, Massachusetts: Education Development Center.

Martin, C. \&Cohill, A. (2000). Managing information in a community network. In A. M. Cohill, \&A. L. Kavanaugh, (Eds). Community networks: Lessons from Blacksburg, Virginia, 2nd edition (pp. 281-312). Boston: Artech House.

Maughan, G. (2001). Technology leadership: Communications and information systems in higher education, in M. Kramer (Ed), New directions for higher education, San Francisco: J ossey-Bass.

Melchoir, A., Thorsetensen, B., \& Shurkin, M. (1998). The uses of technology in youthserving organizations: An initial scan of the field, prepared for Wallace Readers Digest Foundation.

Mineta, N., Rohde, G., McGuire-Rivera, B., \&Downs, S. (2000). Community connections: Preserving local values in the Information Age. U.S. Department of Commerce report.

Morino Institute. (2001). From access to outcomes: Raising the aspirations for technology initiatives in low-income communities. Retrieved (October 28, 2002) from http:/ / www.morino.org/ divides/ report.pdf 
Morino, M. (2000). Closing social divides. Speech made at Networks for People conference. Retrieved J anuary 2, 2001, from http:// morino.org/_closing_sp_dig.asp

National Center for Small Communities. (1999). Getting online: A guide to the Internet for small town leaders. Retrieved October 5, 2002 from http:// nata.org/ ncsc/ (also available in print).

National Center for Small Communities. (2002). Technology and grit at the grassroots: Information technology, community engagement, and jobs in distressed rural communities. Retrieved Oct 5, 2002 from http:/ / www.natat.org/ ncsc/ Pubs/EDA/ 71482_NATT.pdf (also available in print).

National Telecommunications and Information Administration. (2000). Lessons learned from the Telecommunications and Information Infrastructure Assistance Program (TIIAP). U.S. Department of Commerce report.

National Telecommunications and Information Administration and the Rural Utilities Service. (2000). Advanced telecommunications in rural America: The challenge of bringing broadband service to all Americans. Retrieved August 20,2002 from http/ / www.ntia.doc.gov/ reports/ ruralbb42600.pdf

Neighborhood Networks. (1998). Neighborhood networks business plan outline and guide. 
Odasz, F. (n.d.). The good neighbor's guide to community networking. Retrieved August 6, 2001 from http:/ / lone-eagles.com/ cnguide.htm

Odasz, F. (1995). Community networking: Part 1. Online chronicle of distance education and communications. Spring 1995 retrieved October 28, 2002 from http:/ / www.fcae.nova.edu/ disted/ fall95/ article.html

Odasz, F. (1996). Community networking: A planning implementation guide. Online chronicle of distance education and communications. Fall 1995, retrieved October 28, 2002 from http:/ / www.fcae.nova.edu/ disted/spring96/articles.html Patterson, S. (2000). Evaluating the Blacksburg Electronic Village. In A. M. Cohill, A. L. \& Kavanaugh, (Eds), Community networks: Lessons from Blacksburg, Virginia $2^{\text {nd }}$ edition (pp. 59- 75). Boston: Artech House.

Patton, M. (1990). Qualitative research and evaluation methods, $2^{\text {nd }}$ edition. Newbury Park: Sage Publications.

Patton, M. (2002). Qualitative research and evaluation methods, $3^{\text {rd }}$ edition. Thousand Oaks, CA: Sage Publications.

Penuel, W., \& Kim, D. (2000). Promising practices and organizational challenges in community technology centers. Menlo Park, CA: SRI International

Penuel, B., Michalchik, V., Kim, D., \& Shear, L. (2001). The organization of learning in community technology centers: Learning with technology in six communities. U.S. Department of Education Task Order ED-99-CO-0160. 
Perelman, M. (1998). Class warfare in the Information Age. New York: St. Martin's Press

Rifkin, J . (1995). The end of work: The Decline of the global labor force and the dawn of the Post-Market era. New York: G.P. Putman's Sons

Rose, S. (1997). The role of community access centers in bridging the technology gap. Retrieved October 5, 2000 from http:// www.ctcnet.org/rose/ 00title.htm

Schiller, H. (1996). Information inequality: The deepening social crisis in America. New York: Routledge.

Schmidt, K. W. \& Cohill, A. M. (2000). Building an online history database. In A. M. Cohill, \&A. L. Kavanaugh (Eds), Community networks: Lessons from Blacksburg, Virginia, 2nd edition (pp. 313-334). Boston: Artech House

Servon, L., \&Nelson, M. (1999). Creating an information democracy: the role of community technology programs and their relationship to public policy. Rutgers. New Brunswick, NJ : Center for Urban Policy Research.

Stefik, M. (1999). The Internet edge: Social, legal, and technological challenges for a networked world. Cambridge, Massachusetts, The MIT Press.

Spruill, N., Kenney, C., \& Kaplan, L. (2001). Community development and systems thinking: theory and practice. National Civic Review 90(1),_102-117.

Stone, A. (2000). CTCNet Center start-up manual. Retrieved October 5, 2002 from http:/ / www.ctcnet.org/ toc.htm 
Strickland, C. (1998). In the shadow of the Sacred Mountain- the intersection of technology and community development: An ethnographic case study of creating a community network in Taos, New Mexico. Unpublished doctoral dissertation, The Fielding Institute, Santa Barbara, CA.

Telecommunications and Information Infrastructure Assistance Program. (1999). How access benefits children: Connecting our kids to the world of information. Report of TIIAP for U.S. Department of Commerce, NTIA.

Telem@. (2002). Retrieved November 16, 2002 from http://www.telem.co.uk/ index.html .

Tribal Connections. (2000). Taos Publo receives funding for wireless Internet connectivity. Retrieved August 1, 2001 from http:/ / www.laplaza.org/ announce/ tribalConnx/

U.S. Department of Commerce. (1995). Falling through the Net: A survey of the "have nots" in rural and urban America. Retrieved August 23, 2002 from http:// www.ntia.doc.gov/ ntiahome/ fallingthru.html

U.S. Department of Education. (2002). CTC Grants FY 1999-2002. available at http:/ / www.americaconnects.net/ field/Abstracts2002grants.doc

U.S. Department of Housing and Urban Development. (2000). 2002 best Practices Finalists, retrieved from http:// www.hud.gov/ local/ mo/library/archives/ stlbp404.cfm 
Ward, L. (2000). Community network technology. In A. M. Cohill, \&A. L. Kavanaugh, (Eds), Community networks: Lessons from Blacksburg, Virginia, 2nd edition (pp. 201-279). Boston: Artech House

Westatt. (2000). Technology opportunities program 1996 projects. U.S. Department of Commerce report, Order 50SBNT7C1049.

Wresch, W. (1996). Disconnected: Haves and have-nots in the information age. New Brunswick, NewJ ersey: Rutgers University Press. 


\section{A P P E N D I X}

Data collection instruments 
TELEPHONE INTERVIEW PROTOCOL

Cover Letter

Name:

Email address:

Center's name:

You are being asked to participate in a study that consists of a brief telephone interview and a short survey. Participation is completely voluntary. You may choose to withdraw from the study at any time or you may choose not to answer particular questions.

The purpose of this study is to discover what factors make a rural Community Technology Center effective. The results of this study will be shared with other communities wishing to begin or improve their RCTCs.

Please be candid in your responses. Neither your name nor your center's name will be associated in any way with any of your responses. All answers will be kept confidential. The answers of all participants will be combined in the findings without reference to names of either individuals or centers.

A summary of the findings will be forwarded to each of the respondents when the study concludes.

Thank you for participating in this investigation.

Daphne Gooding

Advanced Education Studies- Technology Education program

West Virginia University

Morgantown, WV 26506 


\section{Participant Copy}

Years in

operation

Please answer the following questions with a few sentences:

1. How would you describe the area where your center is located?

2. Please describe the interior of your center. Include the general size, number of computers, overall look.

3. How, would you say, does the Community Technology Center address problems in your community?

4. During a normal week at your center who might participate in activities at your center? 
5. How do people get to and from your center? Do adults bring children? If so, what do the children do? How do people get home?

6. Describe the partnerships with other organizations that have been important to the development of your center.

7. How are major decisions made at your center?

8. Thinking about the people who have been important in the development of your center, who are these people and how have they been important?

9. Explain the technical issues that your center has had to deal with to become effective. How did you solve these problems? 
10. How has your center been funded during its history? How do you plan to fund its operations in the future?

11. What has contributed to the effectiveness of your center? What barriers had to be overcome?

12. If someone asked if your center is successful or effective, what would you say to prove that it is?

13. Based on your own personal experience what would you say is the best way to measure any center's effectiveness?

14. In your opinion, what makes your center special? 
15. Is there anything else that has made your center effective?

Thank you for participating in this study. Your answers will be combined with others to help new centers become effective in their communities. 
Please rate the following areas as to how important they have been in making your center effective:

\begin{tabular}{|c|c|c|c|c|}
\hline \multicolumn{5}{|c|}{ 1. Skills of staff (paid or volunteer) } \\
\hline $\begin{array}{c}\text { Not important } \\
\square\end{array}$ & $\begin{array}{c}\text { Somewhat important } \\
\square\end{array}$ & $\begin{array}{c}\text { Important } \\
\square\end{array}$ & $\begin{array}{c}\text { Very important } \\
\square\end{array}$ & $\begin{array}{c}\text { Critically important } \\
\square\end{array}$ \\
\hline \multicolumn{5}{|c|}{ 2. Strategic planning for the center } \\
\hline $\begin{array}{l}\text { Not important } \\
\square\end{array}$ & Somewhat important & $\begin{array}{c}\text { Important } \\
\square\end{array}$ & $\begin{array}{c}\text { Very important } \\
\square\end{array}$ & Critically important \\
\hline \multicolumn{5}{|c|}{ 3. Community input in planning the center } \\
\hline $\begin{array}{l}\text { Not important } \\
\square\end{array}$ & Somewhat important & $\begin{array}{c}\text { Important } \\
\square\end{array}$ & Very important & Critically important \\
\hline
\end{tabular}

4. An individual or individuals who were excited and motivated others

Not important Somewhat important Important Very important Critically important

$\square \quad \square \quad \square \quad \square \quad \square$

5. "Buy-in" by community groups

Not important Somewhat important Important Very important Critically important

$\square \quad \square \quad \square \quad \square \quad \square$

6. Partnerships with a college or university

Not important Somewhat important Important Very important Critically important

$\square \quad \square$

7. Specific curriculum or programs

Not important Somewhat important Important Very important Critically important

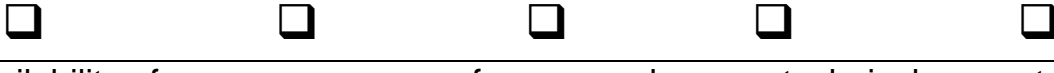

8. Availability of a person or group of persons who gave technical support

Not important Somewhat important Important Very important Critically important

$\begin{array}{lllll}\square & \square & \square & \square & \square\end{array}$

9. Responding to community needs

Not important Somewhat important Important Very important Critically important

10. Foundation funding

Not important Somewhat important Important Very important Critically important

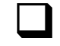

11. Federal funding

Not important Somewhat important
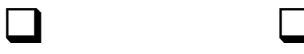

12. State funding

Not important

Somewhat important

Important

Very important

Critically important

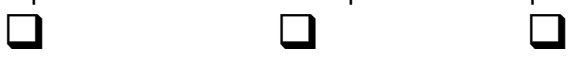




\begin{tabular}{|llll|}
\hline 13. Local fund-raising events & \\
Not important & Somewhat important
\end{tabular}

